\title{
Jogos de Steiner
}

César Gamboa Machado

\author{
DissertaÇÃo APRESENTADA \\ AO \\ Instituto DE MATEMÁtica E EstatísticA \\ DA \\ Universidade DE SÃo Paulo \\ PARA \\ OBTENÇÃO DO TÍTULO \\ $\mathrm{DE}$ \\ Mestre em CiênCIAS \\ Programa: Ciência da Computação \\ Orientador: Prof. Dr. José Coelho de Pina Jr.
}

Durante o desenvolvimento deste trabalho o autor recebeu auxílio financeiro da CAPES

São Paulo, 3 de junho de 2012 


\section{Jogos de Steiner}

Esta tese/dissertação contém as correções e alterações sugeridas pela Comissão Julgadora durante a defesa realizada por César Gamboa Machado em 11/05/2012. O original encontra-se disponível no Instituto de Matemática e Estatística da Universidade de São Paulo.

Comissão Julgadora:

- Prof. Dr. José Coelho de Pina (orientador) - IME-USP

- Prof. Dr. Arnaldo Mandel - IME-USP

- Prof. Dr. Orlando Lee - UNICAMP 


\section{Resumo}

\section{Jogos de Steiner}

Neste projeto analisamos jogos de formação de redes que são variantes do problema da floresta de Steiner, nos quais indivíduos desejam conectar conjuntos de vértices terminais em um grafo de forma a minimizar seus custos, podendo dividir o custo das arestas com os demais participantes. Estudamos como o método de divisão de custos influencia na existência e na qualidade dos equilíbrios desses jogos em comparação com o valor da solução ótima centralizada.

Palavras-chave: teoria dos jogos, jogos de formação de redes, floresta de Steiner. 


\section{Abstract}

\section{Steiner Games}

In this project we analyze network formation games that are variants of the Steiner forest problem, in which individuals wish to connect sets of terminal vertices of a graph in a way that minimizes their costs, being able to divide the cost of an edge with the other participants. We study how the method used to divide the costs influences the existance and quality of the equilibria of these games in relation to the centralized optimal solution.

Keywords: game theory, network formation games, Steiner forest. 


\section{Sumário}

$\begin{array}{ll}\text { Lista de Figuras } & \text { vii }\end{array}$

1 Introdução 1

2 Grafos e Problemas de Steiner $\quad 5$

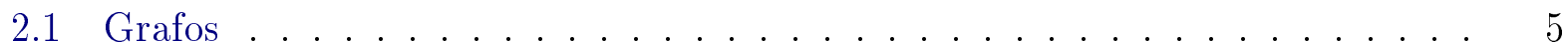

2.2 Problemas de Steiner . . . . . . . . . . . . . . . . 7

3 Jogos, Equilíbrios e Ineficiência $\quad 9$

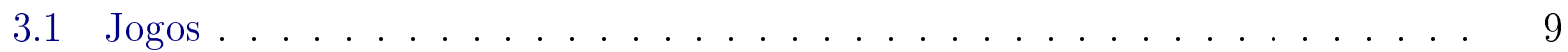

3.2 Equilíbrio ................................ 10

3.3 Ineficiência do equilíbrio . . . . . . . . . . . . . 11

4 Jogos de Steiner com Divisão Justa $\quad 13$

4.1 Modelo com divisão justa dos custos . . . . . . . . . . . . . . . . 13

4.2 Valor de Shapley . . . . . . . . . . . . . . . . . . 14

4.3 Funções potenciais e equilíbrio . . . . . . . . . . . . . . . . . 16

4.4 Complexidade computacional . . . . . . . . . . . . . . . 17

4.5 Preço da anarquia . . . . . . . . . . . . . . . . . 20

4.6 Preço da estabilidade . . . . . . . . . . . . . . . . 21

5 Jogos de Caminhos com Divisão Justa 25

5.1 Preço da estabilidade para dois e três caminhos . . . . . . . . . . 25

5.2 Uma estabilidade cara . . . . . . . . . . . . . . . . . . . 29

5.3 Exemplos de estabilidades caras . . . . . . . . . . . . . . 36

5.4 Multitransmissões e difusões . . . . . . . . . . . . . . . . . . . . 39

5.5 Limite para o preço da estabilidade em difusões . . . . . . . . . . . . 42

6 Jogos de Steiner com Ofertas $\quad 57$

6.1 Modelo com ofertas . . . . . . . . . . . . . . . . 57

6.2 Complexidade computacional . . . . . . . . . . . . . . . 59

6.3 Ineficiência do equilíbrio . . . . . . . . . . . . . . . . 61

6.4 Multitransmissões . . . . . . . . . . . . . . . . . 61 


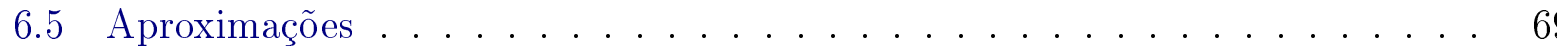

7 Comentários Finais

Referências Bibliográficas

Índice Remissivo

78 


\section{Lista de Figuras}

1.1 Floresta de Steiner de custo mínimo . . . . . . . . . . . . . . . . . 1

1.2 Solução "estável" . . . . . . . . . . . . . . . . . . . . . 2

2.1 Grafos orientados e não-orientados . . . . . . . . . . . . . 5

2.2 Floresta e arborescência . . . . . . . . . . . . . . . . 6

2.3 Floresta de Steiner de custo mínimo . . . . . . . . . . . . . . 7

2.4 Problema de Steiner orientado generalizado . . . . . . . . . . . . 8

4.1 Jogo SteinerJusto e digrafo auxiliar . . . . . . . . . . . . . . 17

4.2 Digrafo auxiliar para o jogo PAR-IMPAR . . . . . . . . . . . . 18

4.3 Equilíbrio com ciclo . . . . . . . . . . . . . . . . . . 18

4.4 Problema do Empacotamento-3-conjuntos . . . . . . . . . . . . . . 19

4.5 Redução do Empacotamento-3-conjuntos para o SteinerJusto . . . . . . . 20

4.6 Instância do SteinerJusto com preço da anarquia $n$. . . . . . . . . 21

4.7 Instância do SteineRJusto com preço da estabilidade $\mathcal{H}_{n} \ldots \ldots \ldots$. . . . 21

4.8 SteinerJusto com preço da estabilidade $\mathcal{H}_{2} \ldots \ldots \ldots \ldots$. . . . . . . 22

4.9 SteinerJusto com três jogadores . . . . . . . . . . . . . . . 23

5.1 Em um equilíbrio os jogadores compartilham um caminho entre $u$ e $v$. . . 26

5.2 Preço da estabilidade para dois jogadores é no máximo $4 / 3 \ldots$. . . . . . 26

5.3 SteinerJustoCam com dois jogadores e preço da estabilidade $4 / 3 \ldots$. . . 27

5.4 SteinerJustoCAm com $S_{13}=0 \ldots \ldots \ldots \ldots \ldots \ldots$

5.5 SteinerJusto com três jogadores e preço da estabilidade $74 / 48 \geq 1,541$. . 30

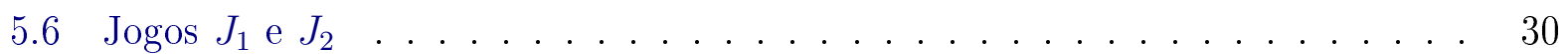

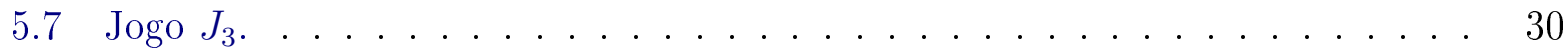

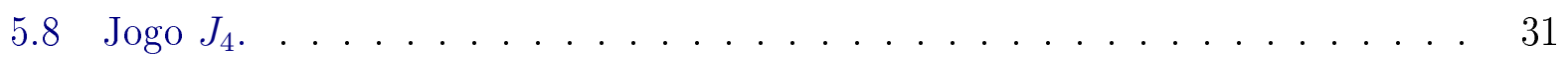

5.9 Ilustração do jogo $J_{k}$. . . . . . . . . . . . . . . . . . 32

5.10 Estratégia direta . . . . . . . . . . . . . . . . . 32

5.11 Estratégia por cima . . . . . . . . . . . . . . . . 33

5.12 Estratégia por baixo . . . . . . . . . . . . . . . 33

$5.13 q$ jogadores atravessam $J_{i} \ldots \ldots \ldots \ldots \ldots \ldots \ldots$

5.14 SteinerJustoCAm com preço da estabilidade $\frac{42}{23}>1,826 \ldots \ldots$ 
5.15 Dispositivo para um SteinerJustoCAm com preço da estabilidade 348/1555 37

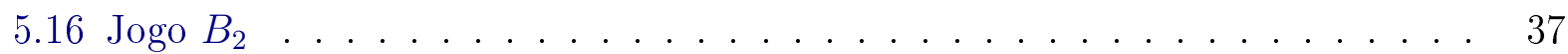

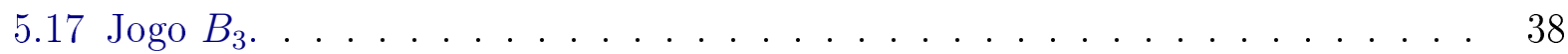

5.18 SteinerJustoM . . . . . . . . . . . . . . . . . . 40

5.19 SteinerJustoB . . . . . . . . . . . . . . . . . . . 40

5.20 SteinerJustoM com $k$ jogadores. . . . . . . . . . . . . . . . . 41

5.21 SteinerJustoB com $k$ jogadores. . . . . . . . . . . . . . . 42

5.22 Movimentos válidos . . . . . . . . . . . . . . . . . . 43

5.23 Arestas de $P_{w}^{v}$ em destaque. . . . . . . . . . . . . . . . . . . . . . . . . . . . . . .

5.24 Estratégia alternativa para $u \ldots \ldots \ldots \ldots \ldots$. . . . . . . . . . . . . . . .

$5.25 \operatorname{LCA}(u, w)$ é ancestral de $\operatorname{LCA}(v, w) \ldots \ldots \ldots \ldots \ldots$

5.26 Grafo modificado para o algoritmo Divis AoOferta . . . . . . . . . . 47

5.27 Conjunto $M_{w} \ldots \ldots \ldots \ldots \ldots \ldots \ldots \ldots$

5.28 Jogadores em $M_{y}$ deixam de utilizar $e \ldots \ldots \ldots \ldots$. . . . . . . 53

6.1 SteinerOfertas sem equilíbrio e apenas com equilíbrio fracionario . . . . . 58

6.2 Dispositivos para a redução do 3-SAT para o STEINEROFERTA . . . . . . . . 60

6.3 SteinerOferta com preço da estabilidade $n-2 \ldots \ldots$. . . . . . . . 61

6.4 SteinerOfertaM em que uma dinâmica de melhor resposta não converge para um equilíbrio . . . . . . . . . . . . . . . . . 62

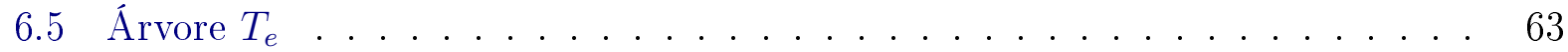

6.6 O caminho alternativo não volta a $T_{e} \ldots \ldots \ldots \ldots$

6.7 Pontos de desvio . . . . . . . . . . . . . . . . . . . 66

6.8 SteinerOfertaM com preço da estabilidade $1 \ldots \ldots . \ldots . \ldots . \ldots$ 


\section{Capítulo 1}

\section{Introdução}

Considere um grafo com custos nas arestas. Dizemos que uma floresta $F$ conecta uma sequência de conjuntos de vértices $\mathcal{R}=\left(R_{1}, \ldots, R_{n}\right)$ se cada $R_{i}$ está contido em algum componente de $F$. Neste caso também dizemos que $F$ é uma $\mathcal{R}$-floresta, ou uma floresta de Steiner quando $\mathcal{R}$ está subentendido. O custo de uma floresta é a soma dos custos de suas arestas.

O problema central deste texto pode ser visto como uma certa variante do problema FSTEINER.

Problema FSteiner $(G, c, \mathcal{R})$ : Dados um grafo $G$, um custo $c_{e}$ em $\mathbb{Q} \geq$ para cada aresta e uma sequência de conjuntos de vértices $\mathcal{R}$, encontrar uma $\mathcal{R}$-floresta de custo mínimo.

Na figura 1.1 vemos um exemplo de uma instância do problema FSTEINER e a sua solução.

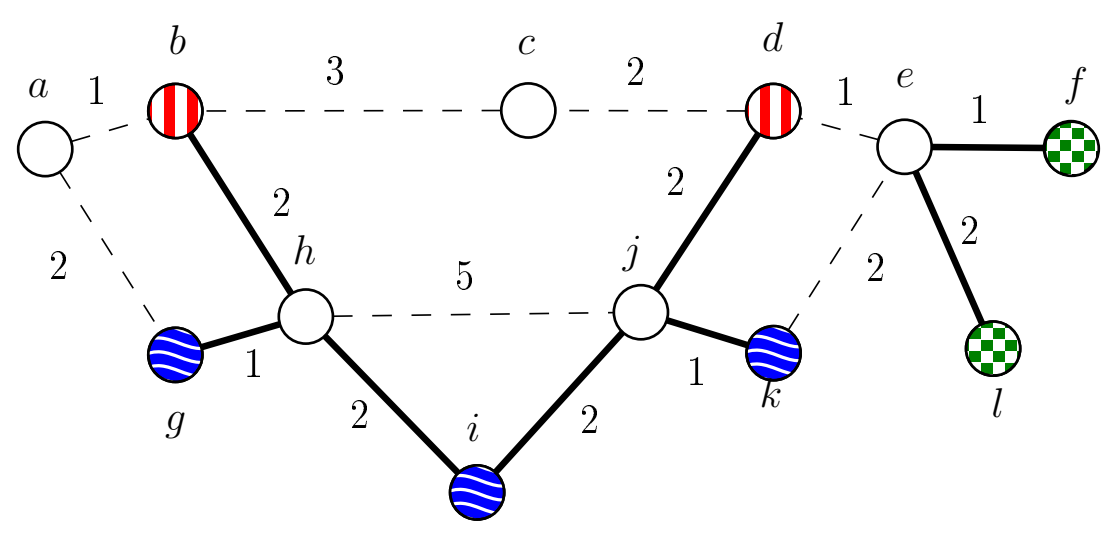

Figura 1.1: Para $R_{1}=\{b, d\}, R_{2}=\{g, i, k\}, R_{3}=\{f, l\}$ as arestas contínuas formam uma floresta de Steiner de custo minimo.

Seja $(G, c, \mathcal{R})$ uma instância do problema FSTEINER. Suponha que para cada conjunto $R_{i}$ em $\mathcal{R}$ há um indivíduo $i$, também chamado de jogador $i$, responsável por construir uma rede que seja um subgrafo de $G$ e que conecte os vértices em $R_{i}$. Como os indivíduos agirão independentemente, permitiremos que o mesmo vértice apareça em mais de um conjunto e que existam dois conjuntos iguais em $\mathcal{R}$, o que não é usual no problema FSTEINER.

O custo de uma rede é a soma dos custos das arestas na rede. Suponha que os indivíduos estão dispostos a dividir os custos da construção de uma rede comum que conecte $R_{1}, \ldots, R_{n}$. 
No entanto, apesar da disposição em colaborar, cada indivíduo tem como objetivo maior gastar o mínimo possível para conectar seu conjunto.

Devemos notar, porém, que para resolver o problema em questão não basta encontrar uma floresta de custo mínimo e dividir seu custo entre os jogadores arbitrariamente.

Como cada jogador age individualmente de forma a minimizar seu gasto, a floresta encontrada e a divisão de custos proposta deve ser tal que nenhum dos jogadores gaste menos se decidir agir de outra forma além da proposta. Assim, a divisão deve ser, de certa forma, "estável".

Dizemos que um jogador utiliza uma aresta de uma floresta se esta aresta é necessária para ligar na floresta os vértices que este pretende conectar.

Considere o exemplo da figura 1.1. Nele o jogador 1 utiliza as arestas $b h, h i, i j$ e $j d$ para conectar os vértices $b$ e $d$, enquanto o jogador 2 utiliza as arestas $g h, h i, i j$ e $j k$ e o jogador 3 utiliza as arestas ef 3 el. Observe que dividir igualmente as arestas da floresta de custo mínimo pelos jogadores que as utilizam não é uma solução aceitável nesse caso, pois o jogador 1 pagará $6=2+\frac{2}{2}+\frac{2}{2}+2$ pela sua parte na floresta enquanto poderia gastar apenas 5 pagando sozinho pelas arestas $\{b c, c d\}$.

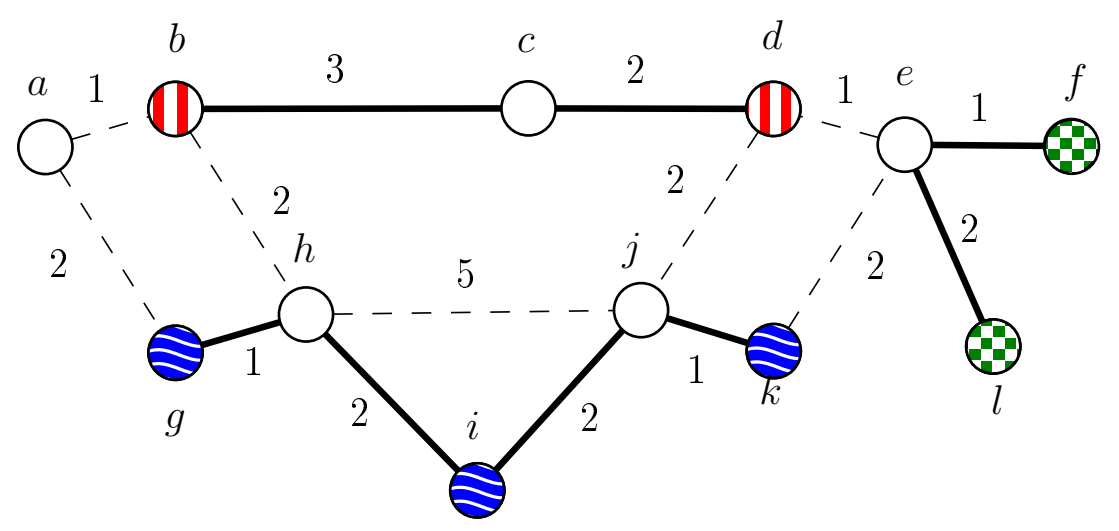

Figura 1.2: $R_{1}=\{b, d\}, R_{2}=\{g, i, k\}, R_{3}=\{f, l\}$. Solução "estável", com custo superior à solução ótima de FSTEINER.

Note que a solução apresentada na figura 1.2, em que cada jogador constrói sozinho uma árvore de custo mínimo que liga os seus vértices é estável, pois nenhum dos jogadores conseguirá pagar menos mudando suas arestas, apesar de esta solução ter um custo global maior que a floresta da figura 1.1.

Neste texto apresentamos políticas de divisão de custos para cenários como o descrito acima, mostramos como estas políticas influenciam a existência de soluções estáveis e a relação dos custos obtidos com o de uma solução ótima para o FSTEINER. Além disso, estamos interessados em métodos para encontrar soluções estáveis com o menor custo global possível.

Nos concentraremos principalmente em instâncias nas quais cada conjunto de terminais $R_{i}$ possui apenas dois elementos. Tal restrição facilita a verificação de estabilidade uma vez que nesta variante cada jogador está buscando um caminho mínimo entre seus terminais, o que pode ser calculado em tempo polinomial.

Analisaremos o problema do ponto de vista de teoria dos jogos algorítmica. O que chamaremos neste texto de jogos de Steiner é comumente conhecido como Network Formation Games.

Este texto está organizado da seguinte maneira. O capítulo 2 apresenta notações básicas de teoria dos grafos e descreve o problema FSTEINER e algumas de suas variantes. Os 
conceitos de teoria dos jogos utilizados tais como jogo, solução estável e ineficiência de uma solução estável estão formalmente descritos no capítulo 3. O critério ou modelo para a divisão dos custos das arestas entre os jogadores considerado nesta introdução é analisado detalhadamente no capítulo 4, enquanto o capítulo 5 analisa como tal modelo se comporta em jogos com restrições adicionais. $\mathrm{O}$ capítulo 6 considera um modelo alternativo para o rateio dos custos. Nesse modelo os jogadores que apresentam ofertas indicando quanto estão dispostos a contribuir no pagamento de cada aresta. Finalmente, no capítulo 7, relatamos as nossas considerações finais e possíveis trabalhos futuros. 


\section{Capítulo 2}

\section{Grafos e Problemas de Steiner}

Neste capítulo apresentaremos algumas das definições e notações básicas de grafos utilizadas neste texto, além do problema da floresta de Steiner e algumas de suas variantes. As notações foram baseadas nas notas de aula de Paulo Feofiloff, Yoshiharu Kohayakawa e Yoshiko Wakabayashi [FKW04].

\section{$2.1 \quad$ Grafos}

Um grafo (não-orientado) é um par $G=\left(V_{G}, A_{G}\right)$ onde $V_{G}$ é um conjunto arbitrário e $A_{G}$ é um conjuto de pares não-ordenados de elementos de $V_{G}$. Chamamos os elementos de $V_{G}$ de vértices e os elementos de $A_{G}$ de arestas. Denotaremos a aresta $\{u, v\}$ por $u v$. A figura 2.1(a)

Quando $A_{G}$ é um conjunto de pares ordenados, dizemos que $G$ é um digrafo, ou grafo orientado e os elementos de $A_{G}$ são chamados de arcos. Usaremos a notação $u v$ para nos referirmos ao $\operatorname{arco}(u, v)$.

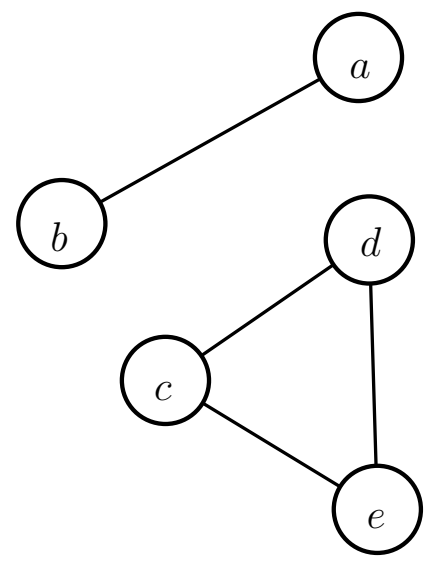

(a)

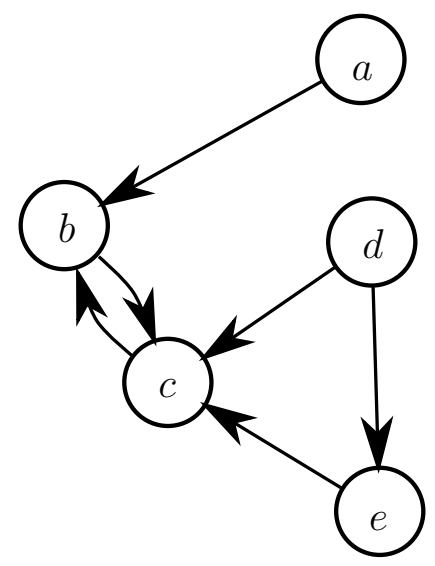

(b)

Figura 2.1: (a) Exemplo de grafo $G=\left(V_{G}, A_{G}\right)$, com $V_{G}=\{a, b, c, d, e\}, A_{G}=\{a b, c d, c e, d e\}$. (b) Exemplo de digrafo, com $V_{G}=\{a, b, c, d, e\}, A_{G}=\{a b, b c, c b, d c, d e, e c\}$

Um caminho em um grafo $G$ é uma sequência $\left\langle v_{1}, a_{1}, v_{2}, a_{2}, \ldots, a_{k-1}, v_{k}\right\rangle$ onde $v_{1}, \ldots, v_{k}$ são vértices distintos e cada $a_{i}$ é a aresta $\left\{v_{i}, v_{i+1}\right\}$ (ou arco $\left(v_{i}, v_{i+1}\right)$ caso o grafo seja 
orientado). Denotamos um caminho por $v_{1} v_{2} \ldots v_{k}$. O grafo da figura 2.1(a) possui o caminho cde (porém o grafo da figura 2.1(b) não). decb é um caminho no grafo da figura 2.1(b).

Um grafo é conexo se para quaisquer dois vértices $u$ e $v$ em $A$, existe um caminho com extremos em $u$ e $v$. O grafo da figura 2.1(a) não é conexo, pois não há caminho entre os vértices $a$ e $d$, por exemplo.

Um ciclo em um grafo $G$ é uma sequência $\left\langle v_{1}, a_{1}, v_{2}, a_{2}, \ldots, v_{k}, a_{k}, v_{1}\right\rangle$ onde $v_{1}, \ldots, v_{k}$ são vértices distintos, $a_{k}$ é a aresta $\left\{v_{k}, v_{1}\right\}$ e cada outro $a_{i}$ é a aresta $\left\{v_{i}, v_{i+1}\right\}$. Denotamos um ciclo por $v_{1} v_{2} \ldots v_{k} v_{1}$. O grafo da figura 2.1(a) possui o ciclo $c d e c$, enquanto o grafo da figura 2.1(b) possui o ciclo $b c b$. Em grafos não orientados não consideramos ciclos de tamanho 2 (aba no grafo da figura 2.1(a)).

Um subgrafo de um grafo $\left(V_{G}, A_{G}\right)$ é qualquer grafo $\left(V^{\prime}, A^{\prime}\right)$ tal que $V^{\prime} \subseteq V_{G}$ e $A^{\prime} \subseteq A_{G}$. O subgrafo induzido de um grafo $G$ por um conjunto de vértices $V^{\prime} \subseteq V_{G}$ é o grafo $\left(V^{\prime}, A^{\prime}\right)$ onde $A^{\prime}=\left\{u v \in A_{G}: u \in V^{\prime}, v \in V^{\prime}\right\}$.

Um componente de um grafo $G$ é qualquer subgrafo conexo maximal de $G$, ou seja, $H$ é um componente de $G$ se $H$ não é subgrafo próprio de nenhum subgrafo conexo de $H$. O grafo da figura 2.1(a) possui dois componentes, correspondentes aos subgrafos induzidos pelos conjuntos $\{a, b\}$ e $\{c, d, e\}$.

Uma floresta é um grafo que não contém ciclos. A figura 2.2(a) mostra um exemplo de floresta.

Uma árvore é um grafo conexo que não contém ciclos. Note que todo componente de uma floresta é uma árvore.

Uma subárvore de um grafo $G$ é um subgrafo de $G$ que é uma árvore. Uma árvore $T$ é geradora de um grafo $G$ se $T$ é subárvore de $G$ e $V_{T}=V_{G}$.

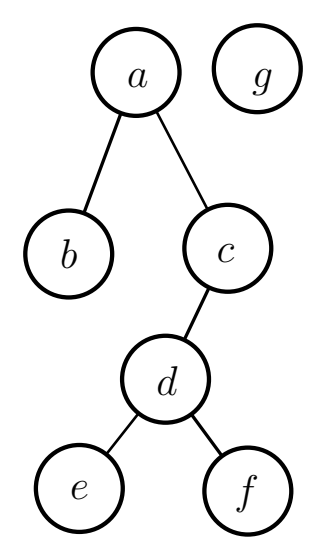

(a)

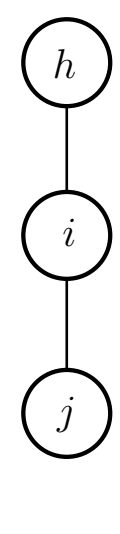

(b)

Figura 2.2: Exemplo de (a) floresta e (b) arborescência.

Uma arborescência é uma sequência $\left\langle v_{0}, a_{1}, v_{1}, a_{2}, \ldots, a_{k}, v_{k}\right\rangle$ em um grafo orientado, na qual $v_{0} \ldots v_{k}$ são vértices distintos e cada arco $a_{j} \operatorname{liga}$ algum $v_{i}$, com $i<j$ a $v_{j}$. Arborescências podem ser vistas como uma generalização do conceito de árvore para grafos orientados.

Uma função de custo para as arestas de um grafo é uma função $c: E_{G} \rightarrow \mathbb{Q}_{\geq}$que atribui um custo a cada aresta. Usaremos a notação $c(G)$ para indicar o custo total das arestas de um grafo

$$
c(G)=\sum_{e \in E_{G}} c(e) .
$$




\section{$2.2 \quad$ Problemas de Steiner}

A seguir apresentamos o problema da floresta de Steiner e algumas das suas variantes.

Considere um grafo com custos nas arestas. Dizemos que uma floresta $F$ conecta uma sequência de conjuntos de vértices $\mathcal{R}=\left(R_{1}, \ldots, R_{n}\right)$ se cada $R_{i}$ está contido em algum componente de $F$. Neste caso também dizemos que $F$ é uma $\mathcal{R}$-floresta, ou uma floresta de Steiner quando $\mathcal{R}$ está subentendido. O custo de uma floresta é a soma dos custos de suas arestas.

O problema da floresta de Steiner (de custo mínimo) consiste em encontrar uma floresta de Steiner de custo mínimo.

Problema FSteiner $(G, c, \mathcal{R})$ : Dados um grafo $G$, um custo $c_{e}$ em $\mathbb{Q}_{\geq}$para cada aresta e uma sequência de conjuntos de vértices $\mathcal{R}$, encontrar uma $\mathcal{R}$-floresta de custo mínimo.

O problema FSTEINER é sabidamente NP-difícil mesmo quando $\mathcal{R}$ possui apenas um conjunto, quando o problema é conhecido como problema da árvore de Steiner (de custo mínimo) [Kar72]. A figura 2.3 mostra uma instância do problema FSTEINER e sua solução.

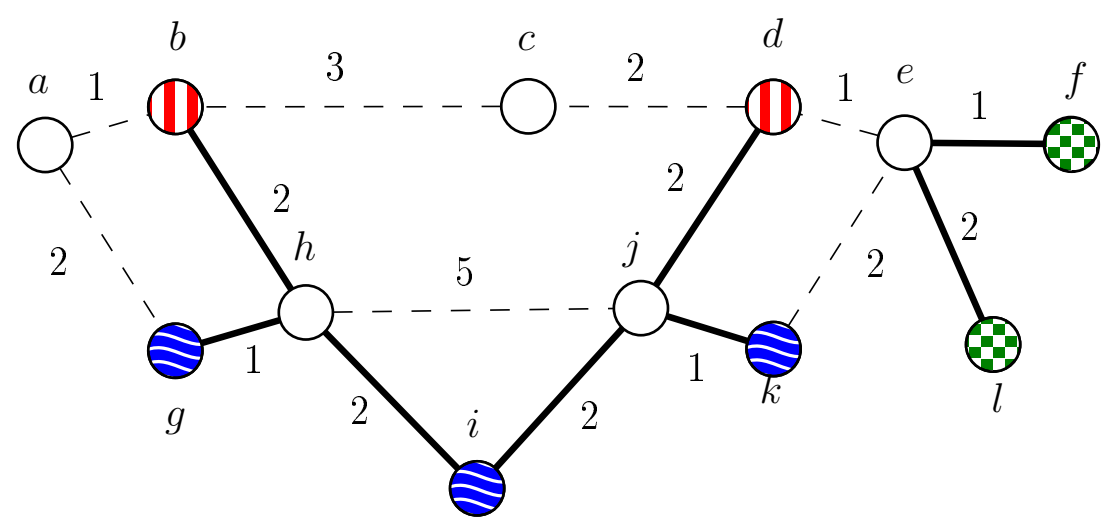

Figura 2.3: Para $R_{1}=\{b, d\}, R_{2}=\{g, i, k\}, R_{3}=\{f, l\}$ as arestas continuas formam uma floresta de Steiner de custo minimo.

Problema ASteiner $(G, c, R)$ : Dados um grafo $G$, um custo $c_{e}$ em $\mathbb{Q}_{\geq}$para cada aresta e um conjunto de vértices $R$, encontrar uma árvore de custo mínimo em $G$ que conecta os vértices em $R$.

Para o problema da árvore de Steiner existe um algoritmo de fator de aproximação 1,39 devido a Jarosław Byrka, Fabrizio Grandoni, Thomas Rothvoß e Laura Sanità [BGRS10]. Já para o caso geral do problema da floresta de Steiner, o algoritmo conhecido de menor fator de aproximação é uma 2-aproximação proposta por Michel Xavier Goemans e David Paul Williamson [GW95].

Quando o conjunto de terminais do problema da árvore de Steiner contém todos os vértices do grafo, o problema é conhecido como problema da árvore geradora mínima, para o qual são conhecidas soluções polinomiais [CLRS01]:

Problema $\operatorname{AGM}(G, c)$ : Dado um grafo $G$, um custo $c_{e}$ em $\mathbb{Q} \geq$ para cada aresta, encontrar uma árvore de custo mínimo em $G$ que contenha todos os vértices do grafo. 
Consideraremos também o problema de Steiner orientado generalizado (directed generalized Steiner network problem) [CCC $\left.{ }^{+} 98\right]$, no qual $G$ é um grafo orientado, cada $R_{i}$ é um par ordenado de vértices e o objetivo é encontrar um subgrafo de $G$ de custo mínimo que possua um caminho do primeiro ao segundo vértice de cada par.

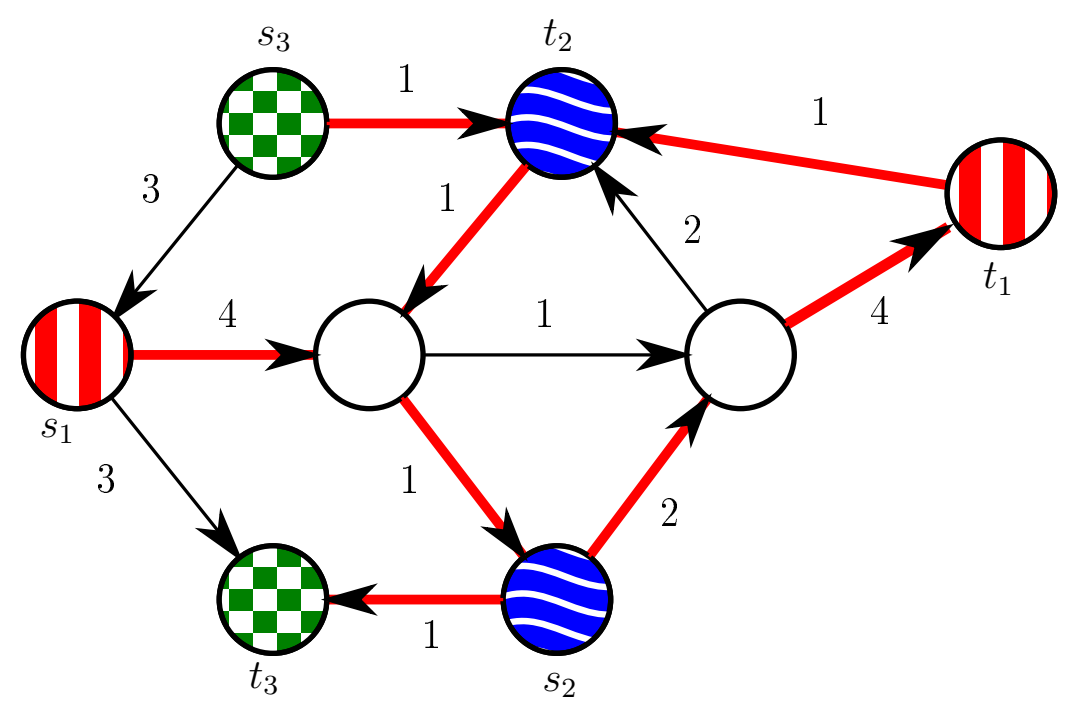

Figura 2.4: Para $R_{1}=\left(s_{1}, t_{1}\right), R_{2}=\left(s_{2}, t_{2}\right), R_{3}=\left(s_{3}, t_{3}\right)$ os arcos em destaque formam um subgrafo de custo minimo que conecta os terminais dos jogadores. 


\section{Capítulo 3}

\section{Jogos, Equilíbrios e Ineficiência}

Neste capítulo apresentaremos conceitos e notações básicas de Teoria dos Jogos [Mye97, NRTV07].

\section{$3.1 \quad$ Jogos}

Na linguagem de teoria dos jogos, um jogo é qualquer situação em que dois ou mais tomadores de decisão, que chamaremos de jogadores, interagem [Mye97]. Assume-se que os jogadores são racionais e inteligentes.

Dizemos que um jogador é racional se este toma decisões consistentemente de forma a atingir seus objetivos, tentando maximizar seus lucros ou minimizar seus custos, por exemplo.

Um jogador é chamado de inteligente se este conhece todos os detalhes do jogo, inclusive as preferências dos demais jogadores, e pode fazer inferências sobre cada situação.

Para modelarmos um jogo, precisamos definir quem são os seus participantes, como cada um destes pode agir, quais são os possíveis resultados destas ações e qual a ordem de preferências entre estes resultados para cada jogador.

Denotaremos o conjunto de jogadores por $N=\{1, \ldots, n\}$. Cada jogador $i$ deverá escolher um elemento, ou estratégia, dentre um conjunto de estratégias $S_{i}, i=1, \ldots, n$.

Um perfil de estratégias é um vetor $s=\left(s_{1}, \ldots, s_{n}\right), s_{i}$ em $S_{i}$, com as estratégias escolhidas pelos jogadores. Chamamos o conjunto de perfis de estratégias $S=S_{1} \times \ldots \times S_{n}$ de espaço de estratégias.

A ordem de preferência entre os elementos do espaço de estratégias para cada jogador pode ser dada através de uma função de custo $p_{i}: S \rightarrow \mathbb{R}$ que deve ser minimizada pelo jogador $i$ ou, quando faz mais sentido, através de uma função de utilidade $u_{i}: S \rightarrow \mathbb{R}$ a ser maximizada. As duas funções podem ser usadas de forma intercambiável, definindo-se $u_{i}(s)=-p_{i}(s)$.

Formalmente, um jogo (na forma estratégica) é um terno $(N, \mathcal{S}, \mathcal{P})$ onde:

- $N=\{1, \ldots, n\}$ é um conjunto não vazio de jogadores;

- $\mathcal{S}$ é uma sequência $\left(S_{1}, \ldots, S_{n}\right)$ de conjuntos de estratégias; e

- $\mathcal{P}$ é uma seqüência $\left(p_{1}, \ldots, p_{n}\right)$ de funções de custo.

A seguir apresentamos dois dos exemplos mais conhecidos em teoria dos jogos, o Dilema do Prisioneiro e o Par ou Ímpar.

No Dilema do Prisioneiro a polícia interroga em salas separadas dois prisioneiros acusados de cometer um crime. Cada um dos prisioneiros deve escolher entre confessar o 


\begin{tabular}{|r|cc|}
\hline Estratégias & confessar & não confessar \\
\hline confessar & $(5,5)$ & $(0,7)$ \\
não confessar & $(7,0)$ & $(1,1)$ \\
\hline
\end{tabular}

Tabela 3.1: Dilema do Prisioneiro.

\begin{tabular}{|r|cc|}
\hline Estratégias & $\mathrm{P}$ & $\mathrm{I}$ \\
\hline $\mathrm{P}$ & $(1,-1)$ & $(-1,1)$ \\
$\mathrm{I}$ & $(-1,1)$ & $(1,-1)$ \\
\hline
\end{tabular}

Tabela 3.2: Par ou Ímpar.

crime ou permanecer calado. Caso ambos confessem, ficarão presos por 5 anos. Caso nenhum dos dois confesse, serão condenados por um crime menor, ficando presos apenas um ano. No entanto, se apenas um dos presos confessar este será libertado e o outro ficará preso por 7 anos.

Podemos então definir o jogo Dilema-Prisioneiro onde $N=\{1,2\}, S_{1}=S_{2}=$ \{confessar, não confessar\} e os valores de $p_{i}$ são dados pela tabela 3.1, onde as linhas representam as estratégias do jogador 1 , as colunas representam as estratégias do jogador 2, e para cada possível escolha $s=\left(s_{1}, s_{2}\right)$ temos o par $\left(p_{1}(s), p_{2}(s)\right)$ representando o custo dos jogadores 1 e 2 , respectivamente.

Note que, apesar de a situação em que os dois prisioneiros ficam em silêncio ser intuitivamente a melhor solução possível para o grupo, cada um deles é incentivado a confessar, independentemente do que o outro faça. Caso o outro jogador confesse, é preferível confessar para cumprir 5 anos em vez de 7 . Caso o outro fique em silêncio, é preferível confessar para não passar um ano na cadeia.

No jogo Par ou Ímpar, dois jogadores escolhem simultaneamente um número. Caso a soma dos dois números seja par o jogador 1 ganha, caso contrário, o jogador 2 ganha. Note que o valor exato do número jogado não importa, cada jogador deve decidir apenas entre jogar um número par $(\mathrm{P})$ ou um número ímpar (I).

Definimos o jogo PAR-Impar onde $N=\{1,2\}, S_{1}=S_{2}=\{\mathrm{P}, \mathrm{I}\}$ e os valores de $p_{i}$ são dados pela tabela 3.2, onde as linhas representam as estratégias do jogador 1, as colunas representam as estratégias do jogador 2, e para cada possível escolha $s=\left(s_{1}, s_{2}\right)$ temos o par $\left(p_{1}(s), p_{2}(s)\right)$ representando o custo dos jogadores 1 e 2 , respectivamente.

Ao contrário do dilema do prisioneiro, em que se espera que um dos perfis aconteça, nenhum dos resultados deste jogo é estável. Em qualquer perfil de estratégias o jogador perdedor desejará trocar sua estratégia.

Para jogos com maior número de jogadores o tamanho do espaço de estratégias cresce rapidamente e geralmente é impraticável definir a função de custo através de uma tabela completa como feito acima. A ordem de preferência de cada jogador sobre os resultados do jogo geralmente é dada de forma "sucinta" [Pap07].

\subsection{Equilíbrio}

Descrevemos aqui de uma maneira mais precisa o conceito que na introdução chamamos de "estabilidade".

A notação $s_{-i}$ é utilizada para indicar o perfil de estratégias $s$ sem a estratégia $s_{i}$. Assim, 
se $s_{i}^{\prime}$ está em $S_{i}$, então $\left(s_{-i}, s_{i}^{\prime}\right)$ é equivalente a $\left(s_{1}, \ldots, s_{i-1}, s_{i}^{\prime}, s_{i+1}, \ldots, s_{n}\right)$.

Dizemos que uma estratégia $s_{i}$ em $S_{i}$ é uma melhor resposta do jogador $i$ para um perfil de estratégias $s$ se $i$ não pode diminuir seus gastos trocando apenas sua estratégia:

$$
p_{i}\left(s_{-i}, s_{i}\right) \leq p_{i}\left(s_{-i}, s_{i}^{\prime}\right) \text { para todo } s_{i}^{\prime} \in S_{i} .
$$

Uma estratégia $s_{i}^{*}$ em $S_{i}$ é uma estratégia dominante para $i$, se esta é uma melhor resposta sempre:

$$
p_{i}\left(s_{-i}, s_{i}^{*}\right) \leq p_{i}(s) \text { para todo } s \in S .
$$

Dizemos que um perfil de estratégias $s$ é um equilíbrio de Nash [Nas51] se todos os jogadores estão jogando uma melhor resposta para $s$. Em outras palavras, um equilíbrio é uma situação em que nenhum dos jogadores tem incentivo para desviar sozinho da estratégia escolhida.

Note que a condição de existência do equilíbrio requer apenas que nenhum jogador possa lucrar mudando sua estratégia sozinho. Um conceito mais exigente é o equilíbrio de Nash forte [Aum74], que corresponde a um perfil de estratégias no qual nenhum grupo, ou coalizão, de jogadores pode mudar suas estratégias de forma que todos os seus integrantes diminuam seus custos. Mais formalmente, um perfil de estratégias $s$ é um equilíbrio de Nash forte se para todo perfil $s^{\prime} \neq s$, existe um jogador $i$ que prefere $s$ a $s^{\prime}$, ou seja, $s_{i} \neq s_{i}^{\prime}$ e $p_{i}(s) \leq p_{i}\left(s^{\prime}\right)$.

No exemplo do Dilema do Prisioneiro, confessar é uma estratégia dominante para os dois jogadores, e o único equilíbrio de Nash é (confessar, confessar). Não há um equilíbrio forte, pois os dois jogadores lucrariam se mudassem suas estratégias de (confessar, confessar) para (não confessar, não confessar).

Nem todos os jogos possuem um equilíbrio de Nash, como o jogo Par ou Ímpar, por exemplo, e quando a função de custo é dada de forma sucinta, decidir se há um equilíbrio de Nash em um jogo arbitrário é um problema computacionalmente difícil [GGS03].

Quando um jogo não admite equilíbrio de Nash, ou quando encontrá-lo é muito custoso, uma alternativa, inspirada por algoritmos de aproximação, é o $\mu$-equilíbrio [CPV05]. Em um $\mu$-equilíbrio, a condição de que nenhum dos jogadores possa diminuir seu custo mudando de estratégia é relaxada, bastando que nenhum jogador possa diminuir seu custo por um fator de $\mu$ : $s$ é um $\mu$-equilíbrio se vale que $p_{i}(s) \leq \mu \cdot p_{i}\left(s_{-i}, s_{i}^{\prime}\right)$ para todo jogador $i$ e para toda estratégia $s_{i}^{\prime}$ em $S_{i}$.

Outra variante são os equilíbrios mistos, quando se permite que o jogador escolha uma distribuição de probabilidade sobre as estratégias em vez de escolher apenas uma deterministicamente. Nesse caso, sempre há ao menos um equilíbrio [Nas51], porém encontrá-lo é um problema PPAD-difícil [Pap07].

Existem ainda outras alternativas ao equilíbrio de Nash, no sentido de identificar quais resultados podem ser considerados aceitáveis em um jogo, como o equilíbrio correlato (correlated equilibrium) [Aum74], o equilíbrio de sorvedouro (sink equilibrium) [GMA05], entre outros, porém neste trabalho vamos nos ater ao equilíbrio de Nash.

\subsection{Ineficiência do equilíbrio}

Os equilíbrios de um jogo podem não ser "eficientes", no sentido de serem "piores" do que uma solução ótima para o grupo. No caso do Dilema do Prisioneiro, parece intuitivo que a solução em que os dois jogadores não confessam é melhor do que a única solução estável em que ambos confessam. Mas como medir tal ineficiência? 
Em primeiro lugar é necessário determinar qual o critério de otimalidade, ou seja, qual a função objetivo a ser considerada para tal medição. Duas candidatas comuns são a função objetivo utilitarista (utilitarian), também conhecida como custo social, que consiste em minimizar a soma dos custos dos jogadores ou maximizar a soma das utilidades, e a função objetivo igualitarista (egalitarian), que consiste em minimizar o maior custo entre os jogadores ou maximizar a menor utilidade.

Diremos que um perfil de estratégias é ótimo se este otimiza a função objetivo escolhida.

Uma vez definida a função objetivo, uma maneira comum de medir a ineficiência dos equilíbrios de um jogo é o preço da anarquia (PA) [KP99, Pap01], definido como a razão entre o pior valor da função objetivo para um equilíbrio e o valor de um perfil de estratégias ótimo. O preço da anarquia nos dá uma análise de pior caso de quanto pode ser perdido com a falta de coordenação entre os jogadores.

Por outro lado, o preço da estabilidade (PE) [SM03, $\left.\mathrm{ADK}^{+} 04\right]$ é definido como a razão entre o melhor valor da função objetivo para um equilíbrio e valor de um perfil de estratégias ótimo. Tal razão nos dá uma medida de quanto é perdido em função do comportamento dos jogadores. Mesmo com uma entidade coordenadora, é necessário que a solução obtida seja um equilíbrio, e, portanto, estamos interessados em analisar a eficiência da melhor solução que pode ser proposta.

No caso do Dilema do Prisioneiro, há apenas um equilíbrio (confessar,confessar) com custo social 10 e, portanto, o preço da anarquia e o preço da estabilidade terão o mesmo valor. Se estamos interessados em minimizar o custo social, o perfil ótimo será (não confessar,nao confessar), com custo 2 e, portanto, $\mathrm{PA}=\mathrm{PE}=\frac{10}{2}=5$.

É de interesse descobrirmos como os fatores da descrição do jogo influenciam estes valores, e quão ruins podem ser estes preços para uma classe de jogos. 


\section{Capítulo 4}

\section{Jogos de Steiner com Divisão Justa}

Seja $(G, c, \mathcal{R})$ uma instância do problema FSteiner (seção 2.2). Suponha, como na introdução, que para cada conjunto $R_{i}$ em $\mathcal{R}$ há um jogador $i$, responsável por construir uma rede que seja um subgrafo de $G$ e que conecte o conjunto de terminais $R_{i}$. O custo de uma rede é a soma dos custos das arestas na rede.

Estamos interessados em encontrar soluções para este problema com o menor custo possível para a rede construída, como no problema da floresta de Steiner. No entanto, cada jogador estará buscando uma árvore de Steiner com custo baixo que conecte seus terminais. O custo da árvore para cada jogador depende de um critério de divisão de custos pré-determinado.

Resta portanto decidir como os jogadores escolherão a rede a ser construída, e como o custo desta será dividido entre eles.

\subsection{Modelo com divisão justa dos custos}

Consideraremos o jogo em que cada jogador escolhe um conjunto de arestas que deseja construir para conectar seus terminais e no qual a divisão dos custos de uma aresta é feita igualmente entre todos os jogadores que a utilizam. Dizemos que uma aresta é comprada se está presente na estratégia de algum jogador.

Como os jogadores desejarão minimizar seus gastos, podemos considerar, sem perda de generalidade, que para cada jogador $i$ o conjunto de estratégias $S_{i}$ é formado pelas árvores de $G$ que contém $R_{i}$. Assim, um perfil de estratégias $s$ é uma lista $\left(T_{1}, \ldots, T_{n}\right)$ de árvores, onde $T_{i}$ é uma árvore que contém os vértices em $R_{i}$.

Suponha que $\left(T_{1}, \ldots, T_{n}\right)$ é um perfil de estratégias. Chamaremos de divisão justa dos custos de $\left(T_{1}, \ldots, T_{n}\right)$ aquela em que os custos das arestas são divididos igualmente entre os jogadores que as utilizam:

$$
p_{i}\left(T_{1}, \ldots, T_{n}\right)=\sum_{e \in T_{i}} \frac{c_{e}}{x_{e}\left(T_{1}, \ldots, T_{n}\right)},
$$

onde $x_{e}\left(T_{1}, \ldots, T_{n}\right)$ é o número de árvores em $\left(T_{1}, \ldots, T_{n}\right)$ que contém a aresta $e$.

Assim, um jogo de Steiner com divisão justa dos custos (StEInERJusto) para $(G, c, \mathcal{R})$ é definido como:

Jogo SteinerJusto $(G, c, \mathcal{R})=(N, \mathcal{S}, \mathcal{P})$

Dados um grafo $G$ com custos $c_{e}$ em $\mathbb{Q}_{\geq}$para cada aresta $e$ de $G$ e uma coleção de conjuntos de vértices $\mathcal{R}=\left(R_{1}, \ldots, R_{n}\right)$, o jogo é aquele em que:

- $N=\{1, \ldots, n\}$ é o conjunto de jogadores; 
- $\mathcal{S}$ é a sequência $\left(\mathcal{T}_{1}, \ldots, \mathcal{T}_{n}\right)$ sendo $\mathcal{T}_{i}$ o conjunto de árvores de $G$ que contém $R_{i}(i=1, \ldots, n) ; \mathrm{e}$

- $\mathcal{P}$ é uma sequência $\left(p_{1}, \ldots, p_{n}\right)$ de funções de custo sendo cada $p_{i}\left(T_{1}, \ldots, T_{n}\right)$ a divisão justa dos custos de $\left(T_{1}, \ldots, T_{n}\right)$ para $i$, onde $T_{j}$ é uma árvore em $\mathcal{T}_{j}(j=1, \ldots, n)$.

Este jogo tem sido estudado por diversos autores [ADK ${ }^{+}$4, Rou06, TW07] e seu modelo de divisão de custos pode ser derivado do chamado valor de Shapley do jogo [MS01]. Esta divisão possui diversas propriedades interessantes, como veremos na próxima sessão.

Analisaremos também a versão orientada do problema, na qual $G$ é um grafo orientado, cada elemento de $\mathcal{R}$ é um par ordenado $\left(a_{i}, b_{i}\right)$ e os jogadores devem pagar por um subgrafo no qual haja um caminho entre cada par. Assim como a versão não orientada do problema é uma extensão do problema da floresta de Steiner, esta variante é uma extensão do problema de Steiner orientado generalizado (seção 2.2).

Como veremos na seção 4.3, o jogo SteinerJusto sempre admite pelo menos um equilíbrio.

O custo social da rede resultante será a soma dos custos de suas arestas, e portanto o custo social de um perfil de estratégias ótimo do jogo $\operatorname{SteineRJusto}(G, c, \mathcal{R})$ corresponde ao custo de uma solução do problema $\operatorname{FSteiner}(G, c, \mathcal{R})$. É de interesse encontrarmos um equilíbrio para o jogo STEINERJusto que tenha custo social tão próximo quanto possível de uma solução do problema FSTEINER.

\subsection{Valor de Shapley}

Nesta seção, para facilitar a notação, utilizaremos a função de utilidade em vez da função de custo, lembrando que $u_{i}=-p_{i}$.

Em jogos com utilidade transferível [Mye97, cap. 9], ou seja, jogos em que os ganhos ou custos existem em um meio transferível, como dinheiro, e nos quais cada jogador, além de sua estratégia, pode decidir redistribuir parte de sua utilidade entre os outros jogadores, podemos definir uma função característica (worth) $v$, que associa a cada conjunto de jogadores $J$ um valor real $v(J)$ que indica a maior utilidade total que os elementos do grupo podem conseguir sem ajuda dos demais jogadores. Como exemplo, considere um jogo em que os jogadores são os funcionários de uma empresa e para cada subconjunto de jogadores $J, v(J)$ é o lucro obtido pela empresa se apenas os funcionários em $J$ existissem.

Assumimos que $v(\emptyset)=0$ e que $v$ é superaditiva, ou seja, a utilidade de uma coalizão, ou seja, um grupo não vazio de jogadores, deve ser no mínimo o que suas partes conseguiriam trabalhando separadamente:

$$
v\left(J_{1}\right)+v\left(J_{2}\right) \leq v\left(J_{1} \cup J_{2}\right) \text { para } J_{1}, J_{2} \subseteq N \text { disjuntos. }
$$

Em jogos com utilidade transferível a função característica é suficiente para descrever quais valores de utilidade podem ser conseguidos pelos membros da coalizão [Mye97]. Um jogo definido apenas por sua função característica é chamado de jogo na forma coalizional, ou simplesmente jogo coalizional.

Um valor $\phi$ para um jogo na forma coalizional $v$ é uma função que determina um número $\phi_{i}(v)$ para cada jogador $i$ que indica quanto este deve ganhar por sua participação no jogo.

Seja $v$ um jogo coalizional e $\pi$ uma permutação dos jogadores de $v$. Definimos o jogo 
coalizional $\pi v$ como o jogo $v$ com as posições dos jogadores permutadas. Mais precisamente,

$$
\pi v(\{\pi(i): i \in J\})=v(J) \text { para toda coalizão } J \subseteq N .
$$

Dizemos que um subconjunto $C$ de $N$ é um portador (carrier) de um jogo se

$$
v(J \cap C)=v(J) \text { para todo } J \subseteq N .
$$

Se $C$ é um portador, qualquer jogador fora de $C$ é um jogador nulo e sua participação em qualquer coalizão não afeta o resultado do jogo.

O valor de Shapley [Sha53] de um jogo coalizional $v$ corresponde a uma divisão $\phi$ dos ganhos que respeita três axiomas:

Simetria: O valor de um jogador não é influenciado por seu nome ou posição. Em símbolos,

$$
\phi_{\pi(i)}(\pi v)=\phi_{i}(v),
$$

para toda permutação $\pi$ dos jogadores.

Eficiência: O lucro total é completamente dividido pelos jogadores não nulos:

$$
\sum_{i \in C} \phi_{i}(v)=v(C) \text { para todo portador } C \text { de } v \text {. }
$$

Linearidade: Se $v$ e $w$ são dois jogos coalizionais com o mesmo conjunto de jogadores $N$, e $v+w$ é o jogo definido por $(v+w)(J)=v(J)+w(J)$ para todo $J$ em $N$, então

$$
\phi_{i}(v+w)=\phi_{i}(v)+\phi_{i}(w) \text { para todo } i \text { em } N
$$

Lloyd Stowell Shapley [Sha53] mostrou que há exatamente uma função $\phi$ que satisfaz estes três axiomas, dada por:

$$
\phi_{i}(v)=\sum_{i \in J \subseteq N} \frac{(|J|-1) !(n-|J|) !}{n !}(v(J)-v(J \backslash\{i\}))
$$

Este valor pode ser entendido como o ganho esperado para $i$ se os jogadores forem chamados a participar do jogo em uma ordem aleatória escolhida de forma uniforme, cada um recebendo o lucro adicionado a cada coalizão com a sua entrada $(v(J)-v(J \backslash\{i\}))$.

Como exemplo de uso do valor de Shapley, considere uma empresa formada por um investidor $i$ e $m$ empregados $e_{1}, \ldots, e_{m}$. Usando os recursos do investidor cada empregado produz um lucro $p$ para a empresa. O problema é decidir como dividir o lucro entre os envolvidos.

O conjunto de jogadores é $N=\left\{i, e_{1}, \ldots, e_{m}\right\}$ e o valor produzido por uma coalizão $S \subseteq N$ é $|S-1| \times p$ se o investidor está em $S(|S-1|$ empregados produzem $p$ cada) e zero caso contrário. Aplicando o valor de Shapley ao jogo, temos que o valor do investidor é $m p / 2$ e o valor de cada empregado é $p / 2$.

O critério de divisão de custos do jogo SteinerJusto pode ser derivado do valor de Shapley fixando-se as estratégias dos jogadores e, portanto, a rede a ser construída. A função característica para um conjunto de jogadores é o custo do grafo formado pela união de suas estratégias. Na divisão justa, o custo de cada aresta comprada é dividido independentemente (satisfazendo o critério de linearidade), o custo de cada aresta é dividido totalmente pelos jogadores que a utilizarão (divisão eficiente) e a divisão é feita igualmente entre estes (respeitando o critério de simetria). 


\subsection{Funções potenciais e equilíbrio}

Uma função potencial (exata) de um jogo [Ros73] é uma função $\Psi: S \rightarrow \mathbb{R}$ tal que, para todo jogador $i$, se $s$ é um perfil de estratégias e $s_{i}^{\prime}$ em $S_{i}$ é uma estratégia para $i$,

$$
\Psi(s)-\Psi\left(s_{-i}, s_{i}^{\prime}\right)=p_{i}(s)-p_{i}\left(s_{-i}, s_{i}^{\prime}\right) .
$$

Uma função potencial indica a variação no custo de um jogador quando este decide mudar sozinho sua estratégia.

Nem todos os jogos admitem funções potenciais ${ }^{1}$ e chamamos aqueles que as admitem de jogos potenciais [MS96].

Funções potenciais nos permitem demonstrar a existência de equilíbrio e fornecem um método para encontrar um limite superior para o preço da estabilidade do jogo.

Teorema 4.1 (da função potencial). Todo jogo SteInERJusto admite uma função potencial.

Demonstração. Considere, para cada aresta $e$ de um jogo $\operatorname{SteinerJusto}(G, c, \mathcal{R})$, a função

$$
\Psi_{e}\left(T_{1}, \ldots, T_{n}\right)=c_{e} \times \mathcal{H}_{k}
$$

onde $k=x_{e}\left(T_{1}, \ldots, T_{n}\right)$ é o número de jogadores que utilizam a aresta $e$ no perfil de estratégias $\left(T_{1}, \ldots, T_{n}\right)$, como definido anteriormente, e $\mathcal{H}_{k}$ é o $k$-ésimo número harmônico $(1+1 / 2+1 / 3+\ldots+1 / k)$. Seja $\Psi\left(T_{1}, \ldots, T_{n}\right)=\sum_{e \in E} \Psi_{e}\left(T_{1}, \ldots, T_{n}\right)$. Vamos mostrar que $\Psi$ é uma função potencial para o jogo STEINERJusto.

Suponha que os jogadores estejam jogando o perfil $\left(T_{1}, \ldots, T_{n}\right)$ e que o jogador $i$ deseja trocar sua estratégia $T_{i}$ por $T_{i}^{\prime}$. Seja $E^{+}=T_{i}^{\prime} \backslash T_{i}$ o conjunto das arestas novas compradas por $i$ e $E^{-}=T_{i} \backslash T_{i}^{\prime}$ o conjunto das arestas descartadas por este.

Para cada aresta $e$ em $E^{-}$, o jogador $i$ deixará de pagar

$$
\frac{c_{e}}{k)}
$$

ao fazer a troca, o que corresponde à variação de potencial da aresta:

$$
\Psi_{e}\left(T_{1}, \ldots, T_{n}\right)-\Psi_{e}\left(T_{1}, \ldots, T_{i}^{\prime}, \ldots, T_{n}\right)=\frac{c_{e}}{x_{e}\left(T_{1}, \ldots, T_{n}\right)} .
$$

Da mesma forma, para cada $e$ em $E^{+}$, o jogador $i$ passará a pagar

$$
\frac{c_{e}}{x_{e}\left(T_{1}, \ldots, T_{i}^{\prime}, \ldots, T_{n}\right)}=\frac{c_{e}}{k+1}
$$

valor correspondente ao crescimento do potencial de $e$ :

$$
\Psi_{e}\left(T_{1}, \ldots, T_{n}\right)-\Psi_{e}\left(T_{1}, \ldots, T_{i}^{\prime}, \ldots, T_{n}\right)=\frac{-c_{e}}{k+1}
$$

Para as demais arestas não haverá mudança no valor pago por $i$ nem no seu potencial, e, como $\Psi\left(T_{1}, \ldots, T_{n}\right)$ é simplesmente a soma do potencial de cada aresta, temos que $\Psi\left(T_{1}, \ldots, T_{n}\right)$ é uma função potencial do jogo SteinerJusto.

\footnotetext{
${ }^{1}$ Como o jogo Par-Impar mostrado no capítulo 3
} 
Corolário 4.2 (da existência do equilíbrio). Todo jogo STEINERJusto possui um equilibrio.

Demonstração. Como a função potencial está associada ao ganho ou perda de cada jogador, no perfil de estratégias que minimiza $\Psi$ nenhum jogador tem incentivo a desviar de sua estratégia, ou chegaríamos em um perfil com menor potencial. Assim, todo jogo potencial admite ao menos um equilíbrio e, mais do que isso, uma dinâmica de melhor resposta em que, a partir de um perfil inicial arbitrário os jogadores vão trocando suas estratégias, um de cada vez, até que todos estejam satisfeitos, convergirá para um equilíbrio.

Outra maneira de visualizar a função potencial é construir um digrafo auxiliar onde os vértices são os perfis de estratégia e há um arco entre dois perfis $s_{1}$ e $s_{2}$ se eles diferem apenas na estratégia de um jogador $i$. Nesse caso, o custo do arco $s_{1} s_{2}$ é dado por $c_{i}\left(s_{1}\right)-$ $c_{i}\left(s_{2}\right)$ (ou, utilizando uma função potencial, $u_{i}\left(s_{2}\right)-u_{i}\left(s_{1}\right)$ ). A figura 4.1 apresenta um jogo SteinerJusto e o digrafo auxiliar correspondente (apenas arcos de custo positivo estão indicados, $\left.\operatorname{CUsto}\left(s_{2} s_{1}\right)=-\operatorname{CUSTO}\left(s_{1} s_{2}\right)\right)$. Um jogo admite função potencial se e somente se é possível atribuir um valor a cada um dos vértices de forma que para todo arco a diferença do valor entre sua ponta inicial e final corresponde ao seu custo.

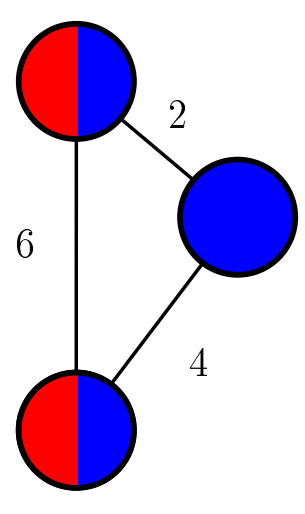

(a)

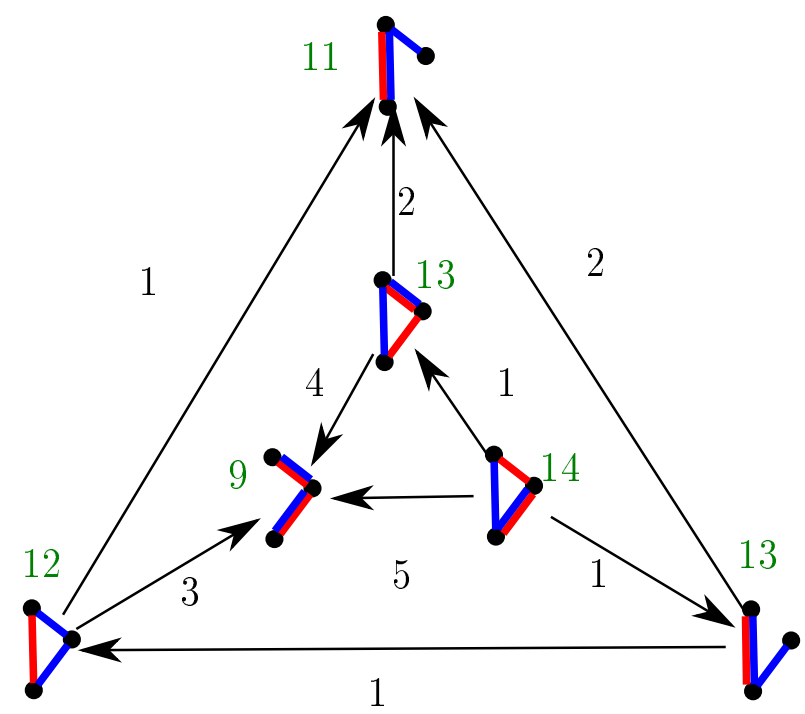

(b)

Figura 4.1: (a) Exemplo de jogo SteinerJusto e (b) digrafo auxiliar correspondente ao espaço de estratégias do jogo em (a). O número próximo a cada estratégia é o seu potencial. Os números próximos aos arcos indicam a variação do potencial entre as estratégias que são extremos do arco. Arcos de custo negativo são omitidos.

A figura 4.2 mostra o digrafo auxiliar do jogo PAR-IMPAR apresentado no capítulo 3, que não admite função potencial.

Apesar de a existência de equilíbrios ser garantida e a estratégia de todo jogador ser uma árvore, a rede resultante de um equilíbrio pode conter ciclos mesmo se cada jogador tiver apenas dois terminais, como mostra a figura 4.3.

\subsection{Complexidade computacional}

Apesar de a existência de equilíbrio em um jogo SteINERJusto ser garantida, decidir se há equilíbrio com custo no máximo $C$ no caso orientado é um problema computacionalmente difícil. 


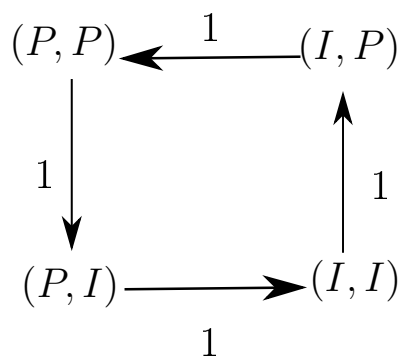

Figura 4.2: Digrafo auxiliar correspondente ao espaço de estratégias do jogo PAR-IMPAR. Como há um ciclo de custo não-nulo, não é possivel construir uma função potencial.

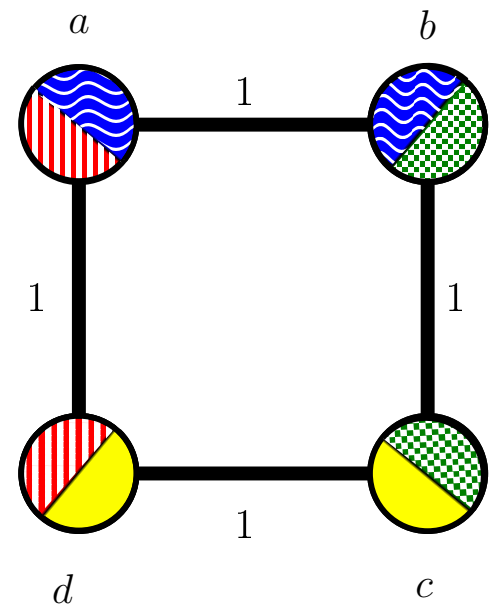

Figura 4.3: O único equilíbrio para o jogo compra todas as arestas do ciclo, formando uma rede redundante 
Teorema 4.3. Dado um jogo SteinerJusto orientado $(G, c, \mathcal{R})$ e um valor $C$, decidir se há um equilíbrio com custo social no máximo $C$ é um problema NP-completo mesmo que todos os jogadores possuam apenas dois terminais, com um deles comum a todos.

Demonstração. A redução é feita a partir do problema do empacotamento de 3-conjuntos, que é sabidamente NP-completo [GJ90]:

Problema Empacotamento-3-Conjuntos $(X, Y, Z, T)$ : Dados 3 conjuntos disjuntos $X, Y$ e $Z$ com $n$ elementos cada, e um conjunto de ternos $T \subseteq X \times Y \times Z$, decidir se existe um conjunto de $n$ ternos de $T$ tal que todo elemento de $X \cup Y \cup Z$ aparece em exatamente um dos ternos.

Chamamos um conjunto de $n$ ternos que é solução do problema EMPACOTAMENTO3-Conjuntos de um empacotamento perfeito. A figura 4.4 mostra uma instância do EMPACOTAMENTO-3-CONJUNTOS e o empacotamento perfeito correspondente.

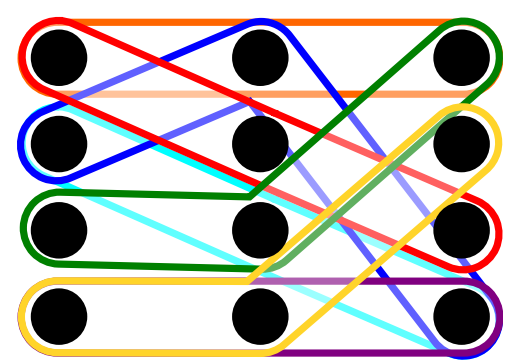

Figura 4.4: Problema do empacotamento de 3-conjuntos

Dada uma instância $X, Y, Z, T$ do problema do EmPACOTAMEnTo-3-Conjuntos, construiremos um jogo $\operatorname{SteinerJusto~}(G, c, \mathcal{R})$ e um valor $C$ como descrito a seguir.

Criaremos um vértice para cada elemento dos conjuntos $X, Y, Z$ e $T$, além de um vértice raiz $r$ :

$$
V_{G}:=X \cup Y \cup Z \cup T \cup\{r\}
$$

Para cada terno $t=(x, y, z)$ em $T$, criaremos arcos dos elementos para o terno e do terno para a raiz:

$$
\begin{aligned}
& A_{1}:=\{u t: u \in X \cup Y \cup Z, u \in t, t \in T\} \\
& A_{2}:=\{t r: t \in T\}
\end{aligned}
$$

Os arcos do tipo $A_{1}$ terão custo 0 enquanto os arcos do tipo $A_{2}$ terão custo 3 e $A_{G}:=A_{1} \cup A_{2}$.

Para cada elemento $x$ em $X \cup Y \cup Z$, haverá um jogador responsável por conectar $x$ a $r$.

$$
\mathcal{R}:=\{u r: u \in X \cup Y \cup Z\}
$$

Finalmente, definimos $C$ como o número de jogadores: $|X|+|Y|+|Z|=3 n$.

Suponha que $(X, Y, Z, T)$ possui um empacotamento perfeito, onde cada elemento $u \mathrm{em}$ $X \cup Y \cup Z$ está associado a um conjunto $t(u)$ em $T$. Então o perfil de estratégias em que o jogador associado a cada $u$ escolhe a estratégia $\{(u, t(u)),(t(u), r)$ é um equilíbrio com custo social exatamente $C$, pois cada jogador tem custo 1 e suas estratégias alternativas tem todas custo 3 . 


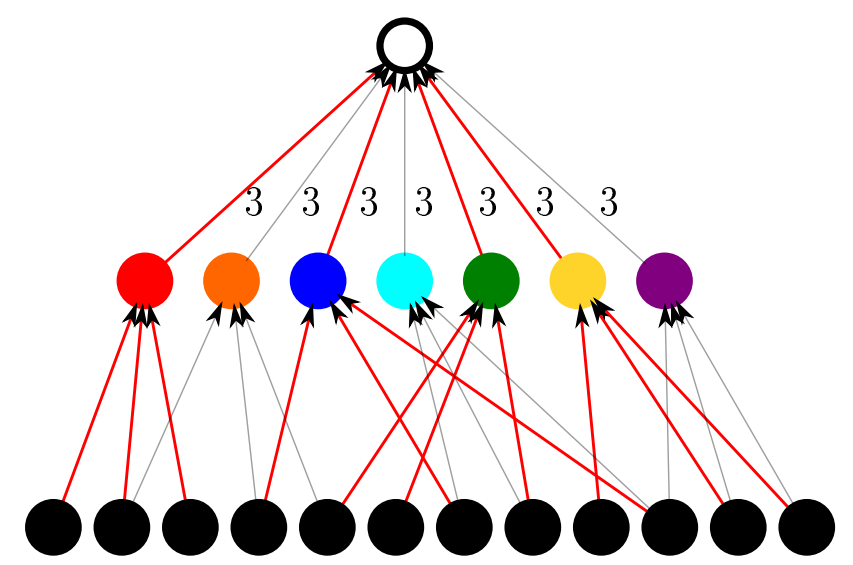

Figura 4.5: Jogo SteineRJusto criado a partir da instância apresentada na figura 4.4. A arborescência comprada por um equilíbrio aparece em destaque.

De forma similar, suponha que exista um equilíbrio para o jogo com custo social não superior a $C$.

Pela construção do grafo, o custo social de um perfil de estratégias nunca será menor que $C$, uma vez que toda estratégia válida usa um arco de custo 3 e cada um desses arcos só pode ser usado por 3 jogadores diferentes.

Se o custo social do equilíbrio é exatamente $C$, este deve usar $C / 3=n$ das arestas de custo 3 . Como cada uma destas arestas só pode ser usada por até 3 jogadores diferentes e o número de jogadores é exatamente $C$ temos que para cada aresta de custo 3 comprada, as três arestas de custo zero associadas a ela também serão usadas. Assim, o conjunto de 3-conjuntos associados às arestas "compradas" pelo equilíbrio forma um empacotamento perfeito.

Teorema 4.4. O problema de decidir se um dado perfil de estratégias para um jogo STEINERJUSTO é um equilíbrio é NP-completo.

Demonstração. Redução a partir do problema de decidir se uma árvore de Steiner dada é solução do problema ASTEINER (seção 2.2).

A partir de uma instância do $\operatorname{ASteiner}(G, c, R)$ podemos criar um jogo SteinerJusto com apenas um jogador, responsável por conectar os terminais de $R$. Uma árvore $T$ é solução do problema ASTEINER se e somente se a estratégia associada a $T$ for um equilíbrio no jogo STEINERJusto.

\subsection{Preço da anarquia}

No exemplo da introdução, a solução apresentada na figura 1.2 em que cada jogador paga pelas arestas de sua componente é um equilíbrio. Como a solução ótima do problema FSTEINER, mostrada na figura 1.1, tem custo 10 e o equilíbrio da figura 1.2 tem custo 11, temos que para esta instância específica o preço da anarquia é não inferior a 1,1 e o preço da estabilidade é não superior a 1,1. Mas como esses dois valores se comportam em uma instância genérica do jogo SteineRJusto?

Podemos verificar que o preço da anarquia em um jogo STEINERJusto não pode ser maior do que o número de jogadores, ou existiria algum jogador pagando mais que o custo da floresta ótima inteira e que, portanto, iria preferir pagar pela solução ótima sozinho a continuar com a sua estratégia. 


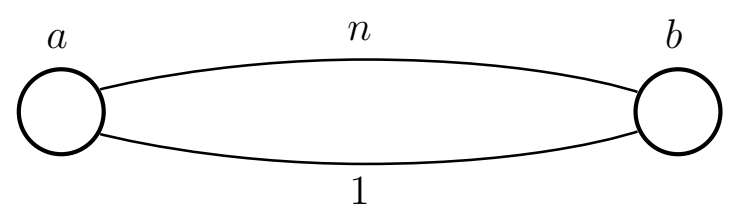

Figura 4.6: Instância com preço da anarquia $n$ onde $R_{i}=\{a, b\}$ para todo $i=1, \ldots, n$.

A figura 4.6 mostra uma instância simples em que o preço da anarquia chega a esse limite. Nesse exemplo todos os jogadores pretendem ligar o mesmo conjunto de vértices e há dois equilíbrios, cada um correspondendo à divisão de uma das arestas do grafo por todos os jogadores. No equilíbrio ótimo, todos os participantes dividem a aresta com custo 1. No entanto, o perfil de estratégias em que todos os jogadores dividem a aresta de custo $n$ também é um equilíbrio, pois nenhum deles conseguirá lucrar trocando sua estratégia sozinho. A próxima seção apresenta o preço da estabilidade, que é uma medida melhor da ineficiência do equilíbrio quando os jogadores estão dispostos a colaborar.

\subsection{Preço da estabilidade}

A figura 4.7 mostra uma instância do problema STEINERJusto na sua "versão orientada" com preço da estabilidade igual ao n-ésimo número harmônico

$$
\mathcal{H}_{n}=1+\frac{1}{2}+\frac{1}{3}+\cdots+\frac{1}{n} .
$$

A solução ótima possui custo $(1+\epsilon)$, a ser dividido igualmente pelos jogadores. Porém, no único equilíbrio cada jogador $i$ comprará sozinho a aresta de custo $1 / i$.

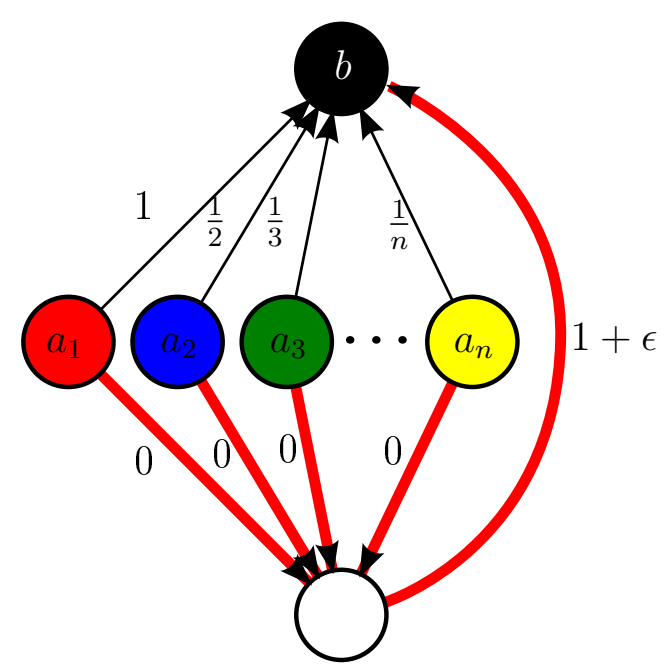

Figura 4.7: Instância com preço da estabilidade $\mathcal{H}_{n}$ onde $R_{i}=\left\{a_{i}, b\right\}$ para todo $i=1 \ldots n$.

Utilizando a função potencial, demonstraremos agora um limite para o preço da estabilidade de uma instância qualquer do STEINERJusto com $n$ jogadores. 
Teorema 4.5. Dado um jogo SteInerJusto, se no perfil de estratégias de menor custo social (floresta de Steiner de custo mínimo) cada aresta é compartilhada por no máximo $k$ jogadores, então o preço da estabilidade desse jogo é no máximo $\mathcal{H}_{k}$.

Demonstração. Seja $c(H)$ o custo social de um perfil de estratégias $\left(T_{1}, \ldots, T_{n}\right)$ qualquer, equivalente ao custo do subgrafo $H$ que contém cada árvore $T_{i}(i=1, \ldots, n)$ e $\Psi$ a função potencial do jogo. Note que

$$
c(H) \leq \Psi\left(T_{1}, \ldots, T_{n}\right) .
$$

Além disso, se cada aresta em $H$ é utilizada por no máximo $k$ jogadores,

$$
\Psi\left(T_{1}, \ldots, T_{n}\right) \leq \mathcal{H}_{k} c(H)
$$

Sejam $H^{\prime}$ o subgrafo correspondente a um perfil de estratégias $\left(T_{1}^{\prime}, \ldots, T_{n}^{\prime}\right)$ que minimiza o valor da função $\Psi$ e $H^{*}$ um perfil com custo social mínimo, ou seja, $H^{*}$ é uma $\mathcal{R}$-floresta de custo mínimo. Como vimos anteriormente, $H^{\prime}$ é um equilíbrio e temos que

$$
c\left(H^{\prime}\right) \leq \Psi\left(T_{1}^{\prime}, \ldots, T_{n}^{\prime}\right) \leq \Psi\left(T_{1}^{*}, \ldots, T_{n}^{*}\right) \leq \mathcal{H}_{k} c\left(H^{*}\right) .
$$

Portanto, o preço da estabilidade é no máximo $\mathcal{H}_{k}$.

Corolário 4.6. O preço da estabilidade de um jogo STEINERJusto com n jogadores é no máximo $\mathcal{H}_{n}$.

Demonstração. Segue do teorema 4.5 notando que cada aresta sempre é compartilhada por no máximo todos os jogadores.

Note que o alto preço da estabilidade desta instância depende fortemente do fato do grafo ser orientado, ou todos os jogadores teriam incentivo para dividir a aresta de custo $1 / n$. Não é conhecido o pior caso do preço da estabilidade para instâncias do jogo STEINERJusto com grafos não-orientados.

Apresentamos a seguir os exemplos de jogos SteINERJusto que encontramos com maior preço da estabilidade para dois e três jogadores.

O exemplo da figura 4.8 possui 2 jogadores e preço da estabilidade $3 / 2=\mathcal{H}_{2}$.

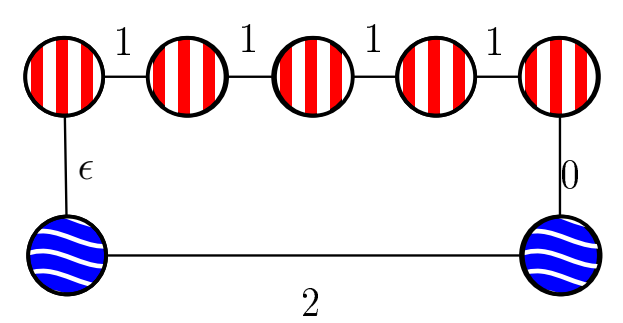

Figura 4.8: Instância não orientada com dois jogadores e preço da estabilidade $\mathcal{H}_{2}$.

A solução ótima possui custo $4+\epsilon$. Porém, o jogador $\mathbb{D}$ deve escolher entre pagar por todas as arestas de custo 1 ou deixar de comprar uma delas para pagar pelo caminho de custo $2+\epsilon$. As estratégias para o jogador $\&$ são pagar pela aresta de custo 2 ou pelo caminho de custo $4+\epsilon$. Como cada aresta será dividida por no máximo dois jogadores, o jogador $\mathbb{D}$ sempre terá incentivo em pagar pelas arestas de custo 1 enquanto o jogador $\&$ pagará pela aresta de custo 2, resultando em um equilíbrio de custo social 6 . 
No entanto, para mais de dois jogadores, não se sabe se o preço da estabilidade pode chegar a este limite. A figura 4.9 mostra o pior exemplo encontrado para três jogadores, com preço da estabilidade $190 / 115=38 / 23=1.652$.

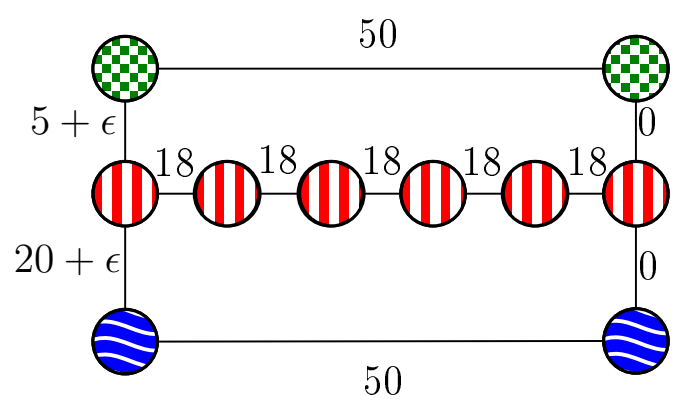

Figura 4.9: Instância não orientada com três jogadores. Preço da estabilidade 38/23.

A solução ótima corresponde à compra das arestas verticais e as de custo 18. Para o jogador $\mathbb{D}$, comprar as arestas de custo 18 é uma estratégia dominante. No entanto, o jogador $\&$ preferirá pagar sozinho pela aresta direta entre seus vértices. Uma vez que o jogador $\approx$ tenha alterado sua estratégia, o jogador $*$ preferirá comprar a aresta direta entre os seus.

Mostraremos a seguir alguns dos limitantes conhecidos para o preço da estabilidade quando o jogo possui algumas restrições. O exemplo da figura 4.7 respeita todas as restrições analisadas e portanto, o limite superior para o preço da estabilidade é o mesmo para as variantes no caso orientado. Assim, as seções seguintes consideram apenas grafos não orientados. 


\section{Capítulo 5}

\section{Jogos de Caminhos com Divisão Justa}

Decidir se um perfil de estratégias de um jogo SteinerJusto é um equilíbrio é computacionalmente difícil (teorema 4.4). Esta seção se restringe a jogos em que cada jogador deseja conectar apenas dois vértices terminais. Com tal restrição, verificar se um perfil de estratégias é um equilíbrio é equivalente a verificar se a estratégia de cada jogador é um caminho mínimo entre os seus terminais no grafo com custos convenientemente alterados.

Jogo $\operatorname{SteinerJustoCam~}(G, c, \mathcal{R})=(N, \mathcal{S}, \mathcal{P})$

Dados um grafo não-orientado $G$, um custo $c_{e}$ em $\mathbb{Q}_{\geq}$para cada aresta e uma sequência de $n$ pares de vértices $\mathcal{R}=\left(R_{1}, \ldots, R_{n}\right)$, com $R_{i}=\left(s_{i}, t_{i}\right)$, o jogo é aquele em que:

- $N=\{1, \ldots, n\}$ é o conjunto de jogadores;

- $\mathcal{S}$ é a sequência $\left(\mathcal{T}_{1}, \ldots, \mathcal{T}_{n}\right)$, sendo $\mathcal{T}_{i}$ o conjunto de caminhos em $G$ entre os vértices de $R_{i}$; e

- $\mathcal{P}$ é uma sequência $\left(p_{1}, \ldots, p_{n}\right)$ de funções de custo sendo cada $p_{i}\left(T_{1}, \ldots, T_{n}\right)$ o valor da divisão justa dos custos de $\left(T_{1}, \ldots, T_{n}\right)$ para o jogador $i$, onde $T_{j}$ é um caminho em $\mathcal{T}_{j}, j=1, \ldots, n$.

George Christodoulou, Christine Chung, Katrina Ligett, Evangelia Pyrga e Rob van Stee $\left[\mathrm{CCL}^{+} 10\right]$ demonstraram que para dois jogadores o preço da estabilidade é não superior a $4 / 3$ em vez de $\mathcal{H}_{2}=3 / 2$ como no caso orientado, mostrando que há uma diferença no preço da estabilidade dos dois jogos. Porém, para um número qualquer de jogadores não é conhecido nenhum limitante superior menor que $\mathcal{H}_{n}$.

O maior limite inferior conhecido para o preço da estabilidade de um jogo justo é $348 / 155 \approx 2,245$ [BCFM10]. A seguir apresentamos alguns dos exemplos com maior preço da estabilidade conhecidos.

\subsection{Preço da estabilidade para dois e três caminhos}

Apesar de a rede resultante de um equilíbrio não ser necessariamente uma floresta (figura 4.3), a união das estratégias de quaisquer dois jogadores não forma ciclos.

Teorema 5.1. Em um jogo SteinerJustoCAm, se dois jogadores compartilham dois vértices em um equilibrio, ambos utilizam um mesmo subcaminho entre estes vértices. 


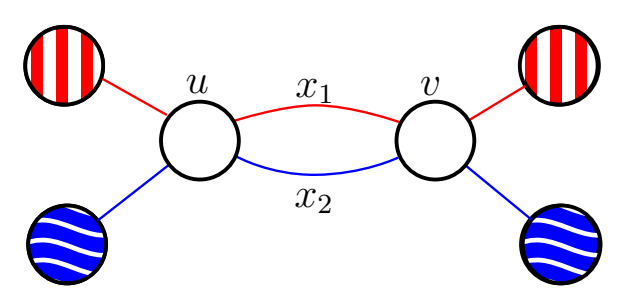

Figura 5.1: Em um equilíbrio os jogadores compartilham um caminho entre u e $v$.

Demonstração. Sejam $u$ e $v$ vértices presentes nas estratégias dos dois jogadores em um equilíbrio. Considere dois caminhos distintos entre $u$ e $v$ (figura 5.1). Suponha que o jogador $i$ utiliza um caminho entre $u$ e $v$ com custo individual $x_{i}$.

Se $x_{1}<x_{2}$ o jogador 2 pagará menos se mudar sua estratégia para o caminho $x_{1}$. Da mesma forma, se $x_{1}>x_{2}$, o jogador 1 será incentivado a desviar. Se $x_{1}=x_{2}$, os dois jogadores terão interesse em se unirem, diminuindo o custo individual do caminho escolhido.

Teorema $5.2\left(\left[\mathrm{CCL}^{+} 10\right]\right)$. O preço da estabilidade para qualquer jogo STEINERJUsToCAM com dois jogadores é não superior a $4 / 3$.

Demonstração. Sejam $\left(T_{1}^{*}, T_{2}^{*}\right)$ o perfil de estratégias de menor custo social e $\left(T_{1}^{\prime}, T_{2}^{\prime}\right)$ o perfil que minimiza a função potencial, e portanto é equilíbrio. Chamaremos de $H^{*}$ e $H^{\prime}$ os grafos construídos pelos perfis $\left(T_{1}^{*}, T_{2}^{*}\right)$ e $\left(T_{1}^{\prime}, T_{2}^{\prime}\right)$, respectivamente.

Caso $T_{1}^{*}$ e $T_{2}^{*}$ não tenham arestas em comum, o preço da estabilidade do jogo é 1, pelo teorema 4.5 .

Pelo teorema 5.1, sabemos que as arestas comuns a $T_{1}^{*}$ e $T_{2}^{*}$ formam um caminho.

Suponha que $\mathcal{R}=\left(\left(s_{1}, t_{1}\right),\left(s_{2}, t_{2}\right)\right)$ e, sem perda de generalidade, supomos que os dois jogadores percorrem seus vértices em comum na mesma ordem ao ir de $s_{i}$ a $t_{i}$. Chamaremos de $u$ o primeiro vértice deste subcaminho comum, e $v$ o último (arestas contínuas da figura 5.2).

Sejam $A^{\prime}$ o custo total das arestas em $T_{1}^{\prime} \backslash T_{2}^{\prime}, B^{\prime}$ o custo das arestas em $T_{2}^{\prime} \backslash T_{1}^{\prime}$ e $S^{\prime}$ o custo das arestas em $T_{1}^{\prime} \cap T_{2}^{\prime}$. Definimos $A^{*}, B^{*}$ e $S^{*}$ analogamente para $T_{1}^{*}$ e $T_{2}^{*}$.

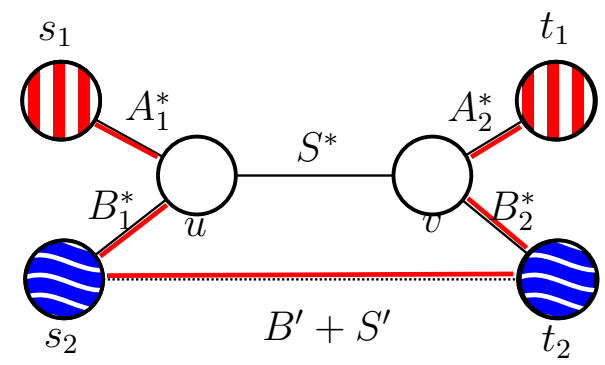

Figura 5.2: Instância genérica do problema. Floresta de Steiner de custo mínimo nas linhas continuas, estratégia do jogador 2 ( $\left(\right.$ ) no equilibrio na linha pontilhada. $A^{*}=A_{1}^{*}+A_{2}^{*}$ e $B^{*}=$ $B_{1}^{*}+B_{2}^{*}$.

Como $\left(T_{1}^{\prime}, T_{2}^{\prime}\right)$ é um perfil que minimiza a função potencial,

$$
A^{*}+B^{*}+\frac{3}{2} S^{*} \geq A^{\prime}+B^{\prime}+\frac{3}{2} S^{\prime} .
$$


Além disso, como $\left(T_{1}^{\prime}, T_{2}^{\prime}\right)$ é equilíbrio, $T_{1}^{\prime}$ deve ser melhor que qualquer outra estratégia para o jogador 1 . Considere a estratégia $P_{1}$ (figura 5.2) que consiste no caminho entre $s_{1}$ e $u$ em $T_{1}^{*}$, entre $u$ e $s_{2}$ em $T_{2}^{*}$, entre $s_{2}$ e $t_{2}$ em $T_{2}^{\prime}$ (aresta pontilhada), entre $t_{2}$ e $v$ em $T_{2}^{*}$ e entre $v$ e $t_{1}$ em $T_{1}^{*}$. $P_{1}$ é uma estratégia válida para o jogador 1 e portanto

$$
A^{*}+B^{*}+\frac{1}{2} B^{\prime}+\frac{1}{2} S^{\prime} \geq A^{\prime}+\frac{1}{2} S^{\prime} .
$$

Construindo a estratégia $P_{2}$ de forma análoga para o jogador 2 ,

$$
B^{*}+A^{*}+\frac{1}{2} A^{\prime}+\frac{1}{2} S^{\prime} \geq B^{\prime}+\frac{1}{2} S^{\prime}
$$

Somando as duas desigualdades acima e multiplicando por dois, obtemos a relação

$$
4 A^{*}+4 B^{*} \geq A^{\prime}+B^{\prime}
$$

E finalmente,

$$
\begin{aligned}
4 c\left(T_{1}^{*} \cup T_{2}^{*}\right) & =4 A^{*}+4 B^{*}+4 S^{*} \\
& =\frac{4}{3}\left(A^{*}+B^{*}\right)+\frac{8}{3}\left(A^{*}+B^{*}+\frac{3}{2} S^{*}\right) \\
& \geq \frac{1}{3}\left(A^{\prime}+B^{\prime}\right)+\frac{8}{3}\left(A^{\prime}+B^{\prime}+\frac{3}{2} S^{\prime}\right) \\
& =3 A^{\prime}+3 B^{\prime}+4 S^{\prime} \\
& \geq 3\left(A^{\prime}+B^{\prime}+S^{\prime}\right) \\
& =3 c\left(T_{1}^{\prime} \cup T_{2}^{\prime}\right)
\end{aligned}
$$

A figura 5.3 mostra uma instância com preço da estabilidade 4/3. Na solução de menor custo social a aresta de custo $1+\epsilon$ é comprada, juntamente com uma das arestas de custo 2. No entanto, cada jogador prefere comprar sua aresta de custo 2 sozinho a compartilhar o caminho alternativo.

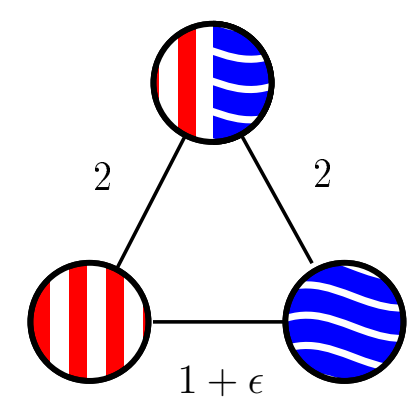

Figura 5.3: SteinerJustoCam com jogadores $\mathbb{D} e$ e preço da estabilidade 4/3.

No entanto, para mais jogadores, não é conhecido um limitante justo para o preço da estabilidade.

De forma semelhante à demonstração anterior, Christodolou et al. mostraram um limite superior de 1,65 para jogos com três jogadores $\left[\mathrm{CCL}^{+} 10\right]$. 
Teorema 5.3 ([CCL $\left.\left.{ }^{+} 10\right]\right)$. O preço da estabilidade para um jogo StEINERJustoCAm com três jogadores é não superior $33 / 20=1,65$.

Demonstração. Considere um jogo SteinerJustoCam $(G, c, \mathcal{R})$. Seja $F^{\prime}=\left(T_{1}^{\prime}, T_{2}^{\prime}, T_{3}^{\prime}\right)$ um perfil de estratégias que minimiza a função potencial do jogo, e portanto, é equilíbrio, e $F^{*}=\left(T_{1}^{*}, T_{2}^{*}, T_{3}^{*}\right)$ um perfil com custo social mínimo, correspondente a uma solução para o problema $\operatorname{FSteineR}(G, c, \mathcal{R})$. Queremos mostrar que $c\left(F^{\prime}\right) \leq 33 / 20 \times c\left(F^{*}\right)$.

Definimos $S_{i}^{\prime}$ como o conjunto de arestas compradas apenas pelo jogador $i$ em $F^{\prime}, S_{i j}^{\prime}$, com $i<j$, o conjunto das arestas compartilhadas apenas entre os jogadores $i$ e $j$ e $S_{123}^{\prime}$ o conjunto das arestas compradas por todos os jogadores. $S_{i}^{*}, S_{i j}^{*}$ e $S_{123}^{*}$ são definidos de forma análoga para o perfil $F^{*}$.

Se $S_{123}^{*}=\emptyset$, pelo teorema 4.5 o preço da estabilidade do jogo é no máximo $\mathcal{H}_{2}=1,5$.

Se $S_{123}^{*} \neq \emptyset$, como $F^{*}$ é uma floresta de Steiner de custo mínimo, o grafo resultante não possui ciclos e podemos concluir que as arestas em $S_{123}^{*}$ formam um caminho e que pelo menos um entre os conjuntos $S_{12}^{*}, S_{13}^{*}$ e $S_{23}^{*}$ é vazio. Vamos assumir, sem perda de generalidade que $S_{13}^{*}=0$.

Além disso, identificaremos os terminais do jogador $i$ como $s_{i}$ e $t_{i}$ de forma que todos os jogadores percorrem $S_{123}^{*}$ na mesma ordem ao ir de $s_{i}$ a $t_{i}$, como na figura 5.4.

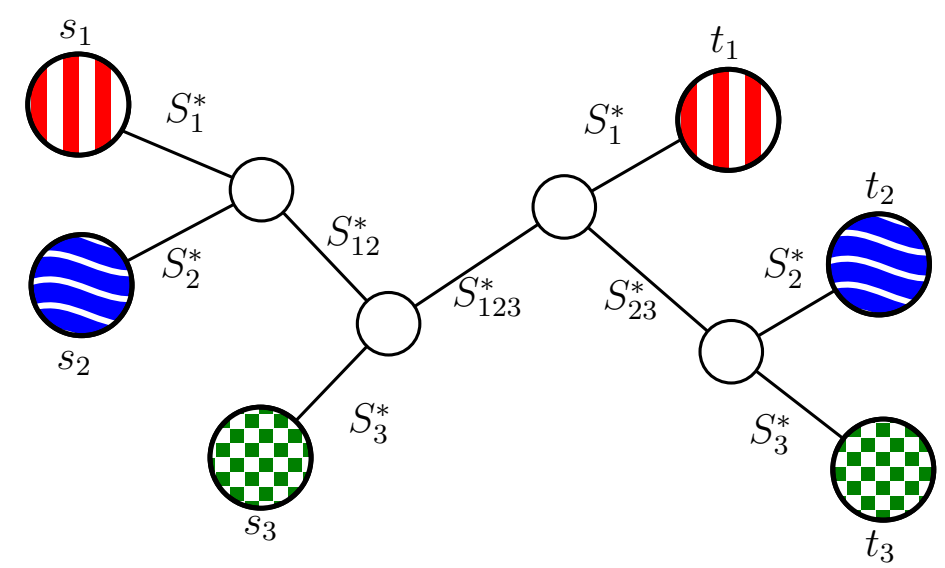

Figura 5.4: SteinerJustoCam com $S_{13}=0$.

Como $F^{\prime}$ é o perfil que minimiza a função potencial, temos que

$$
S_{1}^{\prime}+S_{2}^{\prime}+S_{3}^{\prime}+\frac{3}{2} S_{12}^{\prime}+\frac{3}{2} S_{13}^{\prime}+\frac{3}{2} S_{23}^{\prime}+\frac{11}{6} S_{123}^{\prime} \leq S_{1}^{*}+S_{2}^{*}+S_{3}^{*}+\frac{3}{2} S_{12}^{*}+\frac{3}{2} S_{23}^{*}+\frac{11}{6} S_{123}^{*} .
$$

Além disso, como $F^{\prime}$ é equilíbrio, nenhum jogador diminuirá seus custos mudando sua estratégia. Considere a estratégia $P_{12}$ para o jogador 1 , que consiste no jogador 1 se ligar aos terminais do jogador 2 usando as arestas em $F^{*}$ e utilizar as mesmas arestas que este, ou seja, o jogador 1 pagará pelas arestas de $s_{1}$ a $s_{2}$ no grafo construído por $F^{*}$ (possivelmente usando arestas em $S_{1}^{*}, S_{2}^{*}$ e $S_{23}^{*}$ ), pelas arestas de $s_{2}$ a $t_{2}$ no grafo construído por $F^{\prime}$ (arestas em $S_{2}^{\prime}, S_{12}^{\prime}, S_{23}^{\prime}$ e $S_{123}^{\prime}$ ) e de $t_{2}$ a $t_{1}$ em $F^{*}$ (também possivelmente usando arestas em $S_{1}^{*}, S_{2}^{*}$ e $\left.S_{23}^{*}\right)$. Então

$S_{1}^{\prime}+\frac{S_{12}^{\prime}}{2}+\frac{S_{13}^{\prime}}{2}+\frac{S_{123}^{\prime}}{3}=c_{1}\left(F^{\prime}\right) \leq c_{1}\left(P_{12}, T_{2}^{\prime}, T_{3}^{\prime}\right) \leq S_{1}^{*}+S_{2}^{*}+S_{23}^{*}+\frac{S_{2}^{\prime}}{2}+\frac{S_{12}^{\prime}}{2}+\frac{S_{23}^{\prime}}{3}+\frac{S_{123}^{\prime}}{3}$. 
De forma similar, podemos definir as estratégias $P_{21}$ e $P_{23}$ para o jogador 2 e a estratégia $P_{32}$ para o jogador 3 , obtendo restrições semelhantes:

O jogador 2 não tem interesse em desviar para $P_{21}$ :

$$
S_{2}^{\prime}+\frac{S_{12}^{\prime}}{2}+\frac{S_{23}^{\prime}}{2}+\frac{S_{123}^{\prime}}{3} \leq S_{2}^{*}+S_{1}^{*}+S_{23}^{*}+\frac{S_{1}^{\prime}}{2}+\frac{S_{12}^{\prime}}{2}+\frac{S_{13}^{\prime}}{3}+\frac{S_{123}^{\prime}}{3} .
$$

O jogador 2 não tem interesse em desviar para $P_{23}$ :

$$
S_{2}^{\prime}+\frac{S_{12}^{\prime}}{2}+\frac{S_{23}^{\prime}}{2}+\frac{S_{123}^{\prime}}{3} \leq S_{2}^{*}+S_{3}^{*}+S_{12}^{*}+\frac{S_{3}^{\prime}}{2}+\frac{S_{23}^{\prime}}{2}+\frac{S_{13}^{\prime}}{3}+\frac{S_{123}^{\prime}}{3} .
$$

O jogador 3 não tem interesse em desviar para $P_{32}$ :

$$
S_{3}^{\prime}+\frac{S_{23}^{\prime}}{2}+\frac{S_{13}^{\prime}}{2}+\frac{S_{123}^{\prime}}{3} \leq S_{3}^{*}+S_{2}^{*}+S_{12}^{*}+\frac{S_{2}^{\prime}}{2}+\frac{S_{23}^{\prime}}{2}+\frac{S_{12}^{\prime}}{3}+\frac{S_{123}^{\prime}}{3} .
$$

Multiplicando as restrições associadas a $P_{12}$ e $P_{32}$ por $10 / 99$, as associadas a $P_{21}$ e $P_{23}$ por 8/99, a restrição da função potencial por 6/11 e somando as cinco desigualdades obtemos

$$
\begin{aligned}
\frac{20}{33}\left(S_{1}^{\prime}+\right. & \left.S_{2}^{\prime}+S_{3}^{\prime}\right)+\frac{257}{297} S_{13}^{\prime}+\frac{245}{297}\left(S_{12}^{\prime}+S_{23}^{\prime}\right)+S_{123}^{\prime} \\
& \leq \frac{8}{11}\left(S_{1}^{*}+S_{3}^{*}\right)+\frac{10}{11} S_{2}^{*}+S_{12}^{*}+S_{13}^{*}+S_{123}^{*}
\end{aligned}
$$

e, portanto, $c\left(F^{\prime}\right) \leq \frac{33}{20} c\left(F^{*}\right)$.

Note ainda que pela demonstração acima, se um jogo SteinerJustoCAm com três jogadores possui preço da estabilidade 33/20, então

$$
S_{13}^{\prime}=S_{12}^{\prime}=S_{23}^{\prime}=S_{123}^{\prime}=\emptyset \text { e } S_{1}^{*}=S_{2}^{*}=S_{3}^{*}=\emptyset .
$$

Assim, em palavras, nenhuma aresta do equilíbrio $\left(T_{1}, T_{2}, T_{3}\right)$ é compartilhada por dois caminhos e todas as arestas do perfil $\left(T_{1}^{*}, T_{2}^{*}, T_{3}^{*}\right)$ de menor custo social são compartilhadas por pelo menos dois caminhos.

O maior limitante inferior conhecido para três jogadores é apresentado na figura 5.5, com preço da estabilidade $74 / 48 \geq 1,541\left[\mathrm{CCL}^{+} 10\right]$.

Nesse jogo, o perfil de menor custo social corresponde às quatro arestas horizontais, porém no único equilíbrio cada jogador compra as arestas diretas entre seus terminais.

\subsection{Uma estabilidade cara}

Mostraremos a seguir uma família de jogos SteinerJustoCam com preço da estabilidade $\operatorname{PE}\left(J_{k}\right)=1+\frac{1}{2 !}+\frac{1}{3 !}+\ldots+\frac{1}{k !}$. Portanto, quando $k$ cresce, o valor do preço da estabilidade de $J_{k}$ tende a $e-1>1,718$.

Definiremos os jogos $J_{1}, J_{2}, J_{3}, \ldots$ No jogo $J_{1}$ há um jogador que deseja conectar dois terminais em um grafo com uma única aresta de custo 1, como mostra a figura 5.6(a).

Para $k>1, J_{k}$ corresponde a $k$ cópias do jogo $J_{k-1}$ concatenadas e de um jogador novo (ao qual chamaremos de jogador do nível $k$ ou jogador associado a este $J_{k}$ ) como mostra a figura 5.9. As figuras 5.6(b), 5.7 e 5.8 mostram os jogos $J_{2}, J_{3}$ e $J_{4}$, respectivamente.

Teorema 5.4 (do número de jogadores). O número de jogadores em $J_{k} e ́ \frac{k !}{1 !}+\frac{k !}{2 !}+\frac{k !}{3 !}+\ldots+\frac{k !}{k !}$. 


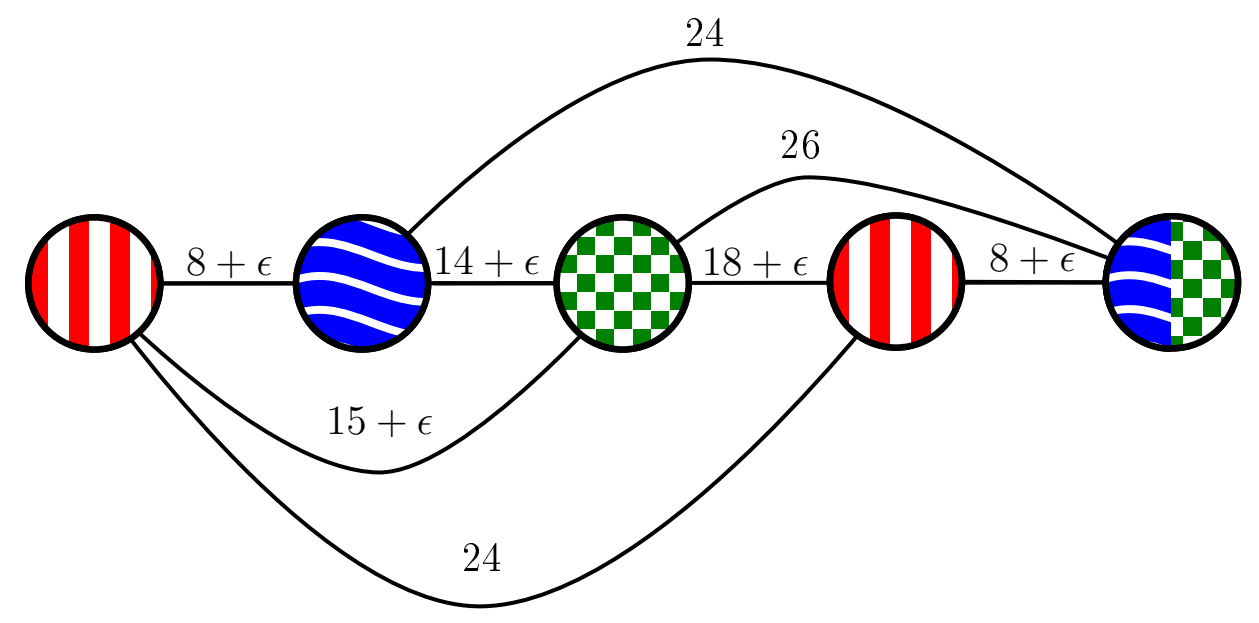

Figura 5.5: SteinerJusto com três jogadores $\mathbb{D}, \theta e$ e preço da estabilidade $74 / 48 \geq 1,541$.

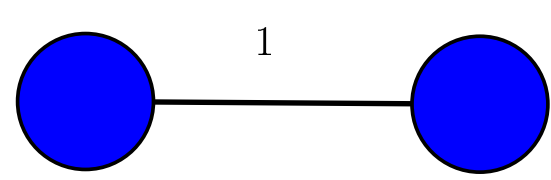

(a)

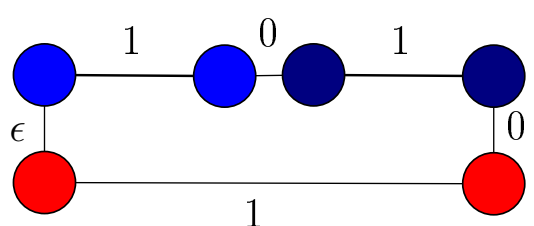

(b)

Figura 5.6: Jogos (a) $J_{1}$ e (b) $J_{2}$.

Demonstração. A demonstração é por indução em $k$. Seja $n_{k}$ o número de jogadores do jogo $J_{k}$. Para $k=1$ há apenas um jogador e portanto $n_{1}=1=\frac{1 !}{1 !}$.

Suponha que $k>1$. Então, pela hipótese de indução, $n_{k-1}=(k-1) !+\frac{(k-1 !)}{2 !}+\cdots+\frac{(k-1) !}{(k-1) !}$.

O jogo $J_{k}$ é formado por $k$ cópias de $J_{k-1}$ e um jogador novo. Assim o número de jogadores em $J_{k}$ é:

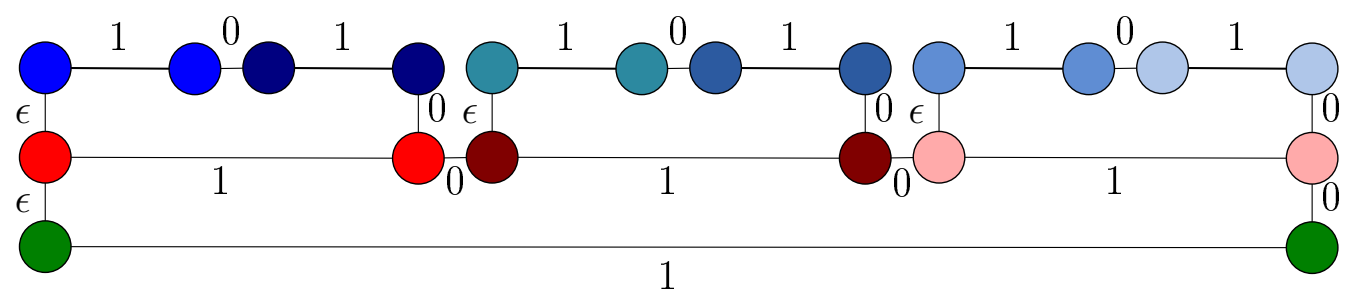

Figura 5.7: Jogo $J_{3}$. 


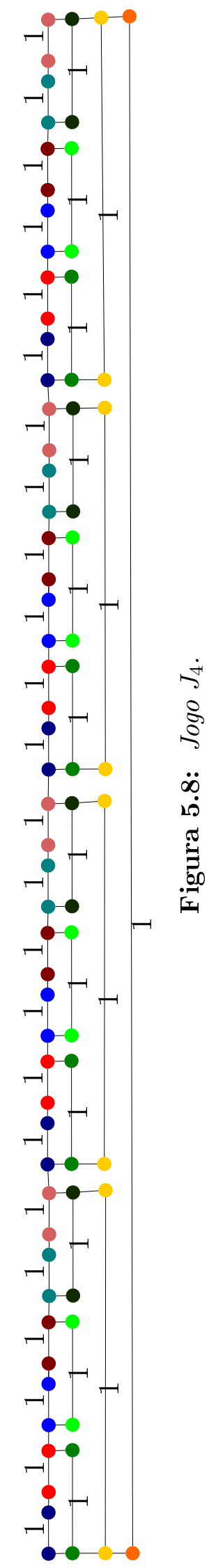




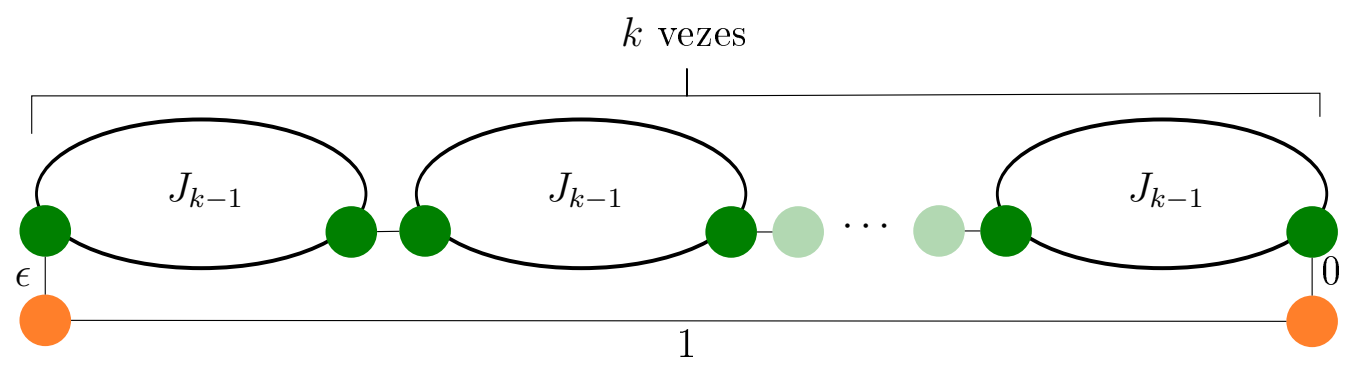

Figura 5.9: Ilustração do jogo $J_{k}$.

$$
\begin{aligned}
n_{k} & =k \times n_{k-1}+1 \\
& =k \times\left((k-1) !+\frac{(k-1 !)}{2 !}+\cdots+\frac{(k-1) !}{(k-1) !}\right)+\frac{k !}{k !} \\
& =k !+\frac{k !}{2 !}+\cdots+\frac{k !}{(k-1) !}+\frac{k !}{k !} .
\end{aligned}
$$

Para facilitar a análise do jogo, dividiremos as possíveis estratégias de cada jogador em três grupos:

- direta: a estratégia que consiste em comprar a aresta direta entre os dois terminais do jogador (figura 5.10).

- por cima: para jogadores de um nível $i>1$, qualquer caminho que passe apenas por arestas horizontais de níveis $j<i$ (figura 5.11).

- por baixo: para jogadores de um nível $<k$, qualquer caminho que utilize alguma aresta horizontal de um nível $j>i$ (figura 5.12).

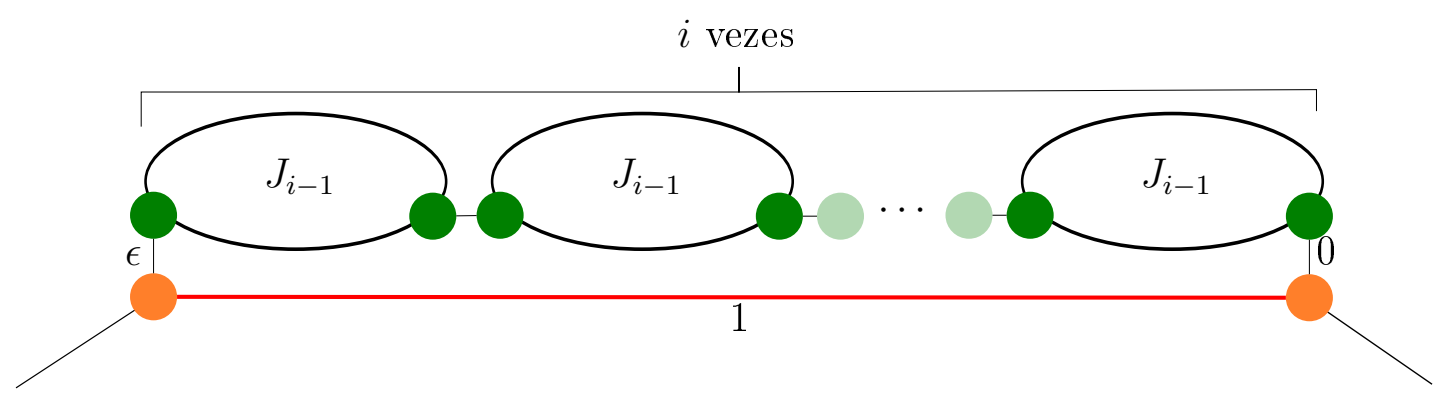

Figura 5.10: Ilustração da estratégia direta de um jogador do nível $i$ (○).

Se um jogador de um nível $i$ que usa uma estratégia por baixo paga por uma aresta do nível $i+h$ dizemos que o jogador desce $h$ níveis. Equivalentemente, dizemos que um jogador de nível $i$ sobe $h$ níveis se este paga por uma aresta horizontal do nível $i-h$.

Dizemos que um jogador atravessa uma cópia de $J_{i}$ em um perfil de estratégias se este não possui terminais em $J_{i}$ mas utiliza alguma de suas arestas. Note que um jogador do 


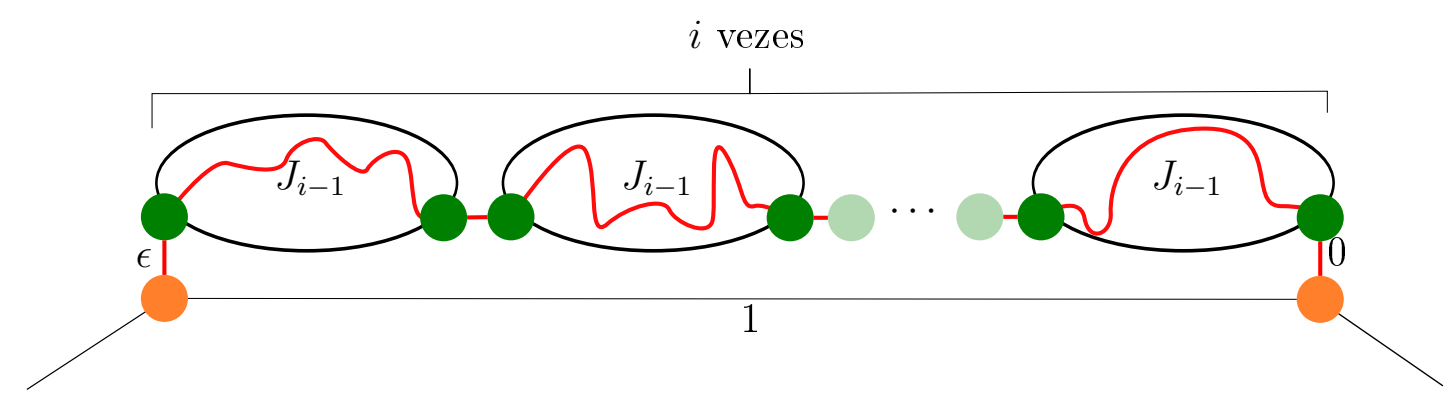

Figura 5.11: Ilustração de uma estratégia por cima de um jogador do nível $i(\bigcirc)$.

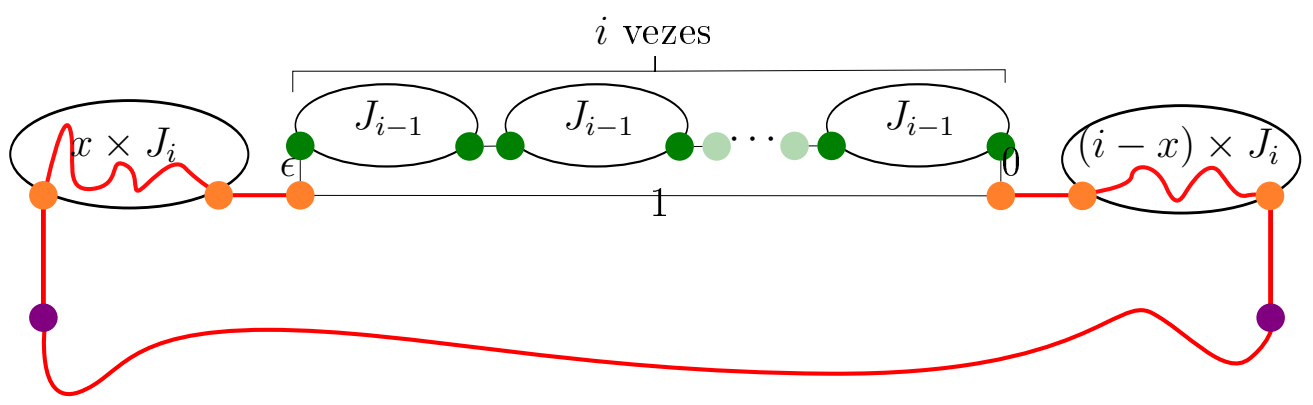

Figura 5.12: Ilustração de uma estratégia por baixo de um jogador de nível $i(\bigcirc)$.

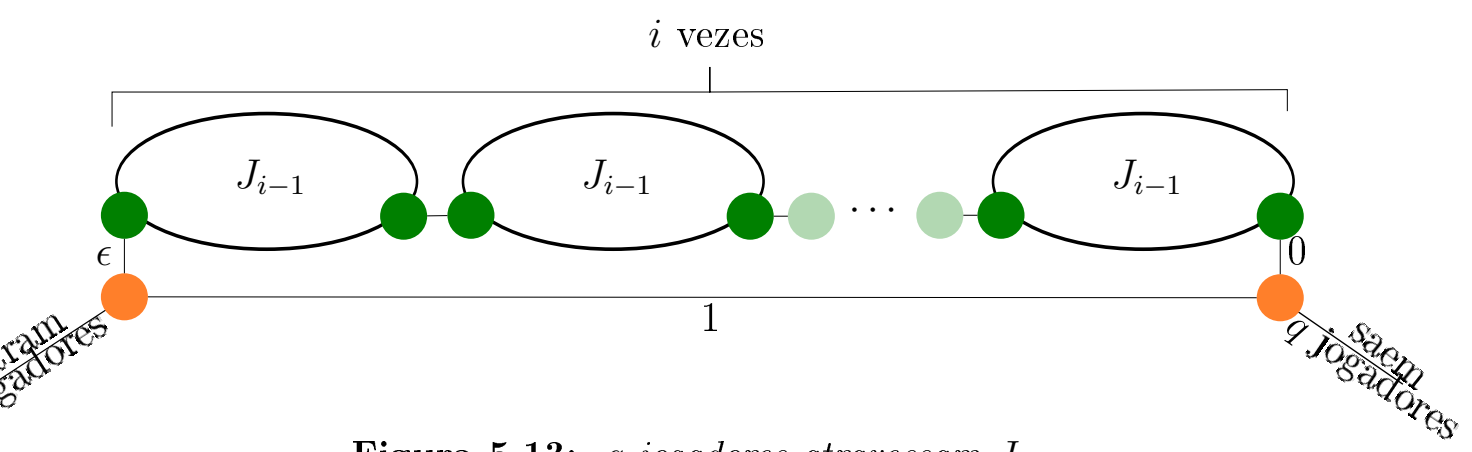

Figura 5.13: q jogadores atravessam $J_{i}$. 
nível $i$ que escolhe uma estratégia por cima deve atravessar $i$ cópias de $J_{i-1}$ e um jogador que escolhe uma estratégia por baixo deve atravessar $i$ cópias de $J_{i}$.

Como o caminho de qualquer jogador que atravessa um $J_{i}$ deve passar pelos terminais do jogador associado a esse $J_{i}$ (figura 5.13), pelo teorema 5.1 todos os jogadores que atravessam um $J_{i}$ pagam pelas mesmas arestas do jogador associado a esse $J_{i}$. Consequentemente, se em um equilíbrio algum jogador atravessa um $J_{i}$ o jogador associado a este subjogo não utiliza uma estratégia por baixo.

Note que em cada cópia de $J_{i+1}$ apenas um dos $i+1$ jogadores do nível $i$ pode utilizar uma estratégia por baixo em um equilíbrio, uma vez que tal jogador deverá para isso atravessar as outras $i$ cópias de $J_{i}$

Teorema 5.5 (do custo social). A floresta de Steiner de custo mínimo correspondente ao jogo $J_{k}$ tem custo $k !+\sum_{i=2}^{k} \frac{k !}{i !} \epsilon$.

Demonstração. Podemos verificar que a árvore geradora mínima do grafo tem custo

$$
k !+\sum_{i=2}^{k} \frac{k !}{i !} \epsilon .
$$

Uma possível árvore com tal custo corresponde às arestas horizontais do nível 1 além de todas as arestas de custo 0 ou $\epsilon$ do grafo.

Seja $\mathcal{F}_{k}$ a floresta de Steiner de custo mínimo que conecta os pares de terminais no grafo. Note que caso $\mathcal{F}_{k}$ não seja conexa, podemos conectá-la adicionando as arestas de custo zero.

Como agora $\mathcal{F}_{k}$ é conexa e liga todos os vértices do grafo (uma vez que todo vértice é terminal), temos que $\mathcal{F}_{k}$ é uma árvore geradora. Além disso, como qualquer árvore geradora mínima $\mathcal{T}$ é uma solução viável para o problema da floresta de Steiner, o custo de $\mathcal{F}_{k}$ deve ser pelo menos o da árvore geradora mínima do grafo e portanto, a árvore descrita acima é solução ótima do problema.

Lema 5.6. O perfil de estratégias do jogo $J_{k}$ em que cada jogador paga apenas pela aresta direta entre os seus terminais é um equilíbrio de custo social $\frac{k !}{1 !}+\frac{k !}{2 !}+\frac{k !}{3 !}+\ldots+\frac{k !}{k !}$.

Demonstração. Na solução proposta, cada aresta de custo 1 é usada por apenas um jogador.

Para um jogador $i$ arbitrário, qualquer caminho que não seja a aresta direta entre seus terminais passará por uma aresta de custo $\epsilon$ e ao menos duas arestas de custo 1, pelas quais este deverá pagar $\frac{1}{2}$. Assim qualquer desvio implicará em um custo mínimo de $1+\epsilon$, enquanto o caminho direto tem custo 1 .

O custo social de tal perfil corresponde ao número de jogadores.

Mostraremos agora que a solução em que todos os jogadores compram as arestas diretas entre seus terminais é o único equilíbrio do jogo. A demonstração será dividida em alguns lemas.

Lema 5.7. Se nenhum jogador de nível menor que $i-1$ desce dois niveis, para que $q$ jogadores externos atravessem uma cópia de $J_{i}$, cada um destes deverá pagar ao menos $\frac{1}{q+2}$.

Demonstração. Por indução em $i$. $J_{1}$.

Se $i=1$, cada um dos $q$ jogadores externos pagará exatamente $\frac{1}{q+1}>\frac{1}{q+2}$ para atravessar

Se $i>1$, os jogadores externos seguirão o jogador $i$, que pode utilizar sua aresta direta, ou atravessar $i$ cópias de $J_{i-1}$. 
Se $i$ utilizar a aresta direta, como nenhum dos jogadores acima desce dois níveis, no máximo um jogador (do nível $i-1$ ) aceitará pagar por um caminho que use a aresta em questão, e o custo para os jogadores externos será de no mínimo $\frac{1}{q+2}$.

Se $i$ não utilizar a aresta direta, $i$ e os $q$ jogadores externos deverão atravessar $i$ cópias de $J_{i-1}$, pagando ao menos $\frac{i}{(q+1)+2}$ pela hipótese de indução e, como $i>1$, tal valor é maior que $\frac{1}{q+2}$.

Lema 5.8. Em um equilíbrio nenhum jogador desce dois níveis.

Demonstração. Por indução em $i$.

Se $i=1$, para um jogador do nível 1 descer dois níveis deverá pagar por uma aresta de custo $\epsilon$, atravessar sozinho uma cópia de $J_{1}$, pagando $\frac{1}{1+1}$ e, junto apenas do jogador do nível 2 abaixo deverá atravessar duas cópias de $J_{2}$, pagando ao menos $\frac{1}{2+2}$ por cada cópia (lema 5.7 ), resultando em um custo total mínimo de $\frac{1}{2}+\frac{2}{4}+\epsilon>1$, e portanto preferirá comprar sua aresta direta sozinho a descer dois níveis.

Se $i>1$, pela hipótese de indução nenhum jogador acima descerá para o nível $i+1 \mathrm{e}$ o lema 5.7 vale para $J_{i}$ e $J_{i+1}$. Portanto, um jogador do nível $i$ deverá atravessar sozinho $i$ cópias de $J_{i}$, pagando $i \times \frac{1}{1+2}$ e, junto do jogador de nível $i+1$ abaixo atravessar $i+1$ cópias de $J_{i+1}$, pagando $(i+1) \times \frac{1}{2+2}$, resultando em um custo total mínimo de $\frac{i}{3}+\frac{i+1}{4}=\frac{7 i+3}{12}$. Como $i>1$, tal custo é maior que 1 e o jogador prefere comprar sua aresta direta a descer dois níveis.

Corolário 5.9. Para que q jogadores atravessem um $J_{i}$, cada um deve pagar no mínimo $\frac{1}{q+2}$

Demonstração. Consequência direta dos lemas 5.7 e 5.8 .

Lema 5.10. Em um equilíbrio, nenhum jogador utiliza uma estratégia por cima.

Demonstração. Seja $i$ o nível de maior índice em que um jogador decide ir por cima. Para que um jogador desse nível vá por cima, nenhum dos $i$ jogadores do nível $i-1$ acima dele está indo por baixo (teorema 5.1), e como nenhum jogador abaixo está subindo, ele deverá atravessar $i$ cópias de $J_{i-1}$ sozinho.

Pelo corolário 5.9, ele deverá pagar ao menos $i \times \frac{1}{1+2}=\frac{i}{3}$ mais uma aresta de custo $\epsilon$. Portanto, nenhum jogador em um nível $i \geq 3$ decidirá ir por cima.

Como para atravessar $J_{1}$ o limite do lema 5.7 é aumentado para $\frac{1}{k+1}$, um jogador do nível 2 que decidisse ir por cima pagaria ao menos $2 \times \frac{1}{1+1}=1$ mais uma aresta de custo $\epsilon$ e preferiria comprar o caminho direto.

Note que os jogadores de nível 1 não tem a opção de ir por cima.

Lema 5.11. Em um equilíbrio, nenhum jogador utiliza uma estratégia por baixo.

Demonstração. Pelos lemas 5.8 e 5.10 em um equilíbrio todo jogador de um nível $i$ ou compra a aresta direta ou desce um nível, comprando uma aresta do nível $i+1$ e atravessando $i$ cópias de $J_{i}$.

Em cada $J_{i+1}$ apenas um dos $i+1$ jogadores de nível $i$ pode utilizar uma estratégia por baixo, e nesse caso, o jogador de nível $i+1$ deve utilizar a aresta direta (teorema 5.1). Como nenhum jogador desce dois níveis ou vai por cima, a aresta do nível $i+1$ é utilizada apenas pelo jogador associado a ela e pelo jogador de nível $i$ que vai por baixo, resultando em um custo individual de $\frac{1}{2}$. Além disso o jogador de nível $i$ que fizer esse caminho deverá pagar também o custo de atravessar $i$ cópias de $J_{i}$, além de comprar uma aresta de custo $\epsilon$. 
Para $i=1$, tal custo corresponde a $\frac{1}{2}+\frac{1}{1+1}+\epsilon>1$.

Para $i \geq 2$, tal custo é no mínimo $\frac{1}{2}+i \times \frac{1}{1+2}(+\epsilon) \geq \frac{1}{2}+\frac{2}{3}>1$.

Assim, todo jogador prefere comprar sua aresta direta a usar uma estratégia por baixo.

Teorema 5.12 (da unicidade do equilíbrio). O único equilíbrio do jogo $J_{k}$ é aquele em que cada jogador paga apenas pela aresta direta entre seus terminais. Esse equilibrio tem custo $\frac{k !}{1 !}+\frac{k !}{2 !}+\frac{k !}{3 !}+\ldots+\frac{k !}{k !}$.

Demonstração. Segue diretamente dos lemas 5.6, 5.10 e 5.11.

Teorema 5.13. O preço da estabilidade do jogo $J_{k}$ é $1+\frac{1}{2 !}+\frac{1}{3 !}+\ldots+\frac{1}{k !}$.

Demonstração. Segue dos teoremas 5.5 e 5.12 .

Conforme $k$ cresce tal valor se aproxima de $e-1 \approx 1,718$.

\subsection{Exemplos de estabilidades caras}

\section{StEINERJ USTOCAM com preço da estabilidade $42 / 23$}

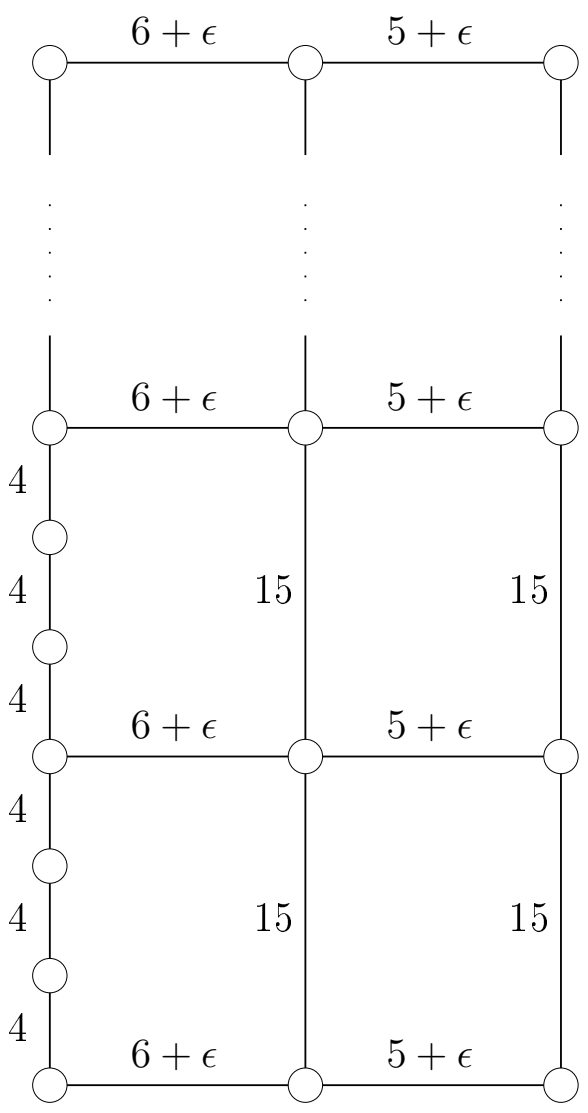

Figura 5.14: Instância com preço da estabilidade $\frac{42}{23}>1,826$. Para cada aresta vertical há um jogador interessado em ligar os seus extremos.

Um limite inferior maior para o preço da estabilidade em jogos SteInERJustoCAm foi encontrado por Christodoulou e colaboradores com uma instância cujo preço da estabilidade 
converge para $\frac{42}{23} \approx 1,826\left[\mathrm{CCL}^{+} 10\right]$. No exemplo da figura 5.14 para cada aresta vertical há um jogador que deseja conectar seus extremos.

A floresta de Steiner de custo mínimo para o problema (equivalente à árvore geradora de custo mínimo) consiste nas arestas de custo 4 e nas arestas horizontais. No entanto, no único equilíbrio, todos os jogadores comprarão a aresta direta entre seus terminais. Se a grade apresentada possui $k$ linhas, o preço da estabilidade será $\frac{42 k+11}{23 k+11}$.

\section{SteinerJustoCam com preço da estabilidade 348/155}

O maior limite inferior conhecido para o preço da estabilidade de jogos SteINERJustoCAM é devido a Bilò e colaboradores, com valor 348/155 2,245 [BCFM10].

Assim como os jogos $J_{k}$ apresentados anteriormente, com preço da estabilidade $1+1 / 2$ ! + $1 / 3$ ! $+\ldots+1 / k$ ! , tal valor é obtido através de uma família de grafos construída recursivamente. Para cada aresta do grafo final, haverá um jogador desejando ligar suas extremidades.

Construiremos os jogos $B_{k}$, onde $k \geq 2$ é o número de níveis da estrutura. No artigo original é utilizado um segundo parâmetro, $t \geq 3$ que indica a quantidade de repetições na formação da estrutura ${ }^{1}$, mas que não afeta o preço da estabilidade do jogo. Para simplificar a notação, fixamos tal valor como 3 .

Para a construção, usaremos o dispositivo apresentado na figura 5.15, que consiste em nove arestas chão (divididas entre "esquerda", "meio" e "direita") e duas arestas de dispositivo.

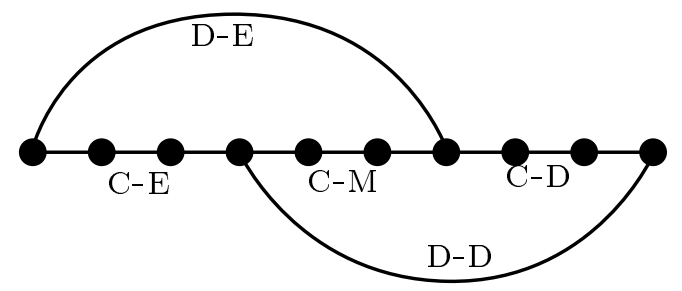

Figura 5.15: Dispositivo consistindo de três arestas chão-esquerda (C-E), três arestas chão-meio (C-M), três arestas chão-direita (C-D) e duas arestas de dispositivo (D-E e D-D).

Dada uma aresta $e$, construímos um bloco abaixo dela utilizando três cópias concatenadas do dispositivo, de forma que o vértice mais à esquerda da primeira coincida com a ponta esquerda de $e$ e o vértice mais à direita da última coincida com a ponta direita de $e$ (figura 5.16).

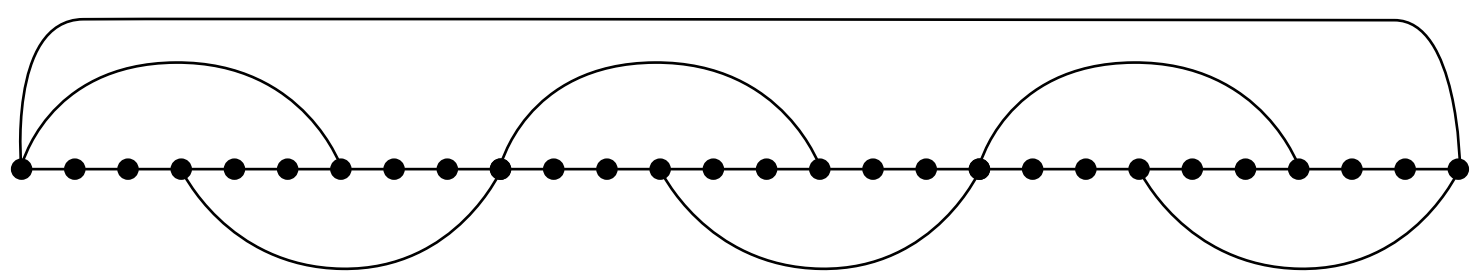

Figura 5.16: Jogo $B_{2}$, equivalente a um bloco construído abaixo de uma aresta

A construção começa com uma aresta "teto" de custo 1, com um bloco abaixo dela. A aresta teto tem nível $k$ e o bloco abaixo tem nível $k-1$. Para construir o nível $k-2$

\footnotetext{
${ }^{1}$ No original, $t$ é o número de níveis e $k$ a quantidade de repetições, mas decidimos invertê-los para manter a consistência com os demais exemplos.
} 
construímos um bloco abaixo de cada aresta chão no nível $k-1$. A construção continua recursivamente até o nível 1. A figura 5.17 mostra uma construção com três níveis.

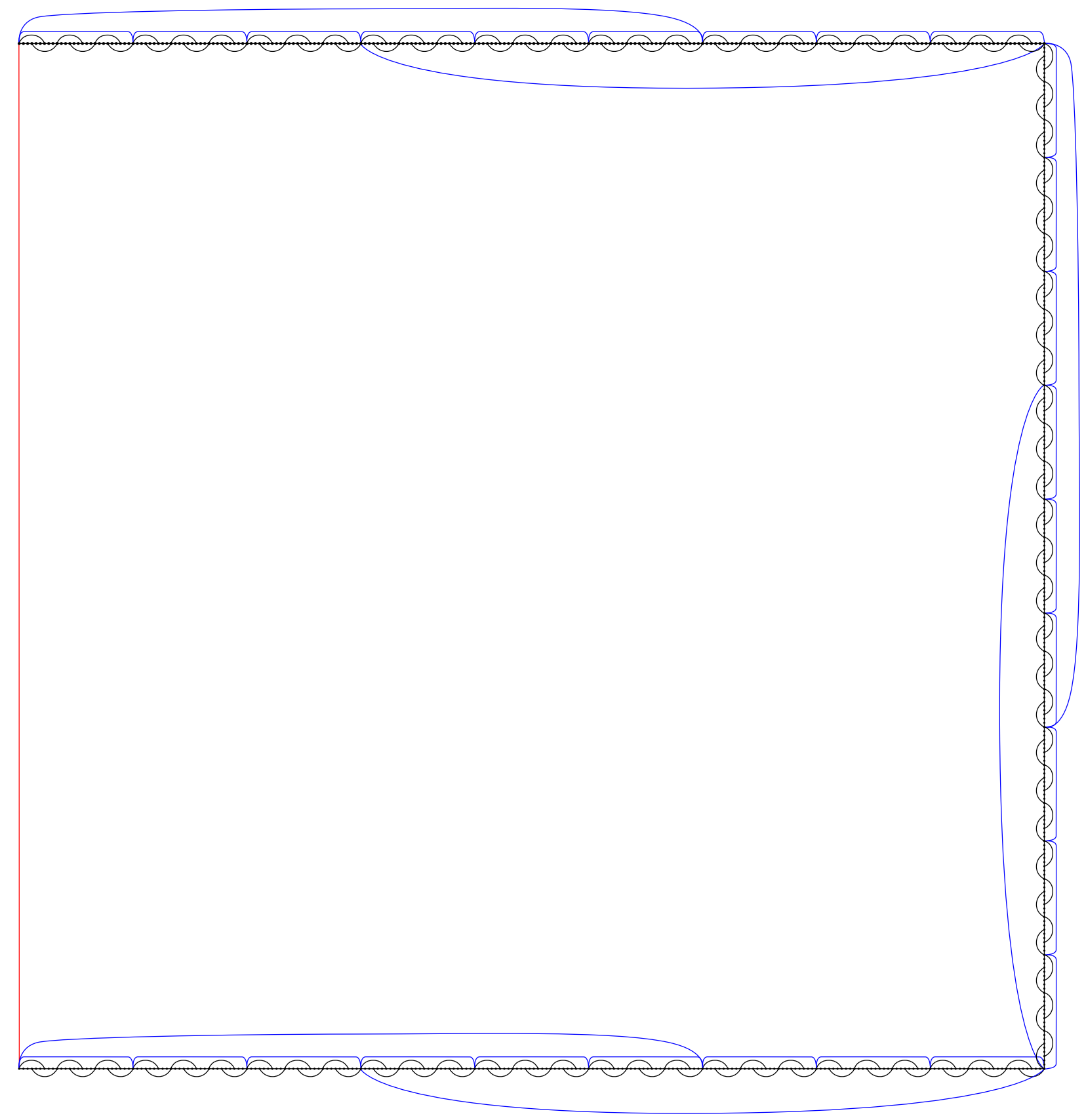

Figura 5.17: Jogo $B_{3}$.

Sejam $x=28 / 109, y=33 / 109, z=30 / 109-\epsilon, w=35 / 109-\epsilon$ e $\alpha=63 / 218-\epsilon$. Os custos são definidos da seguinte forma: supondo que o bloco está sendo construído abaixo de uma aresta de custo $g$, as arestas chão-esquerda custam $\frac{x g}{9 \alpha}$ cada, as chão-meio custam $\frac{(1-x-y) g}{9 \alpha}$, e as chão-direita, $\frac{y g}{9 \alpha}$. As arestas dispositivo esquerda e dispositivo direita terão custos $\frac{z g}{3 \alpha} \mathrm{e}$ $\frac{w g}{3 \alpha}$, respectivamente. Desta forma o custo total das arestas chão de um dispositivo é $g / \alpha$ e o custo total das arestas de um dispositivo é $(1+z+w) g / \alpha$.

Para $j=1, \ldots, k-1$, o custo das arestas chão de nível $j$ é $g \alpha^{j-k}$ e o custo total das arestas de nível $j$ é $g(1+z+w) \alpha^{j-k}$. 
Assim, o custo total de um grafo com $k$ níveis será

$$
1+\sum_{i=1}^{k-1}(1+z+w) \alpha^{-i}=\frac{348-436 \epsilon}{155+218 \epsilon} \alpha^{1-k}-\frac{193-654 \epsilon}{155+218 \epsilon} .
$$

No único equilíbrio existente para o jogo, todas as arestas são compradas. No entanto, o grafo formado apenas pelas arestas chão do nível 1 (que é uma árvore geradora, e portanto um limitante superior para o custo da floresta de Steiner) é $\alpha^{1-t}$.

Assim, para qualquer $\delta>0$ é possível escolher $t$ e $\epsilon$ de forma que o preço da estabilidade do jogo seja pelo menos $348 / 155-\delta$.

\subsection{Multitransmissões e difusões}

Nesta seção analisaremos o preço da estabilidade para jogos SteinerJustoCam com algumas restrições extras.

Quando cada conjunto de terminais possui dois elementos e todos os jogadores possuem um terminal (chamado raiz) em comum, ou seja, $R_{i}=\left(s_{i}, r\right)$ a rede construída será conexa e, assim, da mesma forma que o caso geral do problema é uma extensão do problema da floresta de Steiner, esta variante pode ser vista como uma extensão do problema da árvore de Steiner.

Esta variante pode ser usada para fazer a divisão de custos de multitransmissões (transmissões multicast). Uma multitransmissão ocorre quando uma mensagem deve ser transmitida em uma rede de um nó para uma série de destinatários. Neste caso, em vez de mandar uma cópia separada do sinal para cada participante, é criada uma arborescência ligando a fonte a todos os receptores. A mensagem é duplicada apenas nos pontos de ramificação, fazendo com que apenas uma cópia da mensagem atravesse cada aresta.

\section{Jogo SteinerJustom $(G, c, \mathcal{R})=(N, \mathcal{S}, \mathcal{P})$}

Dados um grafo $G$, um custo $c_{e}$ em $\mathbb{Q}_{\geq}$para cada aresta e uma sequência de $n$ pares de vértices $\mathcal{R}=\left(R_{1}, \ldots, R_{n}\right)$ com $R_{i}=\left(s_{i}, r\right)$, o jogo é aquele em que:

- $N=\{1, \ldots, n\}$ é o conjunto de jogadores;

- $\mathcal{S}$ é a sequência $\left(\mathcal{T}_{1}, \ldots, \mathcal{T}_{n}\right)$, sendo $\mathcal{T}_{i}$ o conjunto de caminhos em $G$ entre $s_{i}$ e $r ; \mathrm{e}$

- $\mathcal{P}$ é uma sequência $\left(p_{1}, \ldots, p_{n}\right)$ de funções de custo sendo cada $p_{i}\left(T_{1}, \ldots, T_{n}\right)$ o valor da divisão justa dos custos de $\left(T_{1}, \ldots, T_{n}\right)$ para o jogador $i$, onde $T_{j}$ é um caminho em $\mathcal{T}_{j}, j=1, \ldots, n$.

Também consideraremos o caso de difusões (broadcast), em que uma mensagem deve ser transmitida a todos os nós de uma rede.

Jogo SteinerJustoB $(G, c, r)=(N, \mathcal{S}, \mathcal{P})$

Dados um grafo $G$ com $n+1$ vértices $v_{1}, v_{2}, \ldots, v_{n}, r$, um custo $c_{e}$ em $\mathbb{Q} \geq$ para cada aresta, o jogo é aquele em que:

- $N=\{1, \ldots, n\}$ é o conjunto de jogadores;

- $\mathcal{S}$ é a sequência $\left(\mathcal{T}_{1}, \ldots, \mathcal{T}_{n}\right)$, sendo $\mathcal{T}_{i}$ o conjunto de caminhos em $G$ entre $v_{i}$ e $r ; \mathrm{e}$ 


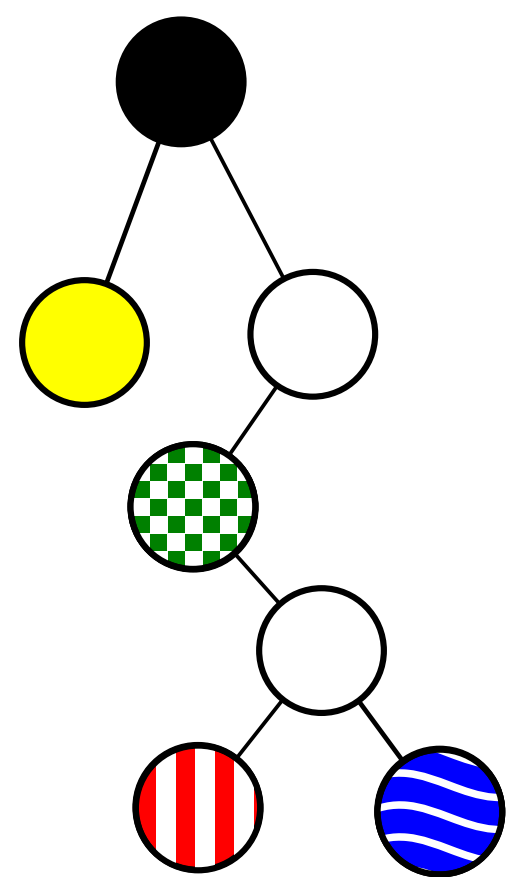

Figura 5.18: Exemplo de jogo SteinerJustom. $R_{1}=\{\mathbb{D}, \boldsymbol{\bigcirc}\}, R_{2}=\{\boldsymbol{\ominus}, \boldsymbol{\Theta}\}, R_{3}=\{\otimes, \boldsymbol{\Theta}$, $R_{4}=\{\bigcirc, \mathbf{O}\}$

- $\mathcal{P}$ é uma sequência $\left(p_{1}, \ldots, p_{n}\right)$ de funções de custo sendo cada $p_{i}\left(T_{1}, \ldots, T_{n}\right)$ o valor da divisão justa dos custos de $\left(T_{1}, \ldots, T_{n}\right)$ para o jogador $i$, onde $T_{j}$ é um caminho em $\mathcal{T}_{j}, j=1, \ldots, n$.

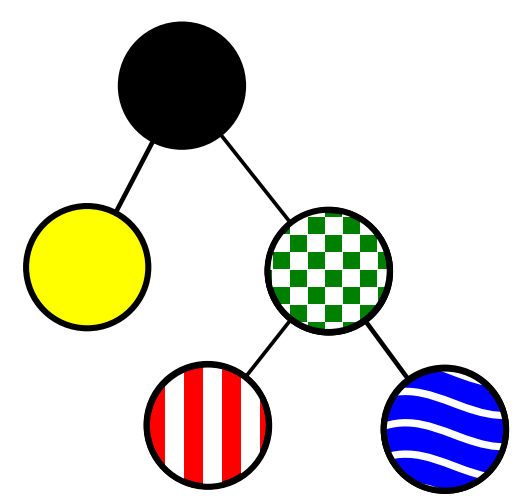

Figura 5.19: Exemplo de jogo SteinerJustoB. $R_{1}=\{\mathbb{D}, \boldsymbol{\bigcirc}\}, R_{2}=\{\boldsymbol{\ominus}, \boldsymbol{\Theta}\}, R_{3}=\{\circledast, \boldsymbol{\Theta}$, $R_{4}=\{\bigcirc, \bigcirc\}$

Podemos modelar a divisão de custos entre os nós através de um jogo de Steiner em que há um vértice raiz $r$ e para cada outro vértice $v_{i}$, temos um jogador $i$ que possui conjunto de terminais $R_{i}=\left(v_{i}, r\right)$.

Como as soluções desejadas são aquelas em que todos os vértices do grafo estão conectados a $r$ (e, portanto, conectados entre si), temos que o perfil de menor custo social para o problema corresponde à solução do problema da árvore geradora mínima, para a qual são conhecidos algoritmos que rodam em tempo polinomial [CLRS01].

Para dois jogadores, a restrição de que todos os jogadores tenham um vértice em comum não altera o valor do maior preço da estabilidade possível (figura 5.3). No entanto, para jogos 
com três ou mais jogadores não se sabe se há uma separação no preço da estabilidade dos dois jogos e o maior limite inferior encontrado para jogos STEINERJustoCAM não corresponde ao maior limite conhecido para jogos STEInERJustoM.

O maior preço da estabilidade conhecido para um jogo SteinerJustoM é 1,862, obtido através de um jogo como o mostrado na figura 5.20 [BCFM10].

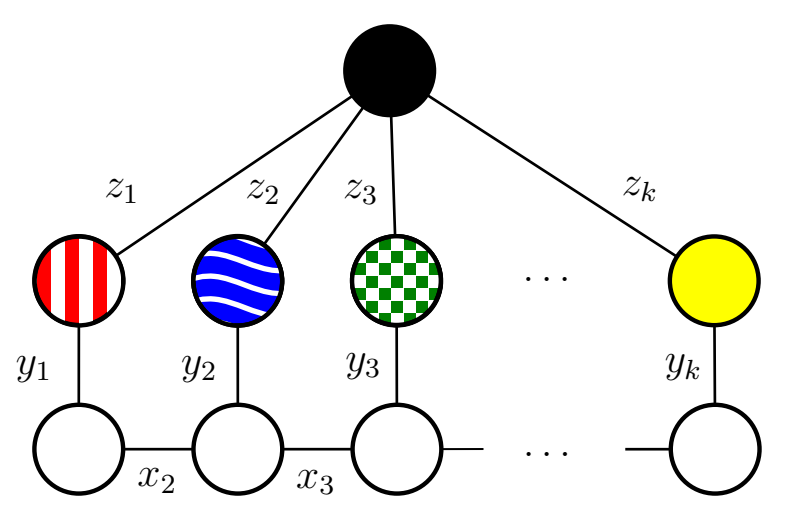

Figura 5.20: SteinerJustoM com $k$ jogadores.

A árvore de Steiner ótima é formada pelas arestas $z_{1}, x_{i}$ para $i$ entre 2 e $k$ e $y_{i}$ para $i$ entre 1 e $k$, enquanto o único equilíbrio consistirá apenas das arestas $z_{i}$, para $i$ entre 1 e $k$.

Bilò e colaboradores [BCFM10] mostraram que o equilíbrio em questão é único se e somente se para $i=2, \ldots, n$ e $k=1, \ldots, i-1$ vale que

$$
z_{k}<\frac{z_{i}}{\min \{2 i-2 k, n-k\}+1}+\frac{y_{i}}{\min \{2 i-2 k, n-k\}}+\sum_{p=0}^{i-k-1} \frac{x_{i-p}}{i-k-p}+y_{k},
$$

e, para $i=1, \ldots, n-1$ e $j=i+1, \ldots, n$ vale que

$$
z_{j}<\frac{z_{j}}{\min \{2 j-2 i, j\}}+\frac{y_{i}}{\min \{2 j-2 i, j\}-1}+\sum_{p=1}^{j-i} \frac{x_{i}+p}{j-i-p+1}+y_{j} .
$$

Assim, é possível modelar um programa linear com as arestas do grafo como variáveis, o custo do equilíbrio $\sum_{i=1}^{n} z_{i}$ como função objetivo e as restrições indicadas acima, além da restrição adicional

$$
z_{1}+\sum_{i=2}^{n} x_{i}+\sum_{i=1}^{n} y_{i} \leq 1
$$

que limita o valor da solução ótima em 1 . O valor 1,862 foi obtido através da solução de um programa linear como o acima quando o número de jogadores $k$ é 100. As desigualdades estritas foram simuladas adicionando-se uma constante de $10^{-6}$ no menor lado. [BCFM10]

Já para jogos SteinerJustoB, o valor do maior preço da estabilidade encontrado é 1,818, [BCFM10] obtido através de um grafo como o da figura 5.21, com a mesma técnica utilizada para o jogo de multitransmissão, mas com as arestas $y_{i}$ contraídas $\left(y_{i}=0\right)$. 


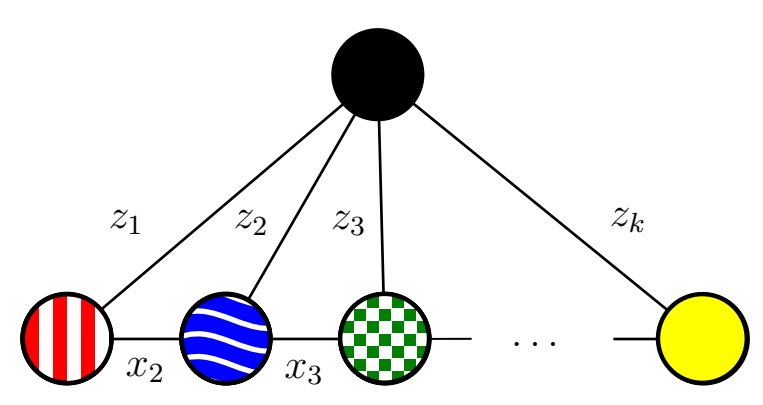

Figura 5.21: SteinerJustoB com $k$ jogadores.

\subsection{Limite para o preço da estabilidade em difusões}

Svetlana Olonetsky, Amos Fiat, Haim Kaplan, Meital Levy e Ronen Shabo [Olo06, $\mathrm{FKL}^{+}$06] mostraram que o preço da estabilidade em jogos STEINERJustoB com $n$ jogadores é $\mathrm{O}(\log \log n)$, o primeiro limite superior melhor que $\mathcal{H}_{n}$ para uma variante do STEINERJusto.

Seja $S$ um perfil de estratégias para um jogo $\operatorname{SteinerJusto~}(G, c, \mathcal{R})$ e $x_{S}(e)$ o número de jogadores que utilizam a aresta $e$ em $S$. Chamamos de $G_{S}$ o subgrafo de $G$ construído pelo perfil $S$, ou seja, $G_{S}=\left(V_{S}, E_{S}\right)$, com $V_{S}=V_{G}$ e $E_{S}=\left\{e \in E_{G}: x_{S}(e) \geq 1\right\}$.

A demonstração é feita fixando uma árvore geradora mínima $T^{*}$ solução do problema $\operatorname{AGM}(G, c)$ e o perfil de estratégias de custo social mínimo correspondente $S^{*}\left(G_{S^{*}}=T^{*}\right)$ e executando uma política de movimentos semelhante a uma dinâmica de melhor resposta, porém mais restritiva, em que um jogador de cada vez modifica sua estratégia, diminuindo seu custo, até que o perfil obtido seja um equilíbrio. O custo das arestas compradas pelo equilíbrio é então analisado.

Para facilitar a demonstração a política de movimentos será executada em uma versão modificada do grafo.

Seja $T^{*}$ uma árvore geradora mínima solução do problema $\operatorname{AGM}(G, c)$ e seja $S^{*}$ o perfil de estratégias correspondente. Para dois vértices $u$ e $v$ em $V_{G}$, definimos $d^{*}(u, v)$ como o custo do caminho entre $u$ e $v$ em $T^{*}$.

Dado um perfil qualquer $S$ e uma aresta $e=\{x, y\}$ em $E_{S}$, dizemos que $e$ aparece na direção $x$ para $y$ se algum jogador $u$ usa $e$ e $y$ está mais perto da raiz do que $x$ na estratégia $S_{u}$.

Um movimento (válido) a partir de um perfil $S$ é devido à mudança da estratégia $S_{v}$ de um jogador $v$ para uma estratégia $S_{v}^{\prime}$, resultando assim em um novo perfil de estratégia $S^{\prime}$ no qual o custo para $v$ diminui. Estamos particularmente interessados nos três tipos de movimentos descritos a seguir. Nesses três tipos de movimentos há uma certa restrição na direção das arestas de $S_{v}^{\prime}$ imposta pelo perfil $S$, mais precisamente,

se a nova estratégia $S_{v}^{\prime}$ de $v$ usa uma aresta $x y$ de $E_{S}$ na direção de $x$ para $y$, então essa aresta já era utilizada por $S$ nessa mesma direção.

Os três movimentos de interesse são:

EE: (Existing Edge) a nova estratégia $S_{v}^{\prime}$ de $v$ usa apenas arestas já utilizadas pelo perfil $S$ 
e, portanto,

$$
E_{S^{\prime}} \subseteq E_{S}
$$

OPT: a nova estratégia $S_{v}^{\prime}$ de $v$ usa apenas arestas presentes em $S$ e alguma aresta da árvore geradora mínima $T^{*}$ e, portanto,

$$
E_{S^{\prime}} \subseteq E_{S} \cup E_{S^{*}}
$$

$\overline{\mathrm{OPT}}$ : a primeira aresta $v w$ da nova estratégia $S_{v}^{\prime}$ de $v$ não é uma aresta de $S$ e não está na árvore geradora mínima $T^{*}$, todas as demais arestas já eram utilizadas pelo perfil $S$ e, portanto,

$$
E_{S_{v}^{\prime}} \subseteq E_{S} \cup\{v w\} \text { para algum vértice } w .
$$

A figura 5.22 ilustra cada um dos tipos de movimento, com exceção feita à figura 5.22(e) que ilustra uma mudança de estratégia para o vértice $d$ que não resulta em um movimento, pois não respeita a restrição na direção das arestas imposta pelo perfil $S$.

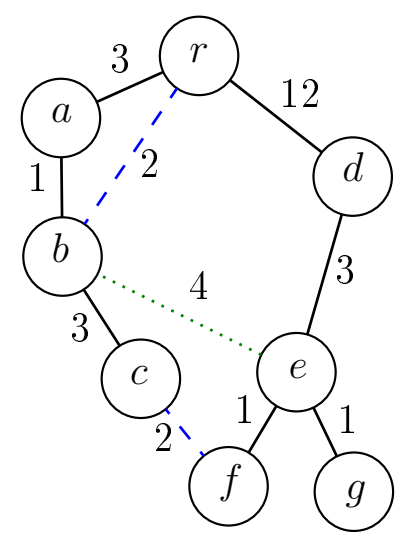

(a)

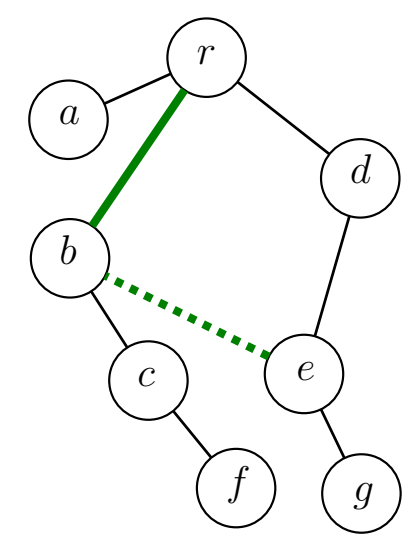

(d)

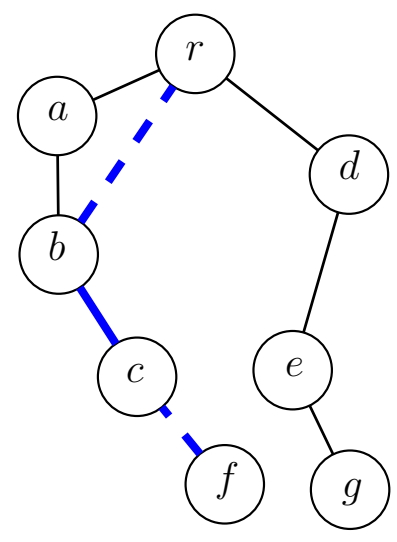

(b)

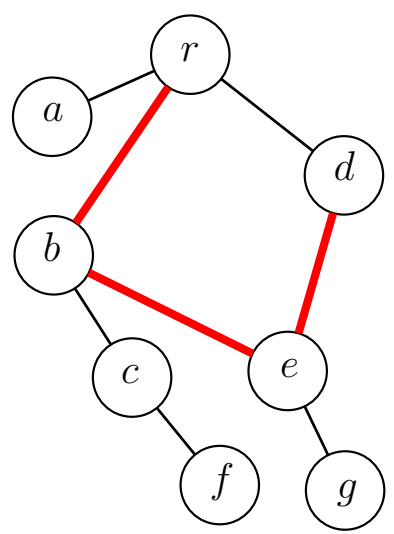

(e)

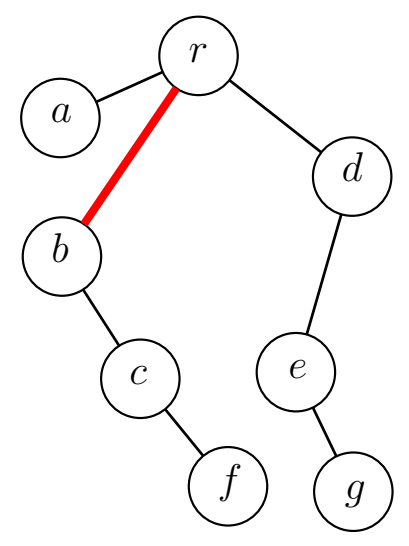

(c)

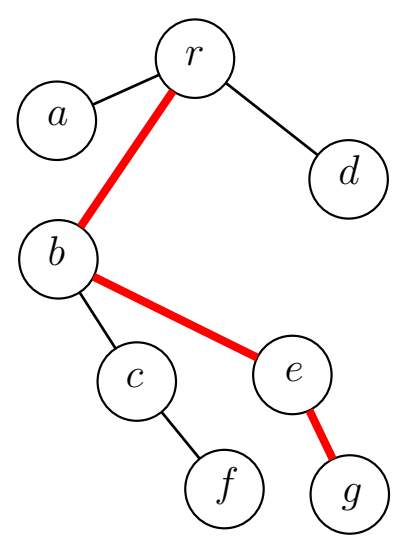

(f)

Figura 5.22: (a) As arestas contínuas formam o grafo para um perfil $S$. Arestas tracejadas (cf e br) estão em $T^{*}$ e eb é uma aresta qualquer fora de $S^{*}$. (b) Movimento OPT para $f$, (c) movimento EE para $b$ e (d) movimento $\overline{\mathrm{OPT}}$ para e. (e) Movimento inválido para d, pois a aresta ed não aparecia na direção $d \rightarrow e$. (f) movimento EE válido para $g$.

Note que começando com o perfil $S^{*}$ e usando apenas os movimentos descritos acima, 
nenhuma aresta fora de $T^{*}$ aparece nas duas direções. Além disso, tal aresta aparecerá apenas na direção determinada pelo movimento $\overline{\mathrm{OPT}}$ que a adicionou.

A seguir, veremos que apesar dos três movimentos anteriores parecerem, até certo ponto, restritivos, se não há um movimento a partir de um perfil $S$, então esse perfil é um equilíbrio. Mais adiante descreveremos um algoritmo de "agendamento" para tais movimentos que nos leva a um equilíbrio. Analisando esse algoritmo será possível mostrar que o preço da estabilidade de jogos SteinerJustoB com $n$ jogadores é $\mathrm{O}(\log \log n)$.

Lema 5.14. Se nenhum movimento EE é possivel a partir de um perfil S, então o subgrafo $G_{S}$ de $G$ construído pelo perfil $S$ é uma árvore.

Demonstração. Suponha que $G_{S}$ não é uma árvore. Como todas as estratégias consistem de caminhos até a raiz, existem $u$ e $w$ tais que $S_{u} \cup S_{w}$ contém um ciclo. Porém, pelo teorema 5.1, como as estratégias de $w$ e $u$ utilizam os vértices $r$ e $w$, em um equilíbrio então ambos devem usar o mesmo caminho de $r$ para $w$. Logo, existe uma nova estratégia $S_{w}^{\prime}$ ou uma nova $S_{u}^{\prime}$ que respeita a restrição na direção das arestas imposta por $S$ e que usa apenas arestas já utilizadas pelo por $S$. Essa nova estratégia diminui o custo para o seu jogador e portanto há um movimento EE a partir de $S$.

Seja $S$ um perfil tal que $T=G_{S}$ é uma árvore. Chamamos de $P_{S}(v, w)$ o caminho entre $v$ e $w$ que usa apenas arestas de $T$ e de $\operatorname{LCA}_{S}(v, w)$ o ancestral comum mais baixo de $v$ e $w$ se considerarmos $T$ enraizada em $r$ (ou seja, o primeiro vértice que aparece nas duas estratégias). Denotamos $\operatorname{LCA}(v, w)$ quando o perfil é subentendido.

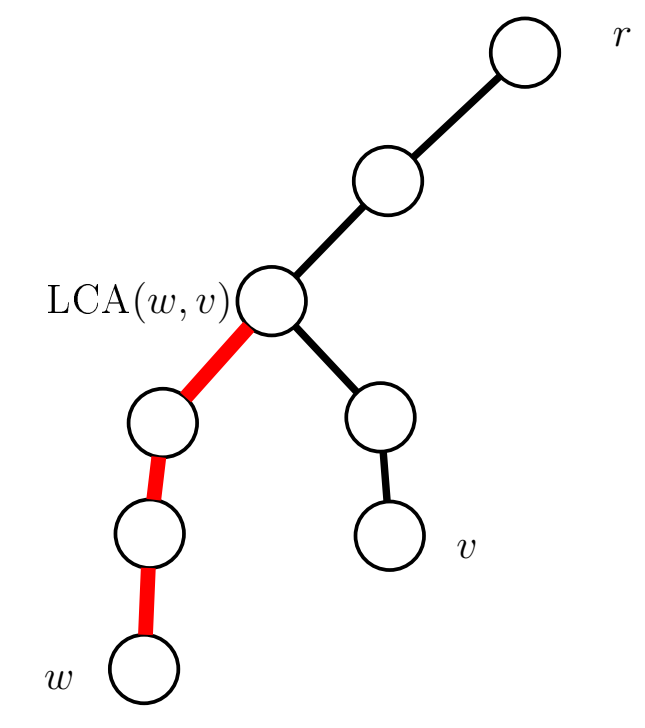

Figura 5.23: Arestas de $P_{w}^{v}$ em destaque.

Seja $P_{w}^{v}=P_{S}(w, \operatorname{LCA}(v, w))$ o caminho de $w$ ao $\operatorname{LCA}(v, w)$. Definimos

$$
C_{S}^{v}(w)=\sum_{e \in P_{w}^{v}} \frac{c(e)}{x_{S}(e)+1}+\sum_{e \in S_{w} \backslash P_{w}^{v}} \frac{c(e)}{x_{S}(e)}
$$

o custo para $w$ se $v$ mudar sua estratégia para um caminho até $w$ seguido por $S_{w}$. Note que $C_{S}^{v}(w) \leq p_{w}(S)$

Teorema 5.15 (do equilíbrio). Seja um jogo $\operatorname{SteinerJusto~}(G, c, \mathcal{R})$ e um perfil de estratégias S. Se nenhum movimento EE, OPT, ou $\overline{\mathrm{OPT}}$ é possivel em um perfil $S$, tal perfil é um equilibrio. 
Demonstração. Pelo lema 5.14, como nenhum movimento EE é possível, $G_{S}$ deve ser uma árvore. Suponha que $S$ não é equilíbrio. Então algum jogador $u$ pode diminuir seu custo trocando sua estratégia de $S_{u}$ para $S_{u}^{\prime}$. Chamamos o perfil em que $u$ troca sua estratégia para $S_{u}^{\prime}$ de $S^{\prime}$.

Como essa mudança de estratégia não é um movimento EE OPT ou $\overline{\mathrm{OPT}}, S_{u}^{\prime}$ contém uma aresta usada em uma direção nova ou uma aresta diferente da primeira que não está em $G_{S}$ ou em $S^{*}$.

Como $G_{S}$ é uma árvore e $S_{u}^{\prime}$ é um caminho de $u$ a $r$, se existe uma aresta $e^{\prime}$ usada em uma direção nova por $u$ então deve existir uma aresta $e$ depois de $e^{\prime}$ em $S_{u}^{\prime}$ que não está em $G_{S}$.

Portanto, se $S_{u}^{\prime}$ não é EE, OPT ou $\overline{\mathrm{OPT}}$, há ao menos uma aresta diferente da primeira que não pertence a $G_{S}$.

Se $u$ tem várias estratégias melhores que $S_{u}$, escolhemos $S_{u}^{\prime}$ como a que usa menos arestas fora de $G_{S}$. Dessas arestas novas, escolhemos $e=v w$ como a mais próxima de $r$. Assim, a partir de $w$ todas as arestas de $S_{u}^{\prime}$ já apareciam em $G_{S}$.

Seja $\bar{v}$ o primeiro vértice em $S_{u}^{\prime}$ que pertence a $S_{v}$. Considere a estratégia $S_{u}^{\prime \prime}$ que consiste de seguir $S_{u}^{\prime}$ até $\bar{v}$ e $S_{\bar{v}}$ daí para a frente. Note que $S_{u}^{\prime \prime}$ usa uma aresta fora de $G_{S}$ a menos que $S_{u}^{\prime}$.

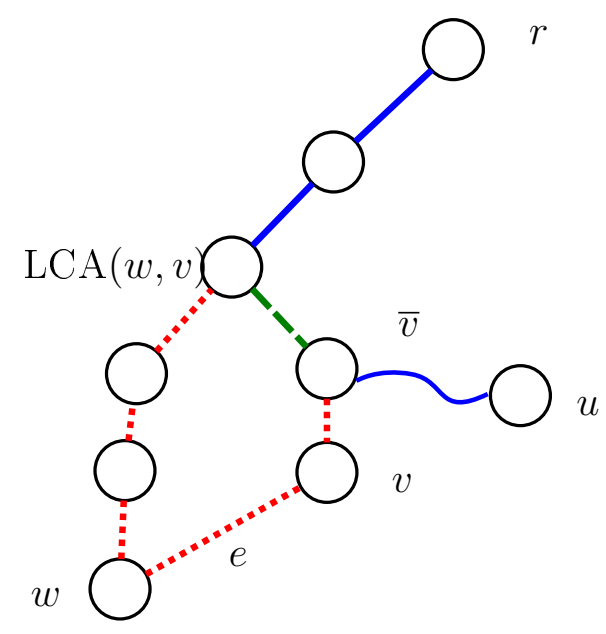

Figura 5.24: As arestas continuas e pontilhadas formam $S_{u}^{\prime}$. As arestas continuas e tracejadas formam $S_{u}^{\prime \prime}$.

Como essa estratégia não foi escolhida por $u$, o custo de $S^{\prime}$ deve ser estritamente menor que o de $S^{\prime \prime}$ para $u$. Portanto,

$$
c(e)+C_{S}^{u}(w)<C_{S}^{u}(\bar{v}) \leq C_{S}^{u}(v) .
$$

Como nenhum movimento $\overline{\mathrm{OPT}}$ é possível, $v$ não tem interesse em pagar por $e$ e seguir a estratégia de $w$, então

$$
p_{v}(S) \leq c(e)+C_{S}^{v}(w)
$$

Como $C_{S}^{u}(v) \leq p_{v}(S)$, concluímos que $C_{S}^{u}(w)<C_{S}^{v}(w)$ e portanto $L C A(u, w)$ é ancestral de $L C A(v, w)$ em $G_{S}$. $S_{u}^{\prime \prime}$.

Sejam $S^{\prime}$ e $S^{\prime \prime}$ os perfis obtidos de $S$ quando o jogador $u$ escolhe, respectivamente $S_{u}^{\prime}$ e

Mostraremos que $p_{u}\left(S^{\prime \prime}\right) \leq p_{u}\left(S^{\prime}\right)$, o que é um absurdo pela escolha de $S_{u}^{\prime}$. 


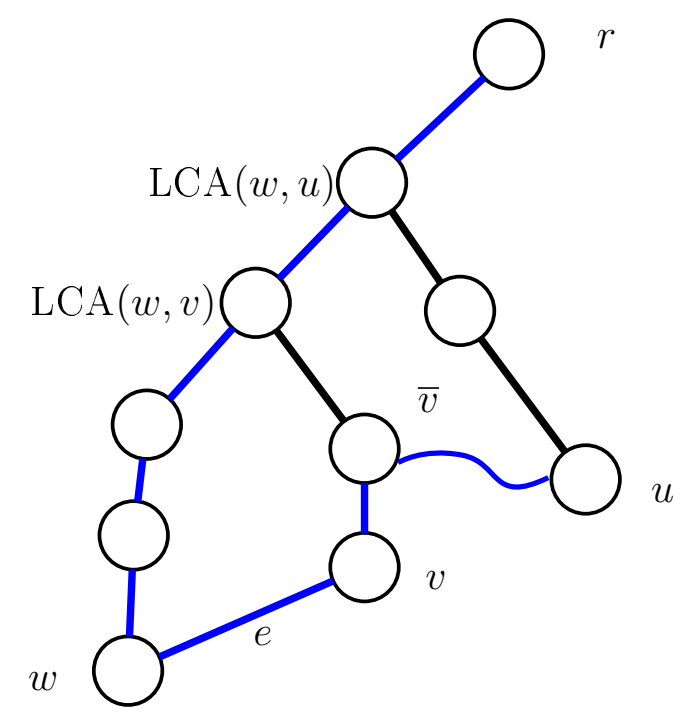

Figura 5.25: $\operatorname{LCA}(u, w)$ é ancestral de $\operatorname{LCA}(v, w)$.

Note que

$C_{S}^{v}(w)-p_{v}(S)=\sum_{e^{\prime} \in P_{w}^{v}} \frac{c\left(e^{\prime}\right)}{x_{S}\left(e^{\prime}\right)+1}-\sum_{e^{\prime} \in P_{v}^{w}} \frac{c\left(e^{\prime}\right)}{x_{S}\left(e^{\prime}\right)} \leq \sum_{e^{\prime} \in P_{w}^{v}} \frac{c\left(e^{\prime}\right)}{x_{S}\left(e^{\prime}\right)+1}-\sum_{e^{\prime} \in P_{v}^{w}} \frac{c\left(e^{\prime}\right)}{x_{S}\left(e^{\prime}\right)+1}$.

Portanto,

$p_{u}\left(S^{\prime}\right)-p_{u}\left(S^{\prime \prime}\right) \geq c(e)+\sum_{e^{\prime} \in P_{w}^{v}} \frac{c\left(e^{\prime}\right)}{x_{S}\left(e^{\prime}\right)+1}-\sum_{e^{\prime} \in P_{w}^{w}} \frac{c\left(e^{\prime}\right)}{x_{S}\left(e^{\prime}\right)+1} \geq c(e)+C_{S}^{v}(w)-p_{v}(S)$.

Como vimos acima, $c(e)+C_{S}^{v}(w)-p_{v}(S) \geq 0$, ou $v$ teria interesse em comprar a aresta $e$ e seguir $w$.

Portanto, $p_{u}\left(S^{\prime}\right)-p_{u}\left(S^{\prime \prime}\right) \geq 0$ e $u$ poderia ter escolhido uma estratégia com uma aresta nova a menos.

Mostraremos agora um algoritmo para a obtenção de um equilíbrio de custo social baixo a partir de uma árvore geradora mínima, através dos movimentos descritos acima.

Para facilitar a análise do preço da estabilidade, em vez de utilizarmos o grafo original $G$, usaremos um grafo modificado $\bar{G}$ durante a execução do algoritmo.

Para cada aresta em $T^{*}$, teremos duas arestas paralelas $e_{1}$ e $e_{2}$ em $\bar{G}$, e para cada aresta de $G$ fora de $T^{*}$, teremos uma aresta $e$. As arestas paralelas serão coloridas de azul ou vermelho durante a execução do algoritmo.

Dado um equilíbrio qualquer $\bar{S}$ em SteinerJustoB $(\bar{G}, c, r)$. Sabemos que $G_{\bar{S}}$ é uma árvore, portanto no máximo uma de cada par de arestas paralelas será comprada. Considere o perfil de estratégias $S$ correspondente a $\bar{S}$ no jogo original.

Suponha que $S$ não é equilíbrio para SteinerJustoB $(G, c, r)$. Então existe um jogador $u$ que diminui seus custos trocando sua estratégia para $S_{u}^{\prime}$ e podemos construir uma estratégia $\bar{S}_{u}^{\prime}$ para $u$ em $\bar{G}$ substituindo cada aresta $e$ em $T^{*} \cap S_{u}^{\prime}$ por $e_{1}$ se $e_{1}$ é usada em $G_{\bar{S}}$ ou $e_{2}$ caso contrário. Como no máximo uma aresta de cada par é usada no novo perfil, o custo de $\bar{S}_{u}$ para $u$ é o mesmo que $S_{u}$ e $\bar{S}$ não seria um equilíbrio.

Assim, para todo equilíbrio em $\operatorname{SteineRJustoB}(\bar{G}, c, r)$ há um equilíbrio de mesmo custo em SteinerJustoB $(G, c, r)$. 


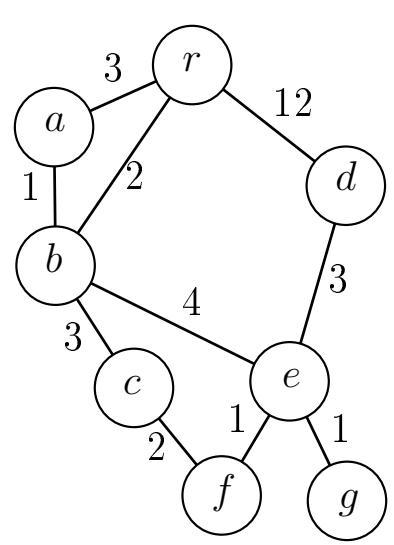

(a)

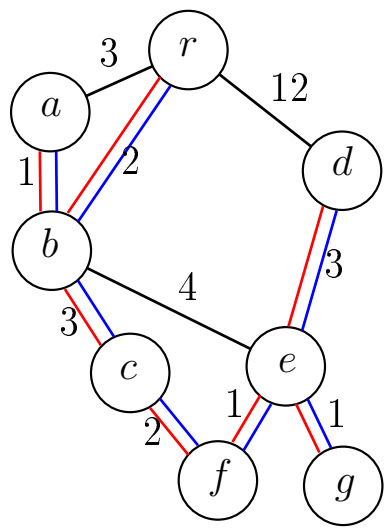

(b)

Figura 5.26: (a) Grafo original $G$ e (b) grafo modificado $\bar{G}$ com arestas da árvore geradora mínima duplicadas.

Dado um perfil $S$ e dois vértices $v$ e $w$ tais que $w$ está no caminho de $v$ a $r$ em $S$, definimos $\operatorname{Follow}(S, v, w)$ como a estratégia para $v$ no qual o jogador compra o caminho em $S_{v}$ de $v$ até $w$, seguido por $S_{w}$. Note que Follow corresponde a um movimento EE.

Se há uma aresta $v w$ de $T^{*}$ colorida de azul em $S$, definimos $\operatorname{OPTFollow}(S, v, w)$ como a estratégia para $v$ que consiste de $v w$ seguida por $S_{w}$. OPTFOLLOW corresponde a um movimento OPT.

O algoritmo de agendamento, apresentado a seguir, recebe um jogo SteinerJustoB com $n$ jogadores e um perfil de estratégias de custo social mínimo correspondente a uma árvore geradora mínima $T^{*}$, e devolve um equilíbrio com custo social $\mathrm{O}\left(c\left(T^{*}\right) \log \log n\right)$.

O algoritmo utiliza duas subrotinas, $\operatorname{OPTFollow}\left(S, v, w, T^{*}, \operatorname{COR}\right)$ e $\operatorname{Follow}(S, v, w)$, que devolvem uma estratégia como descrito anteriormente, onde $T^{*}$ é a árvore geradora mínima e COR é um vetor que define a cor de cada aresta dupla. 


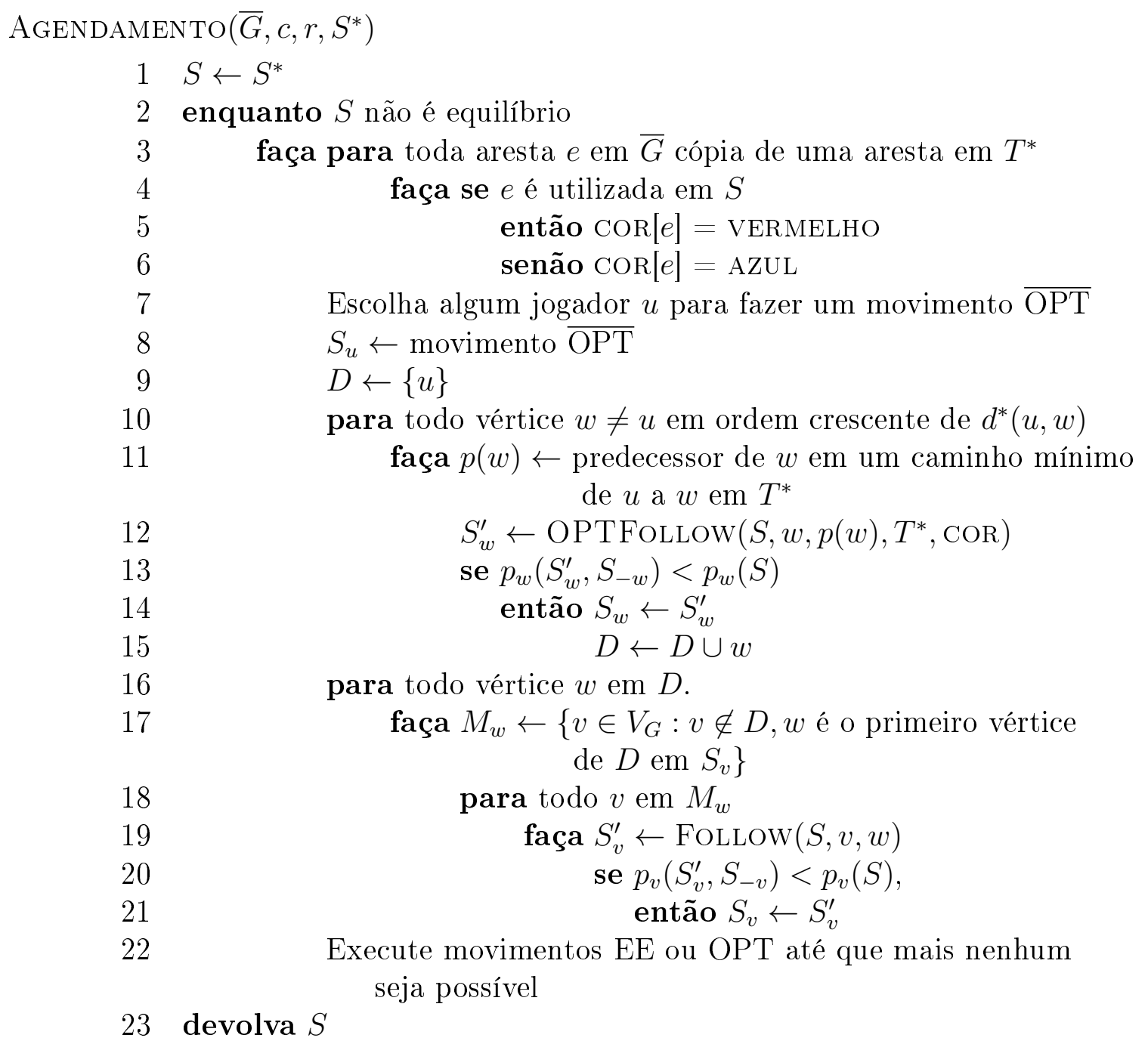

Chamamos o laço das linhas 10-15 de laço OPT, o laço das linhas 16-21 de laço EE e cada iteração do laço das linhas 2-22 de uma fase do algoritmo.

Note que o algoritmo realiza apenas movimentos EE, OPT e $\overline{\mathrm{OPT}}$ e que, como cada movimento diminui o custo do jogador que o realizou, e consequentemente o potencial do perfil, o algoritmo sempre termina.

Mantemos a invariante que no início de cada fase nenhum movimento EE ou OPT é possível. No início do algoritmo tal afirmação vale pois o perfil inicial é uma árvore e já contém todas as arestas de $T^{*}$, e cada fase termina com a execução de todos os movimentos EE ou OPT possíveis. Assim, ou o algoritmo chegou a um equilíbrio, ou existe algum jogador $u$ que tem interesse em realizar um movimento $\overline{\mathrm{OPT}}$.

\section{Análise de uma fase do algoritmo}

Lema 5.16. Se nenhum movimento EE ou OPT é possível em um perfil S, então para quaisquer dois jogadores $v$ e $w$ vale que

$$
p_{v}(S) \leq C_{S}^{v}(w)+d^{*}(v, w)
$$

onde $d^{*}(v, w)$ é o custo do caminho entre $v$ e $w$ na árvore geradora minima $T^{*}$.

Demonstração. Como nenhum movimento EE é possível, $G_{S}$ é uma árvore pelo lema 5.14. Considere a estratégia $S_{v}^{\prime}$ para $v$ que consiste no caminho de $v$ a $w$ em $T^{*}$, seguido por $S_{w}$, e seja $S^{\prime}$ o perfil de estratégias semelhante a $S$, mas com a estratégia de $v$ trocada para $S_{v}^{\prime}$. 


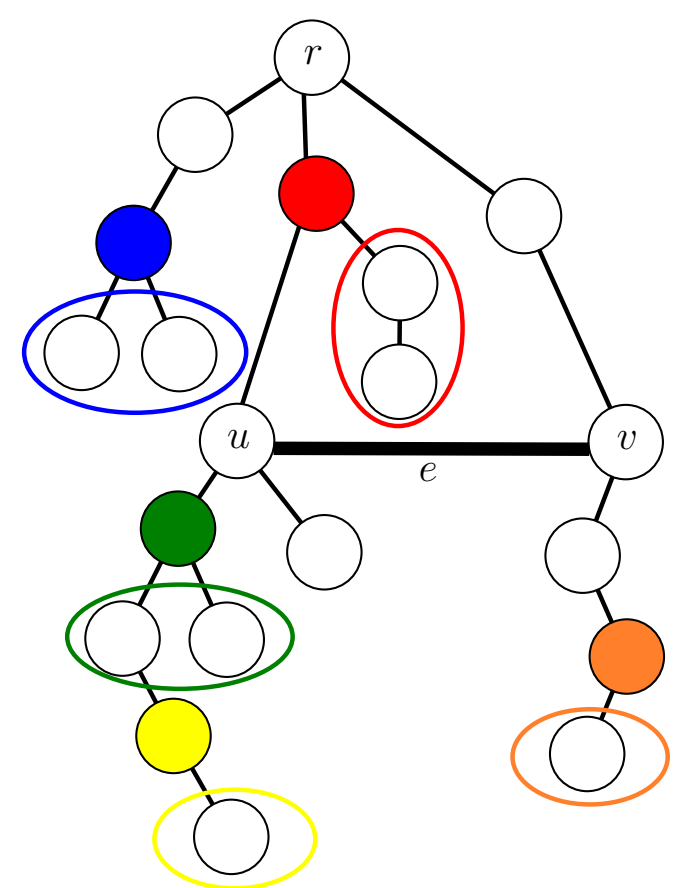

Figura 5.27: Grafo após u adicionar a aresta e, de custo $z$ em um movimento $\overline{\mathrm{OPT}}$. Vértices coloridos realizarão um movimento OPT no laço OPT. Para cada um desses vértices $w$, os vértices circulados com a cor correspondente formam $M_{w}$.

O custo para $v$ utilizar $S_{v}^{\prime}$ será $p_{v}\left(S^{\prime}\right) \leq C_{S}^{v}(w)+d^{*}(v, w)$ e a troca de $S_{v}$ por $S_{v}^{\prime}$ é um movimento OPT. Como nenhum movimento OPT é possível, temos que $p_{v}(S) \leq p_{v}\left(S^{\prime}\right)$, e portanto, $p_{v}(S) \leq C_{S}^{v}(w)+d^{*}(v, w)$.

Considere $S$ o perfil no início de uma fase do algoritmo, e $S^{\prime}$ o perfil após $u$ fazer um movimento $\overline{O P T}$. Seja $z$ o custo da aresta $(u, v)$ adicionada por este movimento. Mostraremos que todo jogador $w$ tal que $d^{*}(u, w) \leq z / 4$ pode diminuir seu custo comprando o caminho de $w$ a $u$ em $T^{*}$ e seguindo $S_{u}^{\prime}$.

Lema 5.17. Sejam $S$ e $S^{\prime}$ respectivamente os perfis de estratégia no início de uma fase e logo após um movimento $\overline{\mathrm{OPT}}$ ter sido executado. Sejam $e^{\prime}=(u, v)$ a aresta adicionada por tal movimento e $z=c\left(e^{\prime}\right)$. Então para cada jogador $w$ tal que $d^{*}(w, u) \leq z / 4$, vale que

$$
p_{w}\left(S^{\prime}\right)>p_{v}\left(S^{\prime}\right)+z / 2+d^{*}(w, u)
$$

Demonstração. A estratégia $S_{u}^{\prime}$ de $u$ em $S^{\prime}$ consiste da aresta $e^{\prime}$ seguida por $S_{v}$, portanto $P_{u}\left(S^{\prime}\right)=p_{v}\left(S^{\prime}\right)+z$. Como $u$ fez um movimento $\overline{\mathrm{OPT}}$, temos que

$$
p_{v}\left(S^{\prime}\right)+z<p_{u}(S)
$$

Como nenhum movimento EE ou OPT era possível em $S$,

$$
p_{u}(S) \leq C_{S}^{u}(w)+d^{*}(w, u)
$$

Vamos mostrar que $C_{S}^{u}(w) \leq p_{w}\left(S^{\prime}\right)$. Note que a estratégia de $w$ nos dois perfis não muda, embora seu custo possa ser diferente. Seja $P_{1}$ o caminho em $S_{w}$ de $w$ até $L C A_{S}(u, w)$ e $P_{2}$ o caminho em $S_{w}$ de $L C A_{S}(u, w)$ a $r$. Em $S$ as arestas de $P_{2}$ são compartilhadas entre $w$ e $u$, mas isso pode não ser verdade em $S^{\prime}$, então para $e$ em $P_{2}, x_{S}(e) \geq x_{S^{\prime}}(e)$. As arestas 
de $P_{1}$ não eram usadas por $u$ em $S$, mas podem ser utilizadas em $S^{\prime}$. Portanto, para $e$ em $P_{1}, x_{S^{\prime}}(e) \leq x_{S}(e)+1$. Assim, pela definição de $C_{S^{\prime}}^{u}(w)$,

$$
C_{S}^{u}(w)=\sum_{e \in P_{1}} \frac{c(e)}{x_{S}(e)+1}+\sum_{e \in P_{2}} \frac{c(e)}{x_{S}(e)} \leq \sum_{e \in S_{w}^{\prime}} \frac{c(e)}{x_{S^{\prime}}(e)}=p_{w}\left(S^{\prime}\right)
$$

Unindo as desigualdades acima,

$$
p_{w}\left(S^{\prime}\right)>p_{v}\left(S^{\prime}\right)+z-d^{*}(w, u) .
$$

$\mathrm{E} \operatorname{como} d^{*}(w, u) \leq z / 4$

$$
p_{w}\left(S^{\prime}\right)>p_{v}\left(S^{\prime}\right)+\frac{3 z}{4} \geq p_{v}\left(S^{\prime}\right)+z / 2+d^{*}(w, u) .
$$

e $w$ diminuirá seu custo comprando o caminho em $S^{*}$ até $u$, dividindo com $u$ a aresta $e$ e seguindo pelo caminho de $v$.

Corolário 5.18. Seja u o jogador executando o movimento $\overline{\mathrm{OPT}}$ que adiciona a aresta $e^{\prime}=(u, v)$, e seja $z=c\left(e^{\prime}\right)$. Para todo $w$ em $S_{v}$ (inclusive $v$ ) vale que $p_{w}\left(S^{\prime}\right) \leq p_{v}\left(S^{\prime}\right)$, e portanto, $d^{*}(u, w)>z / 4$.

Considere $S^{\prime}$ o perfil após $u$ executar o movimento $\overline{\mathrm{OPT}}$ definido pela aresta $e_{u}=(u, v)$, de custo $z$. Considere $w_{0}, w_{1}, \ldots, w_{m}$ os vértices com $d^{*}\left(u, w_{i}\right) \leq z / 4$ em ordem crescente de $d^{*}\left(u, w_{i}\right)$. Em particular, $w_{0}=u$ e $w_{1}$ é adjacente a $u$ em $S^{*}$.

O lema 5.17 implica que o movimento OptFollow $\left(S^{\prime}, w_{1}, u\right)$ é válido para $w_{1}$. Resta mostrar que após tal movimento os demais $w_{i}$ continuarão com interesse em desviar.

Lema 5.19. Seja $w_{k}$ o vértice após $w_{i}$ no caminho entre $w_{i}$ e u em $S^{*}$. Note que $w_{k}$ é o predecessor de $w_{i}$ na busca realizada no laço OPT. Seja $S^{i}$ o perfil imediatamente antes de $w_{i}$ ser processado no laço OPT. Então,

$$
p_{w_{i}}\left(S^{i}\right)>p_{v}\left(S^{i}\right)+\frac{z}{2}+d^{*}\left(u, w_{i}\right)
$$

e, portanto, OptFollow $\left(S^{i}, w_{i}, w_{k}\right)$ é um movimento válido para $w_{i}$ e será executado.

Demonstração. Demonstraremos por indução em $i$ que

$$
p_{w_{\ell}}\left(S^{i}\right)>p_{v}\left(S^{i}\right)+\frac{z}{2}+d^{*}\left(u, w_{\ell}\right), \text { para todo } \ell \geq i
$$

Para $i=1$, temos que $S^{1}=S^{\prime}$ e a desigualdade é válida pelo lema 5.17.

Se $i>1$, mostraremos que para todo $\ell \geq i$,

$$
p_{w_{\ell}}\left(S^{i}\right)-p_{w_{\ell}}\left(S^{i-1}\right) \geq p_{v}\left(S^{i}\right)-p_{v}\left(S^{i-1}\right),
$$

de onde a desigualdade segue pela hipótese de indução.

Para isso mostraremos que toda aresta que contribui com uma quantidade negativa do lado esquerdo da desigualdade contribui com a mesma quantidade do lado direito, e que nenhuma aresta contribui com uma quantidade positiva do lado direito.

Note que $S^{i-1}$ e $S^{i}$ diferem apenas na estratégia do jogador $w_{i-1}$ e para $\ell \geq i$ a estratégia do jogador $w_{\ell}$ em $S^{i}$ ainda é a mesma que em $S$. Além disso, pelo corolário 5.18, a estratégia $S_{v}$ de $v$ não é alterada durante o laço OPT. 
Para um $\ell \geq i$ qualquer, considere uma aresta $e$ que contribui negativamente para o lado esquerdo da inequação 5.1. Tal aresta deve estar em $S_{w_{\ell}}$ e o número de jogadores que a utilizam é maior em $S^{i}$ do que em $S^{i-1}$, portanto ela é uma das arestas compradas por $w_{i-1}$.

Como $S_{w_{\ell}}$ não se alterou desde o estado $S$ e a nova estratégia de $w_{i-1}$ consiste de arestas azuis (que não estavam em $G_{S}$ ), $e_{u}$ (idem) e arestas de $S_{v}$, concluímos que $e$ pertence a $S_{v}$, e portanto contribui igualmente para os dois lados da inequação 5.1.

Além disso, para toda aresta $e$ em $S_{v}$ o número de jogadores que a utilizam apenas aumenta, e portanto nenhuma aresta contribui positivamente para o lado direito da inequação.

Observação: O uso do grafo modificado $\bar{G}$ se deve a esse lema. No grafo original um jogador $w_{i}$ poderia usar uma aresta em $T^{*}$ que já pertence à estratégia $S_{w_{\ell}}, \ell>i$, diminuindo o seu custo. Assim, duplicamos as arestas de $T^{*}$ para garantir que o jogador compre uma aresta que nenhum outro jogador estava utilizando.

Lema 5.20. Sejam u o jogador que faz o movimento $\overline{\mathrm{OPT}}$ no início de uma fase, $e^{\prime}=(u, v)$ a primeira aresta de sua nova estratégia, com custo $c\left(e^{\prime}\right)=z$, e $m$ o número de jogadores (diferentes de u) a distância no máximo z/4 de u na árvore geradora minima $T^{*}$. Se $m \geq 2$, então o valor do potencial no final da fase é menor $\Omega(z m)$ do que no início da fase.

Demonstração. Sejam $w_{1}, \ldots, w_{m}$ os jogadores tais que $d^{*}\left(u, w_{i}\right) \leq z / 4$ em ordem crescente de $d^{*}\left(u, w_{i}\right)$, e $S^{i}$ o estado imediatamente antes de $w_{i}$ ser processado no laço OPT.

Pelo lema 5.19, quando o algoritmo processa $w_{i}$ vale que $p_{w_{i}}\left(S^{i}\right)>p_{v}\left(S^{i}\right)+\frac{z}{2}+d^{*}\left(u, w_{i}\right)$. Além disso, os jogadores $w_{1}, \ldots, w_{i-1}$ utilizam a aresta $e^{\prime}$.

Portanto, o custo da nova estratégia OptFollow $\left(S^{i}, w_{i}, w_{k}\right)$ é no máximo $p_{v}\left(S^{i}\right)+$ $\frac{z}{i+1}+d^{*}\left(u, w_{i}\right)$. Segue que $w_{i}$ diminuiu seu custo em pelo menos $\frac{z}{2}-\frac{z}{i+1}$. Como a variação na função potencial é equivalente à variação no custo dos jogadores que alteram suas estratégias, somando tal valor para os $m$ jogadores obtemos

$$
\sum_{i=1}^{m} \frac{z}{2}=\frac{z}{i+1}=z\left(\frac{m}{2}-\left(\mathcal{H}_{m+1}-1\right)\right)=\Theta(z m),
$$

e, portanto, durante a execução da fase o valor da função potencial diminui $\Omega(z m)$.

Mostraremos agora que se um jogador $w$ realiza um movimento no laço OPT, seus descendentes $\left(M_{w}\right)$ realizarão um movimento no laço EE.

Lema 5.21. Sejam u o vértice que executou o movimento $\overline{\mathrm{OPT}}$ a partir de um perfil S, $e^{\prime}=(u, v)$ a aresta adicionada por tal movimento, $D$ o conjunto de vértices que fizeram um movimento durante o laço OPT, juntamente com u e $S^{\prime \prime}$ o perfil após o término do laço EE. Seja e $\notin T^{*}$ a primeira aresta de uma estratégia $S_{w}$ para algum $w$ em $D$ e seja $S^{\prime \prime}$ o perfil após o término do laço EE. Então todos os jogadores de $M_{w}$ executaram um movimento EE, e e não está em $G_{S^{\prime \prime}}$.

Demonstração. Os únicos jogadores que podem utilizar $e$ em $S^{\prime \prime}$ são aqueles que já a utilizavam em $S$. Como $G_{S}$ é uma árvore, tais jogadores correspondem a $w$ e seus descendentes em $G_{S}$. Desses jogadores, aqueles que estão em $D$ não utilizam $e$ em $S^{\prime \prime}$, portanto consideramos apenas jogadores fora de $D$ que são descendentes de $w$.

Seja $\ell$ um jogador descendente de $w$ e não pertencente a $D$. Se $\ell$ executa um movimento durante o laço EE, então $\ell$ não paga mais por $e$ em sua nova estratégia.

Vamos mostrar que todo descendente de $w$ troca sua estratégia. 
Seja $M_{w}$ o conjunto de vértices tal que $\ell$ pertence a $M_{w}$ se $\ell$ não está em $D$ e $w$ é o primeiro vértice de $D$ na estratégia $S_{\ell}$, como na figura 5.27. Note que todo descendente de $w$ em $G_{S}$ está em $D, M_{w}$ ou $M_{y}$, para algum vértice $y$ descendente de $w$ em $S$. Portanto, todo descendente de $\ell$ teve a oportunidade de executar um movimento.

Seja $\ell$ um vértice fora de $D$ descendente de $w$ em $G_{S}$, e seja $y$ tal que $\ell$ está em $M_{y}$. Note que $\ell$ não muda sua estratégia entre o início da fase e o momento em que é processado no laço EE. Seja $S^{1}$ o perfil imediatamente após $y$ trocar sua estratégia no laço OPT, e $S^{2}$ o perfil ao processarmos $\ell$ no laço EE.

Seja $F$ a estratégia Follow $\left(S^{1}, \ell, y\right)$. Mostraremos que em todos os perfis entre $S^{1}$ e $S^{2}$, inclusive, $\ell$ tem interesse em trocar sua estratégia para $F$.

No perfil $S^{1}$, os jogadores $\ell$ e $y$ compartilham os vértices $y$ e $r$ e como $y$ acabou de trocar sua estratégia, pelo teorema 5.1, o jogador $\ell$ diminuirá seus custos trocando sua estratégia para $F$.

Para um perfil qualquer $T$, chamaremos de $F(T)$ o perfil obtido de $T$ quando o jogador $\ell$ troca sua estratégia para $F$. Suponha que $p_{\ell}(T)>p_{\ell}(F(T))$ vale para algum perfil após $S^{1}$, mas antes de $S^{2}$, ou seja

$$
\sum_{e \in T_{\ell}} \frac{c(e)}{x_{T}(e)}>\sum_{e \in F} \frac{c(e)}{x_{F(T)}(e)} .
$$

Seja $q$ o próximo jogador a mudar de estratégia e $T^{\prime}$ o perfil resultante. Precisamos provar que $p_{\ell}\left(T^{\prime}\right)>p_{\ell}\left(F\left(T^{\prime}\right)\right)$ e portanto,

$$
\sum_{e \in T_{\ell}} \frac{c(e)}{x_{T^{\prime}}(e)}>\sum_{e \in F} \frac{c(e)}{x_{F\left(T^{\prime}\right)}(e)} .
$$

Dividimos as arestas em três grupos, (a) aquelas que $q$ utiliza em $T$ mas não em $T^{\prime}$, (para as quais $x_{F\left(T^{\prime}\right)}(e)=x_{F(T)}(e)-1$ e $\left.x_{T^{\prime}}(e)=x_{T}(e)-1\right)$, (b) aquelas que $q$ utiliza em $T^{\prime}$ mas não em $T$ (para as quais $x_{F\left(T^{\prime}\right)}(e)=x_{F(T)}(e)+1$ e $\left.x_{T^{\prime}}(e)=x_{T}(e)+1\right)$ e $(\mathrm{c}$ ) as demais (para as quais $x_{F\left(T^{\prime}\right)}(e)=x_{F(T)}(e)$ e $\left.x_{T^{\prime}}(e)=x_{T}(e)\right)$.

As arestas em (a) ficaram mais caras, as em (b) mais baratas, e as demais continuam com mesmo custo.

Note que como $q$ compra $e^{\prime}=(u, v)$ e as arestas em $S_{v}$, e nenhuma aresta do tipo (a) é azul, toda aresta em $F$ do tipo (a) deve estar no caminho entre $\ell$ e $y$, e portanto em $T_{\ell}$.

Além disso, toda aresta em $T_{\ell}$ do tipo (b) deve estar em $S_{v}$ (uma vez que as demais arestas em (b) não existiam em $S$ ), e portanto também está em $F$.

Como a inequação desejada era válida antes do movimento de $q$, toda aresta cujo custo aumentou do lado direito da inequação também aparece no lado esquerdo e toda aresta cujo custo diminuiu do lado esquerdo também aparece no lado direito, concluímos que a inequação continua válida até o momento em que examinamos $\ell$ e portanto $\ell$ trocará sua estratégia para $F$.

\section{Análise do preço da estabilidade}

Seja $S^{N}$ o equilíbrio alcançado pelo algoritmo. Queremos relacionar o custo social de $S^{N}$ com o custo de $T^{*}$. Para isso particionaremos as arestas de $G_{S^{N}}$ em duas classes: as que estão em $T^{*}$ e as que não estão. Claramente o custo das arestas do equilíbrio que estão em $T^{*}$ não é maior que o custo da solução ótima. Desejamos limitar então o custo das arestas em $G_{S^{N}} \backslash T^{*}$. Cada uma dessas arestas foi adicionada ao perfil por um movimento $\overline{\mathrm{OPT}}$ e 


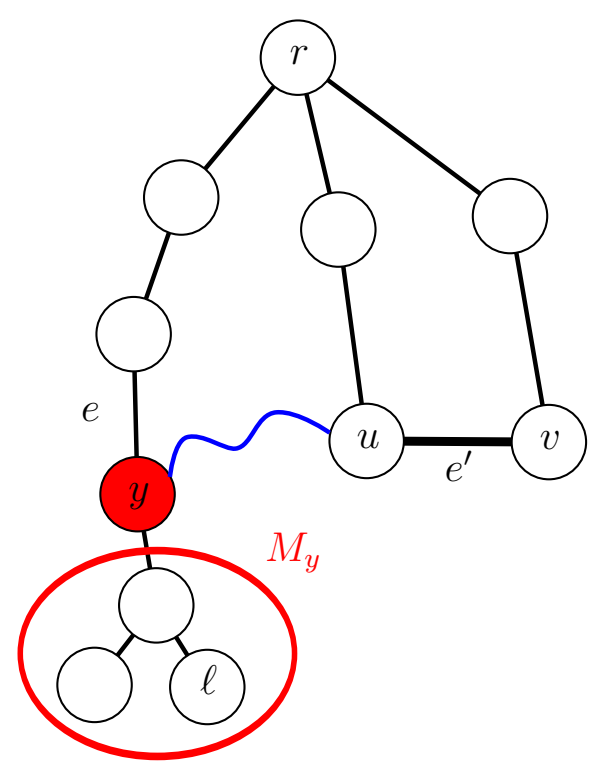

Figura 5.28: Se o jogador y faz um movimento OPT no laço OPT, todos os jogadores em $M_{y}$ farão um movimento $\mathrm{EE}$ no laço $\mathrm{EE}$ e a aresta e deixará de ser utilizada.

permaneceu até o fim do algoritmo. Note que se uma dessas arestas foi removida e adicionada varias vezes, consideramos apenas a última adição.

Associamos cada uma dessas arestas com o jogador $u$ que a adicionou.

Para cada uma dessas arestas $e^{\prime}=(u, v)$, seja $m_{e^{\prime}}$ o número de vértices a distância no máximo $c\left(e^{\prime}\right) / 4$ de $u$ na árvore geradora mínima $T^{*}$. Dizemos que $e^{\prime}$ é uma aresta pesada se $m_{e^{\prime}} \geq \log n$, e dizemos que $e^{\prime}$ é uma aresta leve caso contrário.

Lema 5.22. O custo total das arestas pesadas é $\mathrm{O}\left(C\left(T^{*}\right)\right)$.

Demonstração. Seja e uma aresta pesada de $G_{S^{N}}$. Pelo lema 5.20, durante a fase em que a aresta $e$ foi adicionada a função potencial diminuiu $\Omega(c(e) \log n)$. Como o potencial inicial é $\mathrm{O}\left(C\left(G_{S^{N}}\right) \log n\right)$ e somente diminui durante a execução do algoritmo, segue que tal diminuição só pode ocorrer $\mathrm{O}\left(C\left(T^{*}\right)\right)$ vezes.

Lema 5.23. O custo total das arestas leves é $\mathrm{O}\left(C\left(T^{*}\right) \log \log n\right)$.

Demonstração. Seja $U$ o conjunto de jogadores associados a arestas leves. Chamaremos os elementos desse conjunto de vértices leves e para cada $v$ em $U$, chamamos de $e_{v}$ a aresta associada a $v$ e de $z_{v}$ seu custo.

Para todo $v$ em $U, e_{v}$ foi adicionada no início de uma fase. Pelo lema 5.16, $p_{v}(S) \leq$ $p_{r}(S)+d^{*}(v, r)=d^{*}(v, r)$, e como $v$ diminuiu seus custos com o novo caminho, segue que

$$
z_{v} \leq d^{*}(v, r)
$$

Escolhemos um subconjunto $F$ de $U$ através do algoritmo a seguir. 
Subconjunto-Relevante $(U)$

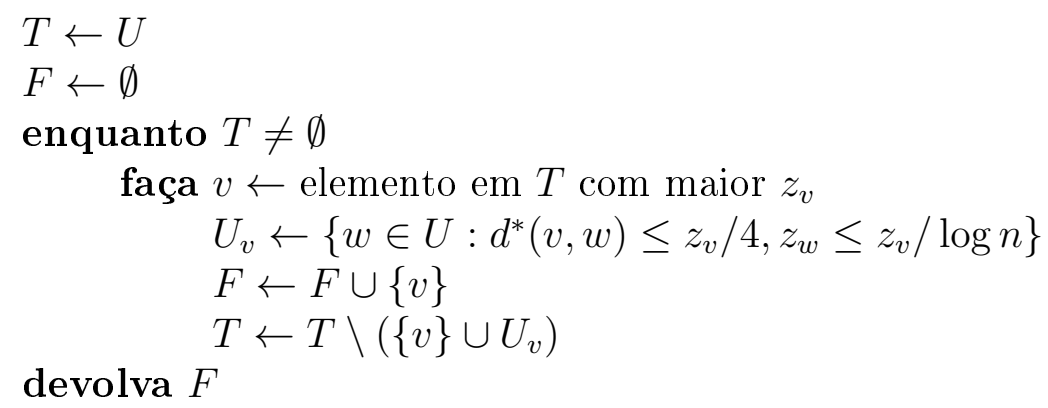

Para facilitar a notação, chamaremos de arestas de $F$ às arestas associadas aos jogadores em $F$.

Como todo vértice em $F$ é um vértice leve, há no máximo $\log n$ elementos em cada $U_{v}$ e portanto,

$$
\sum_{w \in U_{v}} z_{w} \leq \log n \times z_{v} / \log n=z_{v}
$$

e o custo das arestas eliminadas pelo algoritmo acima é proporcional ao custo das arestas em $F$. Limitaremos portanto nossa análise apenas às arestas em $F$.

Seja $T^{*}$ a árvore geradora de custo mínimo fixada. Considere uma representação gráfica de $\left(T^{*}, c\right)$, em que o comprimento de cada aresta é proporcional ao seu custo. Em tal representação, podemos dividir uma aresta em segmentos, onde o custo de cada segmento será o seu comprimento.

Para todo $v$ em $F$, considere uma bola $B_{v}$ de raio $z_{v} / 12$ centrada em $v$ na representação gráfica, contendo o conjunto de arestas e segmentos de arestas a distância no máximo $z_{v} / 12$ do vértice $v$. Como $z_{v} \leq d^{*}(v, r)$, a soma dos custos dos segmentos em $B_{v}$ é no mínimo $z_{v} / 12$, correspondente ao início do caminho entre $v$ e $r$.

Vamos provar que todo ponto $\xi$ na representação gráfica de $T^{*}$ está contido em no máximo $\log \log n$ bolas. Com tal resultado, podemos limitar o custo das arestas leves da seguinte forma: Seja $Z=\sum_{v \in F} z_{v}$. Sabemos que $Z$ é proporcional ao custo das arestas leves construídas. Os custos dos segmentos dentro de cada bola $B_{v}$ é $\Omega\left(z_{v}\right)$, e consequentemente, a soma dos custos em todas as bolas é $\Omega(Z)$. Como cada ponto de $T^{*}$ aparece em no máximo $\log \log n$ bolas, a soma dos custos dos segmentos em todas as bolas é no máximo $c\left(T^{*}\right) \log \log n$ e portanto, o custo total das arestas leves é $\mathrm{O}\left(c\left(T^{*}\right) \log \log n\right)$.

Seja $e$ uma aresta em $T^{*}$ e $\xi$ um ponto na aresta $e$. Seja $A_{\xi}$ o conjunto de vértices em $F$ cujas bolas contém $\xi$ e sejam $v_{1}, v_{2}, \ldots, v_{m}$ os vértices de $A_{\xi}$ na ordem em que suas arestas $e_{v_{1}}, e_{v_{2}}, \ldots, e_{v_{3}}$ foram adicionadas pelo algoritmo (se alguma aresta foi adicionada mais de uma vez durante a execução do algoritmo, considere a última inserção).

Seja $1 \leq i<j \leq m$. Sabemos que $v_{i}$ não mudou sua estratégia após o movimento que adicionou $e_{v_{i}}$ e portanto, pelo lema 5.19 temos que

$$
\frac{z_{v_{j}}}{4}<d^{*}\left(v_{i}, v_{j}\right)
$$

Como $d^{*}\left(v_{i}, \xi\right) \leq z_{v_{i}} / 12$ e $d^{*}\left(v_{j}, \xi\right) \leq z_{v_{j}} / 12$,

$$
d^{*}\left(v_{i}, v_{j}\right) \leq \frac{z_{v_{i}}}{12}+\frac{z_{v_{j}}}{12}
$$

Substituindo $j$ por $i+1$ nas duas inequações acima, concluímos que $z_{v_{i+1}}<z_{v_{i}} / 2$ e portanto, $z_{v_{i+1}}<z_{v_{1}} / 2^{i}$. 
Pela definição de $F$, temos que $z_{v_{1}} / \log n<z_{v_{i+1}}$, ou $v_{i+1}$ teria sido eliminado. Assim,

$$
\frac{z_{v_{1}}}{\log n}<v_{i+1}<\frac{z_{v_{1}}}{2^{i}}
$$

e portanto $i \leq \log \log n$ e $\left|A_{\xi}\right| \leq \log \log n$.

Teorema 5.24. O equilibrio obtido pelo algoritmo tem custo social $\mathrm{O}\left(C\left(T^{*}\right) \log \log n\right)$ e o preço da estabilidade de um jogo STEINERJUSTOB qualquer é $\mathrm{O}(\log \log n)$.

Demonstração. Segue dos teoremas acima, somando o custo de todas as arestas. 


\section{Capítulo 6}

\section{Jogos de Steiner com Ofertas}

Vamos agora considerar um modelo alternativo para a divisão dos custos das arestas. Tal modelo foi estudado por Elliot Anshelevich, Anirban Dasgupta, Éva Tardos e Tom Wexler [ADTW08] e, apesar de possuir desvantagens em relação ao modelo com divisão justa, tem preço da estabilidade baixo em alguns casos especiais.

\subsection{Modelo com ofertas}

Seja $(G, c, \mathcal{R})$ uma instância do problema FSTEINER. No modelo com ofertas deixaremos a forma de divisão dos custos das arestas a cargo dos jogadores. Portanto, em vez dos jogadores escolherem apenas quais arestas pretendem utilizar, estes farão uma oferta de pagamento por cada aresta, indicando quanto contribuirão para a sua construção. Desta forma, para cada jogador $i$, uma estratégia passa a ser uma função oferta $o_{i}$ de $E_{G} \operatorname{em} \mathbb{R}_{\geq 0}$.

Se as ofertas para uma determinada aresta somarem o suficiente para pagar seu custo, esta será considerada comprada e será "construída", podendo ser então utilizada por qualquer jogador, mesmo que este não tenha contribuído em nada para a sua construção. Assim, se $o=\left(o_{1}, \ldots, o_{n}\right)$ é um perfil de estratégias, uma aresta $e$ é comprada por $o$ se

$$
\sum_{i=1}^{n} o_{i}(e) \geq c_{e}
$$

Denotamos por $G_{o}$ o subgrafo de $G$ formado pelas arestas compradas por um perfil de estratégias $O$.

Jogo $\operatorname{SteinerOferta~}(G, c, \mathcal{R})=(N, \mathcal{S}, \mathcal{P})$

Dados um grafo $G$ com custos $c_{e}$ em $\mathbb{Z}_{\geq}$para cada aresta $e$ em $E_{G}$ e uma coleção de conjuntos de vértices $\mathcal{R}=\left(R_{1}, \ldots, R_{n}\right)$, o jogo é aquele em que

- $N=\{1, \ldots, n\}$ é o conjunto de jogadores;

- $\mathcal{S}$ é a uma sequência $\left(O_{1}, \ldots, O_{n}\right)$ onde $O_{1}=\cdots=O_{n}$ é o conjunto de todas as funções de oferta de $E_{G}$ em $\mathbb{R}_{\geq 0}$; e

- $\mathcal{P}$ é uma sequência $\left(p_{1}, \ldots, p_{n}\right)$ de funções de custo sendo

$$
p_{i}(o)=\left\{\begin{aligned}
\sum_{e \in E_{G}} o_{i}(e), & \text { se } G_{o} \text { conecta } R_{i} \\
+\infty, & \text { caso contrário. }
\end{aligned}\right.
$$

Seja o um equilíbrio para um jogo SteinerOfERTA e $G_{o}$ o grafo das arestas compradas por $o$. Note que os jogadores preferem pagar pelo grafo completo a deixar seus terminais 
desconectados, portanto $R_{i}$ está conectado em $G_{o}$. Seja $T_{i}(o)$ uma árvore de custo mínimo em $G_{o}$ que conecta $R_{i}$.

Como cada jogador está interessado em minimizar seus pagamentos, podemos concluír que $G_{o}$ é uma floresta, pois se houvesse algum ciclo em $G_{o}$ qualquer jogador que pagasse por uma de suas arestas poderia simplesmente deixar de comprá-la sem desconectar seus terminais.

Além disso, pelos mesmos motivos, cada jogador $i$ não pagará por nenhuma aresta fora de $T_{i}(o)$, e para cada aresta $e$, a soma de seus pagamentos $\sum_{i=1}^{n} o_{i}(e)$ será exatamente $c_{e}$ ou zero.

Note, porém, que este jogo nem sempre admite um equilíbrio de Nash, como mostra o exemplo da figura 6.1(a). Suponha que haja um equilíbrio o para a instância em questão. Então, como visto anteriormente, $G_{o}$ deve ser uma floresta e podemos assumir, sem perda de generalidade, que as arestas compradas serão $a b, b c$ e $c d$. Apenas o jogador $\mathbb{D}$ aceitará pagar pela aresta $a b$ e apenas o jogador $\&$ aceitará pagar por $c d$, então cada um deles pagará pelo menos 1 e a aresta $b c$ deve ser dividida por eles de alguma forma.

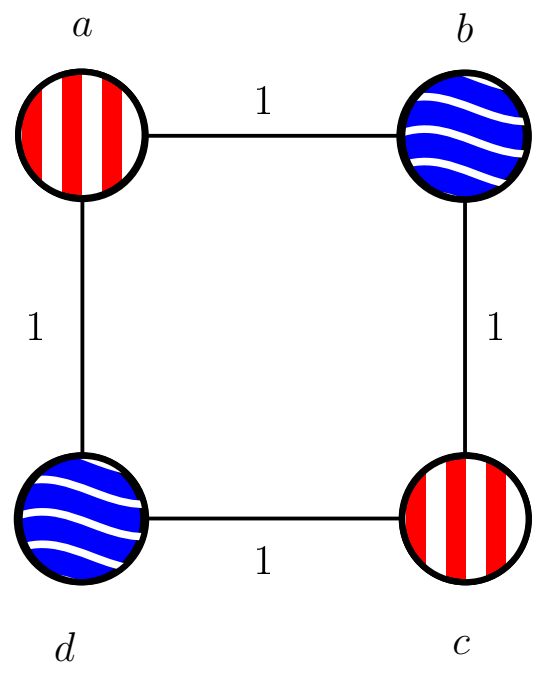

(a)

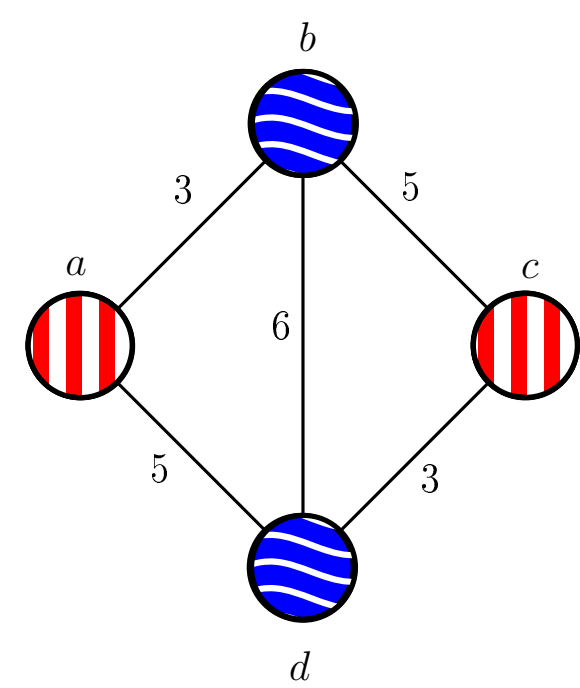

(b)

Figura 6.1: (a) Instância sem equilíbrio, onde $R_{\mathbb{D}}=\{a, c\}, R_{\mathscr{\vartheta}}=\{b, d\}$ e (b) Instância apenas com equilíbrio fracionário, onde $R_{\mathbb{D}}=\{a, c\}, R_{\vartheta}=\{b, d\}$

No entanto, nenhum dos jogadores aceitará pagar nada pela aresta $b c$, pois uma vez que a aresta $c d$ tenha sido inteiramente comprada pelo jogador $\theta$, o jogador $\mathbb{D}$ será incentivado a deixar de pagar por $a b$ e comprar apenas a aresta ad com custo 1. Analogamente, se o jogador $\mathbb{D}$ comprar a aresta $a b$, o jogador $\&$ irá preferir comprar apenas a aresta $a d$, e concluímos que esta instância não admite equilíbrio de Nash.

Note que a decisão de dividir o custo de uma aresta entre vários jogadores é necessária, ou seja, não é possível assumir que se um equilíbrio existe, cada aresta é paga por apenas um jogador. Equilíbrios desse jogo em que mais de um jogador paga por uma aresta são chamados de equilíbrios fracionários ${ }^{1}$ [ADTW08]. No exemplo da figura 6.1(b), podemos

\footnotetext{
${ }^{1} \mathrm{O}$ nome fracionário (fractional) é usado mesmo quando todas as ofertas são inteiras.
} 
verificar que o perfil em que o jogador $\mathbb{D}$ paga $o_{1}(a b)=3, o_{1}(b d)=1, o_{1}(d c)=3$ e em que o jogador paga apenas $o_{2}(b d)=5$ é um equilíbrio.

Verificaremos agora que não há um equilíbrio em que cada aresta é comprada por apenas um jogador no exemplo da figura 6.1(b). Note que se a aresta $b d$ não for comprada, teremos um exemplo análogo ao da figura 6.1(a), que não apresenta equilíbrio. Se bd for comprada inteiramente pelo jogador $\mathbb{D}$, o jogador $\&$ não aceitará pagar nada, pois seus terminais já estarão conectados. Nesse caso, a melhor estratégia para $\mathbb{D}$ será comprar $a b$ e $b c$ (ou $a d$ e $d c)$ com custo 8 sem pagar por $b d$. Já se a aresta $b d$ for comprada somente pelo jogador $\vartheta$, o jogador $\mathbb{D}$ preferirá comprar $a b$ e $d c$ com custo 6 , fazendo com que o jogador $\theta$ tenha incentivo em deixar de pagar por $b d$, comprando $b c$ e diminuindo seu gasto para 5 .

\subsection{Complexidade computacional}

Teorema 6.1 ([ADTW08]). O problema de decidir se há um equilibrio de Nash em um jogo SteinerOferta $(G, c, \mathcal{R})$ é um problema NP-completo.

Demonstração. A redução é feita a partir do 3-SAT.

Seja $X=\left\{x_{1}, \ldots, x_{n}\right\}$ um conjunto de variáveis binárias. Uma valoração das variáveis em $X$ é uma função $t: X \rightarrow\{$ verdadeiro, FALSO $\}$. Se $x$ é uma variável, $x$ e $\bar{x}$ são literais. Um literal $x$ é verdadeiro se $t(x)=$ VERDADEIRO e um literal $\bar{x}$ é verdadeiro se $t(x)=$ FALSO.

Uma cláusula $C$ é um conjunto de literais de $X$, representando a disjunção dos literais. Dizemos que uma cláusula é satisfeita se algum dos seus literais é verdadeiro.

Problema 3 -SAT $\left(x_{1}, \ldots, x_{n}, C_{1}, \ldots, C_{m}\right)$ : Dadas cláusulas $C_{1}, \ldots, C_{m}$, cada uma com 3 literais, sobre variáveis $x_{1}, \ldots, x_{n}$, decidir se há uma valoração das variáveis que satisfaz todas as cláusulas.

Considere uma instância do 3-SAT com cláusulas $C_{j}$ e variáveis $x_{i}$.

Para cada variável $x_{i}$, costruiremos um dispositivo como o da figura 6.2(a) e um jogador que deseja conectar $s_{i}$ a $t_{i}$. Chamaremos esse jogador de $i$-ésimo jogador-variável. O caminho da esquerda na figura está associado a um valor VERDADEIRO para a variável, e o da direita a FALSO.

Para cada cláusula $C_{j}$, construiremos um dispositivo como o da figura 6.2(b) e associaremos dois jogadores a ele, um com terminais $\left\{s_{j 1}, t_{j 1}\right\}$ e outro com terminais $\left\{s_{j 2}, t_{j 2}\right\}$. Chamaremos tais jogadores de jogadores-cláusula.

Note que os dispositivos têm arestas em comum. No exemplo da figura 6.2(b), associado a uma cláusula $C_{j}=\left(x_{1} \vee x_{2} \vee \neg x_{3}\right)$, as arestas $e_{1 T}, e_{2 T}$ e $e_{3 F}$ são as mesmas dos dispositivos das variáveis. Todas as arestas tem custo unitário.

Suponha que exista uma valoração das variáveis que satisfaça todas as cláusulas. Considere então a estratégia em que o $i$-ésimo jogador-variável paga completamente pelo caminho da esquerda de seu dispositivo se nessa valoração $x_{i}=$ VERDADEIRO, ou pelo da direita caso contrário.

Como a valoração satisfaz as cláusulas, em cada dispositivo de cláusula há ao menos uma aresta interna que já foi inteiramente paga por um jogador-variável. Para cada $C_{j}$, seja $e_{j}$ tal aresta. Os dois jogadores de $C_{j}$ compram o caminho de tamanho 3 entre seus terminais que passa por $e_{j}$.

Todos os jogadores-cláusula tem custo 2 e não tem incentivo em desviar, pois se os demais jogadores obedecerem as estratégias descritas, qualquer caminho alternativo tem ao menos esse custo. Da mesma forma, os jogadores-variável tem custo 2 e não desejarão desviar. Portanto, o perfil descrito é um equilíbrio. 


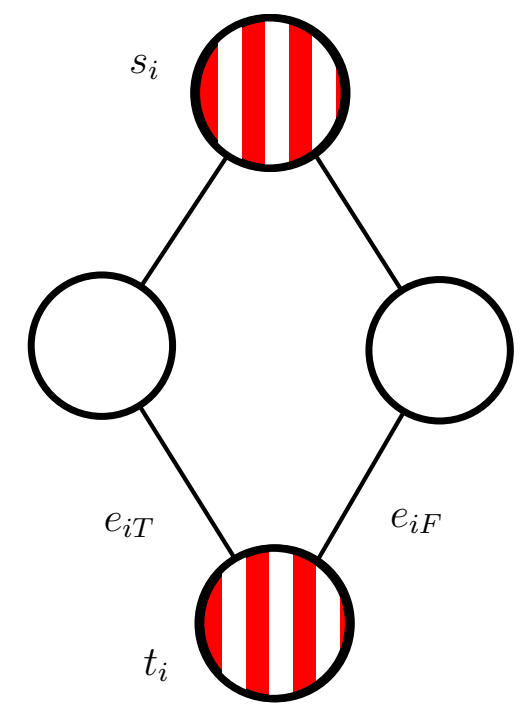

(a)

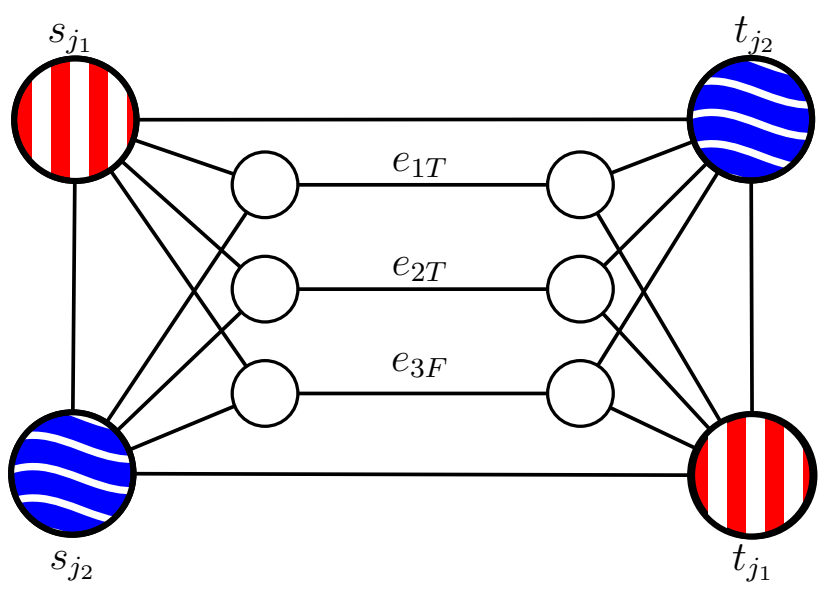

(b)

Figura 6.2: (a) Dispositivo para a variável $x_{i}$ e (b) Dispositivo para a cláusula $C_{j}=x_{1} \vee x_{2} \vee \neg x_{3}$

Suponha agora que existe um equilíbrio qualquer para o jogo.

Sabemos que cada jogador aceita pagar no máximo 2, que é o custo do menor caminho entre seus vértices.

Considere um dispositivo cláusula. Queremos mostrar que em um equilíbrio as arestas compradas neste dispositivo correspondem aos seus dois jogadores utilizando uma das arestas centrais, como no equilíbrio obtido anteriormente.

O grafo formado pelo equilíbrio deve ser uma floresta. Considere uma componente que contém um jogador dessa cláusula. Seja $x$ o número de jogadores-cláusula nesta componente e y o número de jogadores-variável. O número de vértices na componente é pelo menos $2 x+3 y$, pois temos os dois terminais de cada jogador-cláusula e três dos vértices de cada dispositivo-variável.

Como a componente é uma árvore, o número de arestas deve ser pelo menos $2 x+3 y-1$ e a média dos pagamentos dos jogadores na componente é no mínimo $\frac{2 x+3 y-1}{x+y}=2+\frac{y-1}{x+y}$. Como cada jogador paga no máximo 2, concluímos que $y \leq 1$.

Se $y=0$, a componente consiste apenas dos jogadores da cláusula em questão, pois para que qualquer jogador cláusula saia de seu dispositivo, deve passar por um terminal de um jogador-variável e incluí-lo na componente. Porém, para que os dois jogadores liguem seus terminais pagando menos que 2, é necessário que eles dividam entre si as arestas do perímetro do dispositivo, um problema que sabemos que não admite equilíbrio.

Portanto, $y=1$ e concluímos que todo jogador deve pagar exatamente 2 pela sua parte.

Suponha que em um dispositivo de cláusula, uma ou mais arestas do perímetro tenham sido compradas. Tais arestas não podem ter sido paga apenas pelos jogadores do dispositivo ou cairíamos novamente em um caso que não admite equilíbrio. No entanto, se algum jogador externo pagar uma quantia positiva por uma dessas arestas, os dois jogadores da cláusula terão uma estratégia que custa menos que 2, o que não é possível. Portanto, nenhuma aresta do perímetro de um dispositivo cláusula é comprada.

Como nenhuma aresta de perímetro é comprada e há apenas um jogador variável por componente, os jogadores variáveis devem comprar apenas caminhos dentro de seus dispositivos. Como sabemos que todo jogador deve pagar exatamente 2, tais jogadores pagam completamente por um dos dois caminhos mínimos entre seus terminais.

Finalmente, para que os jogadores cláusula conectem seus terminais com custo 2 sem 
usar arestas do perímetro, é necessário que uma das arestas internas tenha sido comprada por um jogador variável.

Assim, dado um equilíbrio, se atribuirmos à variável associada a um jogador variável o valor VERDADEIRO se o jogador utiliza o caminho esquerdo e FALSO caso utilize o direito, todas as cláusulas serão satisfeitas.

\subsection{Ineficiência do equilíbrio}

Mesmo em instâncias que admitem equilíbrio, estes podem ser muito ruins. O preço da anarquia pode ser proporcional ao número de jogadores, como no jogo STEINERJUSTO (o exemplo da figura 4.6 também vale para jogos STEINEROFERTA) e o preço da estabilidade também pode chegar a esse limite, como mostra o exemplo da figura 6.3.

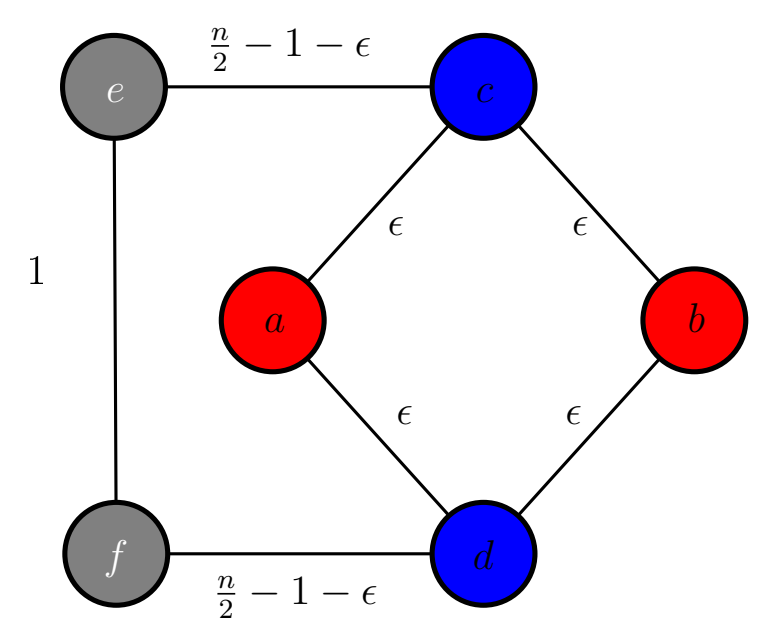

Figura 6.3: Instância com preço da estabilidade $n-2 . R_{1}=\{a, b\}, R_{2}=\{c, d\}, R_{i}=\{e, f\}$ para $3 \leq i \leq n$.

Nesse exemplo, a solução ótima tem custo $1+3 \epsilon$. No entanto, se a aresta ef for comprada, nenhum jogador $i>2$ aceitará pagar nada pelas demais, fazendo com que 1 e 2 caiam no caso da figura 6.1(a), que não possui equilíbrio. Assim, se houver um equilíbrio, este deve pagar pelas duas arestas de custo $\frac{n}{2}-1-\epsilon$ e por três das arestas de custo $\epsilon$. De fato, podemos verificar que a solução em que os jogadores $i>2$ dividem o custo de um caminho de custo $n-2$ igualmente entre si (ecbdf, por exemplo), e em que o jogador 1 paga $\epsilon$ para se ligar a este (aresta ac por exemplo) é um equilíbrio.

Apesar destas desvantagens, o jogo STEINEROFERTA apresenta um preço da estabilidade baixo para o caso em que todos os jogadores tem um vértice em comum, como veremos na próxima sessão.

\subsection{Multitransmissões}

Nesta sessão analisaremos a existência de equilíbrio e o preço da estabilidade em jogos STEINEROFERTA para multitransmissões.

Como definido no capítulo anterior, uma multitransmissão ocorre quando uma mensagem deve ser transmitida em uma rede de um nó para uma série de destinatários. Neste caso, em 
vez de mandar uma cópia separada do sinal para cada participante, é criada uma arborescência ligando a fonte a todos os receptores. A mensagem é duplicada apenas nos pontos de ramificação, fazendo com que apenas uma cópia da mensagem atravesse cada aresta.

Jogo SteinerOfertaM $(G, c, \mathcal{R})=(N, \mathcal{S}, \mathcal{P})$

Dados um grafo $G$, um custo $c_{e}$ em $\mathbb{Q}_{\geq}$para cada aresta e uma sequência de $n$ pares de vértices $\mathcal{R}=\left(R_{1}, \ldots, R_{n}\right)$ com $R_{i}=\left(s_{i}, r\right)$, o jogo é aquele em que:

- $N=\{1, \ldots, n\}$ é o conjunto de jogadores;

- $\mathcal{S}$ é uma sequência $\left(O_{1}, \ldots, O_{n}\right)$, sendo $O_{1}=\ldots=O_{n}$ o conjunto de funções de oferta de $E_{G}$ em $\mathbb{Q}_{\geq}$; e

- $\mathcal{P}$ é uma sequência $\left(p_{1}, \ldots, p_{n}\right)$ de funções de custo sendo

$$
p_{i}(o)=\left\{\begin{aligned}
\sum_{e \in E_{G}} o_{i}(e), & \text { se } G_{o} \text { conecta } R_{i} \\
+\infty, & \text { caso contrário }
\end{aligned}\right.
$$

Como mostraremos a seguir, jogos STEINEROFERTAM sempre admitem equilíbrio e tem preço da estabilidade 1 . Note, no entanto, que uma dinâmica de melhor resposta pode não convergir para um equilíbrio, como mostra o exemplo da figura 6.4.

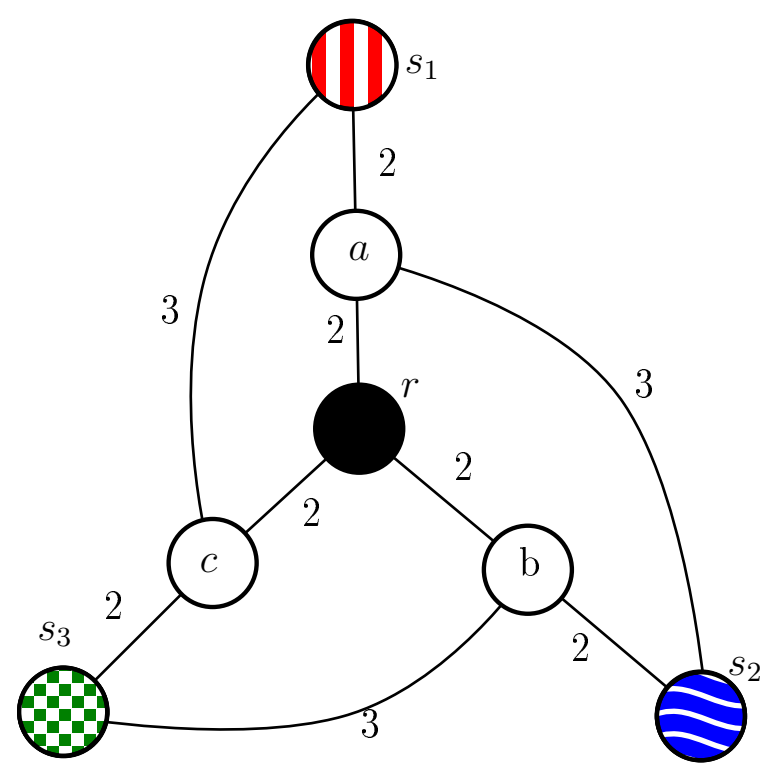

Figura 6.4: SteinerOfertaM em que uma dinâmica de melhor resposta não converge para um equilíbrio

Considere um perfil inicial em que os três jogadores compram caminhos de custo 4 entre seus terminais e a raiz. O jogador $\mathbb{D}$ terá interesse em trocar sua estratégia, comprando a aresta de $s_{1} c$ entre seu terminal e o caminho de $\otimes$. Da mesma forma, o jogador $*$ terá interesse em trocar sua estratégia, comprando a aresta de $s_{3} b$ entre seu terminal e o caminho de $₹$, desconectando os terminais de $\mathbb{D}$, que então retornará à sua estratégia inicial. Nesse ponto, o jogador $\&$ terá interesse em trocar sua estratégia, comprando a aresta $s_{2} a$ entre seu terminal e o caminho de $\mathbb{D}$, desconectando os terminais de $*$, e assim por diante, nunca chegando em um equilíbrio. 
No entanto, se os jogadores $\mathbb{D}$ e $\otimes$ dividirem igualmente a aresta $\mathrm{cr}$, com o jogador $\mathbb{D}$ pagando pela aresta $s_{1} c$, o jogador $\&$ pagando pelo caminho de custo 4 entre seus terminais e o jogador $\otimes$ pagando pela aresta $s_{3} c$, temos um equilíbrio com custo social ótimo.

Anshelevich e colaboradores [ADTW08] demonstraram que em multitransmissões a divisão dos custos por ofertas não só garante a existência de um equilíbrio, como possui preço da estabilidade 1. Tal demonstração é feita através de um algoritmo que recebe uma árvore (ou arborescência) de Steiner de custo mínimo e devolve, em tempo polinomial, um vetor de ofertas que é um equilíbrio. Analisaremos o algoritmo a seguir.

Seja $T^{*}$ uma árvore de Steiner de custo mínimo associada a uma instância $(G, c, \mathcal{R})$ do SteinerOferta. Para toda aresta $e$, seja $T_{e}$ a subárvore de $T^{*}$ não conectada a $r$ quando a aresta $e$ é eliminada do grafo.

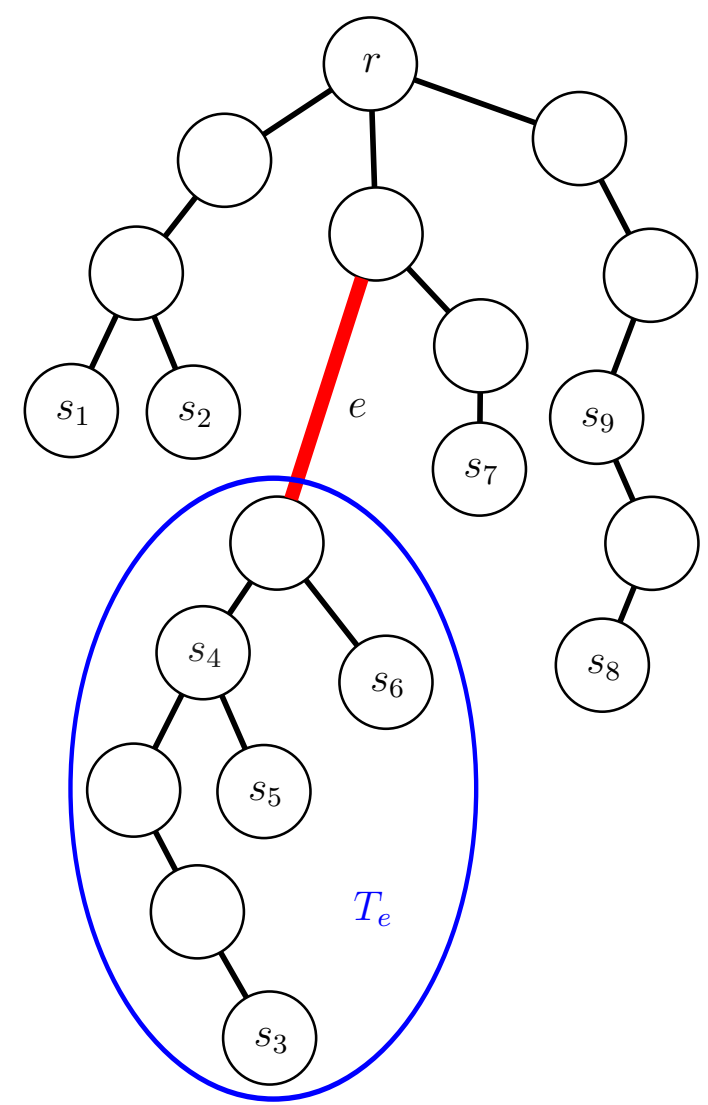

Figura 6.5: Uma aresta e e a árvore $T_{e}$. Apenas jogadores em $T_{e}(3,4,5$ e 6) aceitarão pagar por e.

Dado um jogo SteinerOferta $(G, c, \mathcal{R})$ no qual todos os jogadores tem um terminal em comum e uma árvore de Steiner de custo mínimo $T^{*}$ para o problema $\operatorname{FSteiner}(G, c, \mathcal{R})$, o algoritmo devolve um perfil de estratégias dado pelas ofertas de cada jogador que paga por $T^{*}$ e é equilíbrio. 


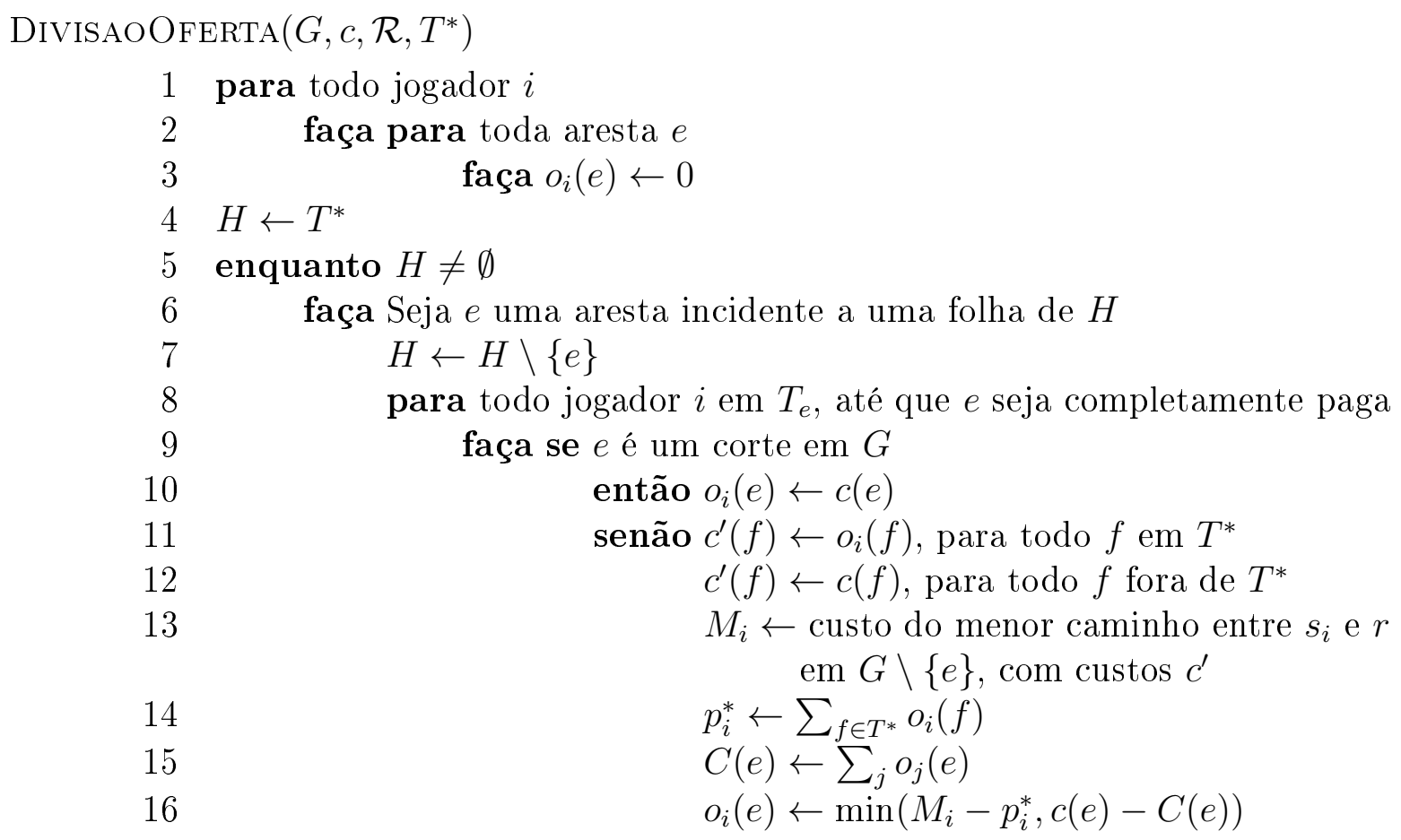

O algoritmo analisa as arestas uma a uma, processando a àrvore das folhas à raiz, determinando a oferta de cada jogador por tal aresta. Note que o algoritmo analisa uma aresta $e$ apenas após todas as arestas em $T_{e}$ terem sido analisadas.

Para cada aresta, cada jogador que a utiliza paga o maior valor aceitável, supondo que o resto dos jogadores aceite pagar pelo resto da árvore, até que as ofertas pela aresta sejam iguais ao seu custo.

No algoritmo acima, $o_{i}(e)$ representa a oferta de $i$ pela aresta $e, C(e)$ representa o quanto os jogadores já aceitaram pagar por $e$, e $p_{i}^{*}$, o quanto o jogador $i$ já aceitou pagar.

Cada jogador $i$ oferece por uma aresta $e$ em $T^{*}$ o máximo que está disposto a pagar antes de desviar para um caminho mínimo (com custos $c^{\prime}$ ajustados assumindo que os outros jogadores aceitam pagar pelo resto do custo da árvore) que não usa a aresta $e$ (possivelmente deixando de pagar sua parte pelas arestas de $T_{e}$ ).

Note que se o algoritmo terminar, ou seja, a cada iteração a aresta analisada for completamente paga pelos jogadores, a solução encontrada será um equilíbrio, uma vez que os custos de cada jogador são ajustados exatamente para que este não tenha interesse em desviar se os demais comprarem sua parte. Assim, precisamos demonstrar apenas que para toda aresta $e$ os jogadores em $T_{e}$ aceitam pagar completamente por ela.

Suponha que alguma aresta $e$ não seja completamente paga pelo algoritmo. Isso quer dizer que todo jogador em $T_{e}$ tem um caminho alternativo (que não usa $e$ ) que impede que este pague mais por $e$. Mostraremos que se isso ocorre, é possível utilizar tais caminhos para alterar a árvore de Steiner, diminuindo o seu custo, o que contraria a hipótese de que esta é a ávore de Steiner ótima.

Para um jogador $i$, defina o caminho alternativo $A_{i}$ como o caminho de custo $M_{i}$ encontrado pelo algoritmo. Se há mais de uma possibilidade, escolha $A_{i}$ de forma a incluir o maior número de ancestrais de $s_{i}$ em $T_{e}$ antes de incluir arestas fora de $T^{*}$.

Lema 6.2. Suponha que $A_{i}$ é o caminho alternativo para $i$ com maior prefixo em $T^{*}$ para alguma etapa do algoritmo. Então existem dois vértices $v$ e $w$ em $A_{i}$ tais que todas as arestas em $A_{i}$ de $s_{i}$ a $v$ estão em $T_{e}$, todas as arestas entre $v$ e $w$ estão em $E \backslash T^{*}$ e todas as aresta entre w e r estão em $T^{*} \backslash T_{e}$. 
Demonstração. Toda aresta $f$ em $T^{*} \backslash T_{e}$ tem custo alternativo $c^{\prime}(f)=0$, portanto uma vez que $A_{i}$ alcance um vértice $w$ em $T^{*} \backslash T_{e}$, poderá chegar a $r$ com custo 0 e todos os vértices a seguir estarão em $T^{*} \backslash T_{e}$.

Suponha que $A_{i}$ começa com um caminho $P_{1}$ em $T_{e}$ seguido por um caminho $P_{2}$ contendo apenas arestas fora de $T^{*}$ até um vértice $x$ em $T_{e}$. Seja $y$ o ancestral comum mais baixo de $x$ e $s_{i}$ em $T_{e}$. Seja $P_{3}$ o caminho de $s_{i}$ a $y$ em $T_{e}$ e $P_{4}$ o caminho de $x$ a $y$ em $T_{e}$.

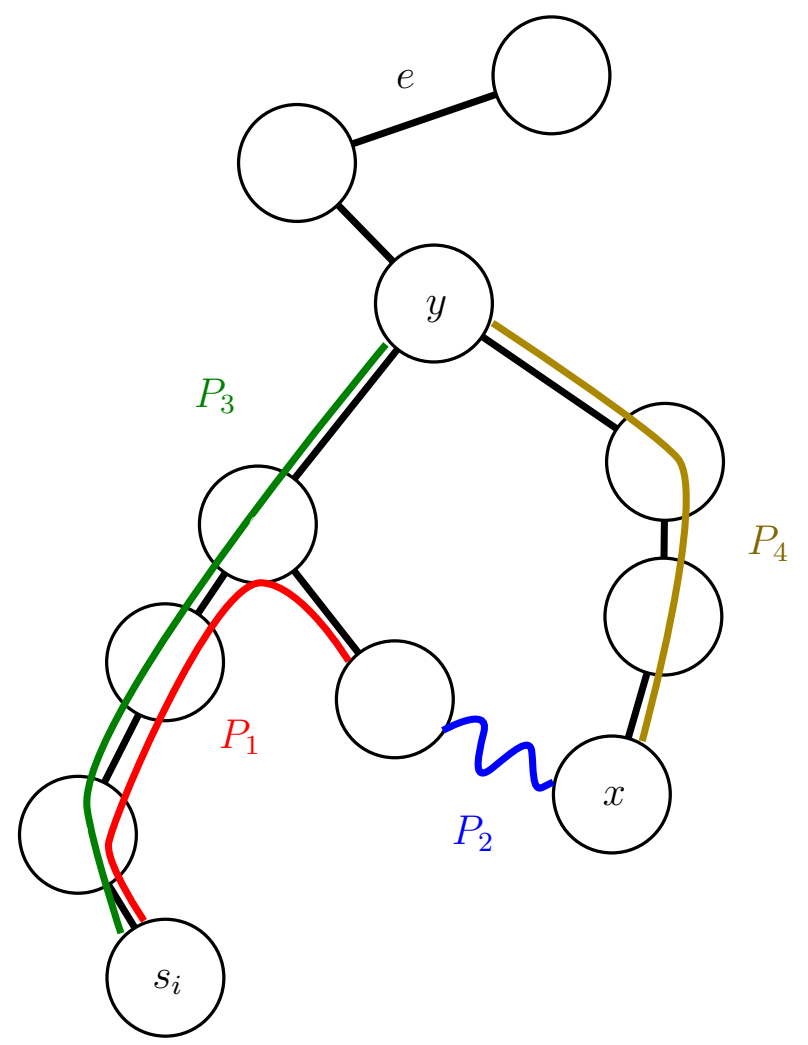

Figura 6.6: $O$ caminho alternativo do jogador $i$ não pode consistir de $P_{1}$ e $P_{2}$

Note que $c^{\prime}\left(P_{4}\right)=0$, pois nenhuma das arestas de $P_{4}$ é usada no caminho entre $s_{i}$ e $r$ em $T^{*}$. Portanto, como $A_{i}$ é um caminho mínimo sob os custos modificados, $c^{\prime}\left(P_{3}\right)=$ $c^{\prime}\left(P_{3} \cup P_{4}\right) \geq c^{\prime}\left(P_{1} \cup P_{2}\right)$. Note ainda que $c^{\prime}\left(P_{2}\right)$ deve ser estritamente positivo e portanto $c^{\prime}\left(P_{3}\right)>c^{\prime}\left(P_{1}\right)$ e $P_{1}$ está estritamente abaixo de $y$.

Mostraremos que sob os custos modificados $c^{\prime}$ o caminho $P_{3} \cap P_{4}$ é tão ou mais barato que $P_{1} \cap P_{2}$, contrariando a escolha de $A_{i}$.

Considere as iterações do algoritmo que analisaram arestas em $P_{3}$. Em cada uma dessas iterações é computado um caminho mínimo de $s_{i}$ a $r$. Em qualquer instante, $p_{i}^{*}$ é não superior ao custo ao custo do caminho alternativo mínimo para $i$, que por sua vez é não superior ao custo alternativo de qualquer outro caminho, em particular, $A_{i}$.

Em cada uma dessas iterações o custo das arestas acima de $x$ é 0 . Portanto a contribuição de $i$ para $P_{3}$ é no máximo o custo modificado de $P_{1} \cup P_{2}$. O custo modificado para $P_{4}$ é sempre 0 e portanto,

$$
c^{\prime}\left(P_{3} \cup P_{4}\right)=c^{\prime}\left(P_{3}\right) \leq c^{\prime}\left(P_{1} \cup P_{2}\right) .
$$

Portanto, os caminhos alternativos encontrados podem usar inicialmente arestas em $T_{e}$ mas subsequentemente usarão apenas arestas fora de $T_{e}$. 
Teorema 6.3. Se $T^{*}$ é uma árvore de Steiner de custo mínimo, o algoritmo DivisAoOFERTA paga completamente por toda aresta em $T^{*}$.

Demonstração. Suponha que, para uma aresta $e$, após todos os jogadores contribuírem para seu pagamento, $C(e)<c(e)$. Mostraremos que é possível modificar a árvore, conectando $T_{e}$ a $T \backslash T_{e}$ sem aumentar o pagamento dos jogadores, contrariando a escolha de $T^{*}$.

Considere para cada jogador $i$ o maior prefixo de $A_{i}$ que contém arestas em $T_{e}$. Denotaremos o ponto mais alto de tal prefixo em $T^{*}$ por $d_{i}$, o ponto de desvio de $i$. Note que é possível que $s_{i}=d_{i}$.

Seja $D$ um conjunto minimal de pontos de desvio tal que todo terminal em $T_{e}$ tem um ancestral em $D$.

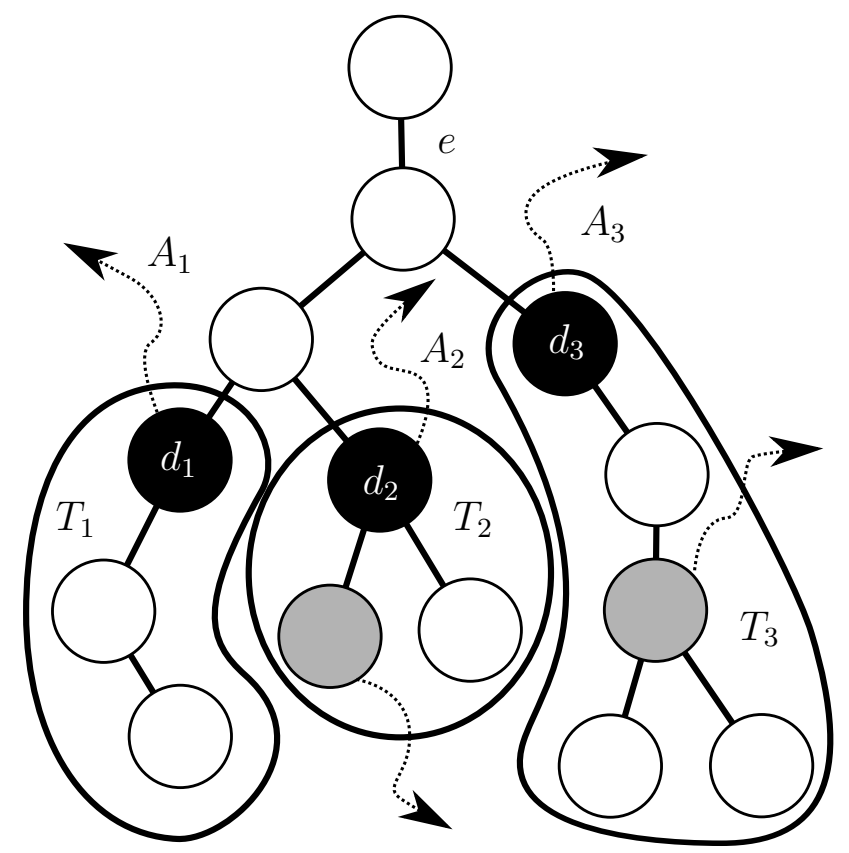

Figura 6.7: Pontos de desvio em destaque. O conjunto $D$ consiste de $d_{1}, d_{2}$ e $d_{3}$.

Modificamos a árvore da seguinte forma. Todo jogador $i$ associado a um ponto de desvio em $D$ desvia $A_{i}$, pagando $c^{\prime}(e)$ por cada aresta desse caminho. Os demais jogadores mantém seus pagamentos.

Note que nenhum jogador aumentou seus gastos. Resta mostrar que todos os terminais em $T_{e}$ estão conectados a $T^{*} \backslash T_{e}$ no novo grafo.

Seja $T_{i}$ a subárvore enraizada em $d_{i}$ para algum $d_{i}$ em $D$. Considere uma aresta $f$ em $T_{i}$. Pelo lema 6.2, $i$ é o único entre os jogadores que poderia estar pagando por $f$. Se $i$ pagava por $f$, então $f$ está no único caminho entre $s_{i}$ e $d_{i}$ em $T_{e}$ e $i$ continua pagando sua parte. Se $i$ não pagava por $f$, então ela é comprada apenas por jogadores que não mudaram de estratégia.

Pelo lema 6.2 sabemos que $A_{i}$ consiste de um caminho em $T_{e}$, seguido de um caminho em $E_{G} \backslash T^{*}$ seguido por um caminho em $T^{*} \backslash T_{e}$. O custo modificado $c^{\prime}$ para arestas em $E_{G} \backslash T^{*}$ é o próprio custo da aresta, portanto $i$ pagará completamente por um caminho que conecta $T_{i}$ a $T^{*} \backslash T_{e}$.

O grafo resultante é portanto uma árvore de Steiner e, como nenhum jogador aumentou seus custos, $T^{*}$ não poderia ser uma árvore de Steiner de custo mínimo.

Corolário 6.4 ([ADTW08]). O preço da estabilidade para jogos STEINEROFERTAM em grafos não-orientados é 1 . 
Demonstração. Segue do teorema 6.3.

O algoritmo funciona mesmo quando o grafo é orientado. Novamente, se o algoritmo pagar por todas as arestas o resultado é um equilíbrio. Devemos mostrar que toda aresta é completamente paga pelos jogadores. A prova é feita de forma semelhante ao caso nãoorientado, através da construção de uma arborescência alternativa de custo menor que a árvore da entrada. Porém, em grafos orientados o lema 6.2 não vale, ou seja, pode acontecer que um dos jogadores que deve pagar por $e$ tenha um caminho alternativo que usa alternadamente arestas em $T_{e}$ e $E_{G} \backslash T$ e é necessária uma definição ligeiramente diferente de $D$.

Note que é necessário alterar a verificação de aresta de corte na linha 9 do algoritmo. A maneira mais simples de fazer isso é eliminar tal verificação e atribuir um valor infinito a $M_{i}$ caso não haja caminho entre $s_{i}$ e $r$ em $G \backslash\{e\}$.

Teorema 6.5. O algoritmo DIVISAOOFERTA paga completamente por $T^{*}$ em grafos orientados.

Demonstração. Suponha que durante a execução do algoritmo uma aresta $e$ não seja completamente paga. Neste ponto, todo jogador $i$ com terminal em $T_{e}$ tem um caminho alternativo $A_{i}$ e aceitou pagar por sua parte em $T^{*}$ exatamente o custo de $A_{i}$. Seja $D^{\prime}$ o conjunto de vértices em $T_{e}$ que estão em pelo menos um desses caminhos alternativos. Note que $D^{\prime}$ contém todos os terminais de $T_{e}$.

Criamos $D$ o conjunto de vértices mais altos de $D^{\prime}$, ou seja, aqueles que não tem nenhum ancestral em $D^{\prime}$. Todo terminal de $T_{e}$ tem um ancestral único em $D$ e todo vértice de $D$ está associado a pelo menos um caminho $A_{i}$.

Para todo $v$ em $D$, seja $A_{v}$ um caminho alternativo que contém $v$ e $A_{v}^{\prime}$ o subcaminho de $v$ até o primeiro vértice em $T \backslash T_{e}$.

Formaremos o grafo alternativo $T^{\prime}$ como a união das arestas de $T \backslash T_{e}$, dos caminhos $A_{v}^{\prime}$ e das subárvores $T_{v}$ enraizadas em vértices $v$ de $D$. Note que $T^{\prime}$ pode não ser uma arborescência, mas nesse caso podemos diminuir ainda mais o custo eliminando arestas redundantes.

Como todo terminal de $T_{e}$ está conectado a algum vértice em $D$ e todo vértice em $D$ está ligado ao resto da árvore, temos que todos os jogadores conectaram seus terminais. Resta mostrar que a arborescência obtida tem custo menor que o de $T^{*}$.

Para isso, assumimos que todos os jogadores continuam pagando sua oferta inicial por arestas abaixo de $D$ e o custo adicional para construir $A_{v}^{\prime}$ é pago pelo jogador para o qual $A_{v}$ era um caminho alternativo. Note que o jogador que paga por $A_{v}^{\prime}$ pode não utilizar tal caminho no grafo resultante.

Os jogadores que não estão associados a nenhum vértice de $D$ não pagam mais do que antes, uma vez que suas ofertas consistem apenas de um subconjunto das ofertas originais.

Se o jogador que paga por um $A_{v}^{\prime}$ tem seu terminal na subárvore enraizada em $v$, ele está pagando exatamente o valor de seu caminho alternativo $A_{v}$ e portanto seu custo não aumentou.

Suponha que o jogador $i$ que paga por um $A_{v}^{\prime}$ tem seu terminal na subárvore enraizada em algum $v^{\prime} \neq v$ de $D$. Seja $u$ o ancestral comum mais baixo de $v$ e $v^{\prime}$ em $T_{e}$. Note que como $D$ é minimal, $u$ não é nem $v$ nem $v^{\prime}$. Seja $P_{1}$ o valor dos pagamentos de $i$ pelas arestas entre seu terminal e $u$ e $P_{2}$ o valor dos pagamentos de $i$ pelas arestas após $u$ (inclusive o quanto ele aceitou pagar por $e$ ). Seja $P_{3}$ o custo alternativo $c^{\prime}$ de $A_{v} \backslash A_{v}^{\prime}$ e $P_{4}$ o custo alternativo de $A_{v}^{\prime}$. Pela escolha de ofertas do algoritmo,

$$
P_{1}+P_{2}=P_{3}+P_{4}
$$


Além disso, como o caminho até $u$ já foi completamente pago, concluímos que $P_{1} \leq P_{3}$, ou $i$ teria desviado para $P_{3}$ e usado o caminho de $v$ a $r$ na árvore com custo alternativo 0 nesse momento. Portanto, segue que $P_{2} \geq P_{4}$.

Quando a aresta $e$ foi analisada, o jogador $i$ aceitou pagar $P_{1}+P_{2}$. No grafo resultante, o jogador $i$ paga apenas por arestas em $T_{v^{\prime}}$ e $A_{v}^{\prime}$. As arestas de $T_{v^{\prime}}$ custam para ele no máximo $P_{1}$, pois $v^{\prime}$ está abaixo de $u$. As arestas de $A_{v}^{\prime}$ custam $P_{4}$, que é no máximo $P_{2}$. Portanto o custo do jogador não aumentou.

Como tais pagamentos não eram suficientes para pagar por $T_{e} \cup\{e\}$, segue que o custo da arborescência diminuiu, o que é um absurdo.

Assim, apesar do preço da estabilidade alto no caso geral, para jogos de multitransmissão, o preço da estabilidade da divisão por ofertas é 1 mesmo para grafos orientados. A figura 6.8 mostra o mesmo exemplo para o qual a divisão justa tem o pior caso e uma possível divisão feita pelo algoritmo DivisAOOFERTA.

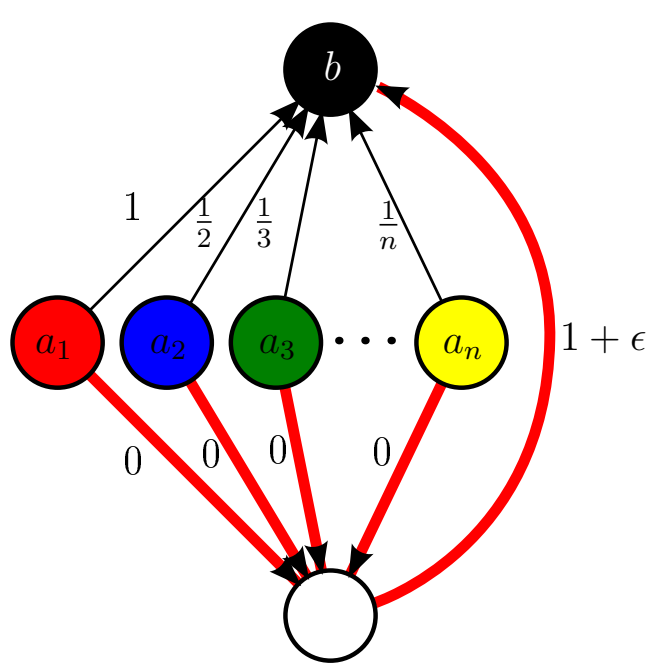

Figura 6.8: Instância do SteinerOfertaM onde $R_{i}=\left\{a_{i}, b\right\}$ para todo $i=1 \ldots n$, com arborescência de custo social mínimo em destaque. Em uma possível divisão estável o jogador 1 paga 1 , o jogador 2 paga $\epsilon$ e os demais não pagam nada.

Note, no entanto, que o valor das ofertas devolvidas pelo algoritmo DivisAoOferTA depende da ordem em que os jogadores são analisados. Em particular, arestas de corte são pagas completamente pelo primeiro jogador analisado. No exemplo da figura 6.8, se analisarmos os jogadores em ordem crescente de índice, o jogador 1 pagará por praticamente todo o custo do caminho, com o jogador 2 pagando o resto. Analisando os jogadores na ordem inversa, obtemos uma divisão um pouco melhor, mas ainda assim, os últimos jogadores analisados (aproximadamente um terço) não pagará nada pela sua parte.

Surge então a questão de como obter uma divisão mais "justa".

Note que cada jogador aceita pagar qualquer valor até $M_{i}-p_{i}^{*}$.

Podemos então modificar o algoritmo para que a linha 8 analise os jogadores em ordem crescente de $\left(M_{i}-p_{i}^{*}\right)$. Se há $k$ jogadores com terminais em $T_{e}$, ao processar o $i$-ésimo jogador $j_{i}$, faremos com que ele pague

$$
o_{j_{i}}(e)=\min \left(M_{i}-p_{i}^{*}, \frac{c(e)-C_{e}}{k-i+1}\right)
$$


e se é um corte, cada jogador pagará $o_{j_{i}}(e)=c(e) / k$.

Dessa forma, os primeiros jogadores analisados pagarão o máximo possível, até que os demais aceitem dividir o custo da aresta igualmente entre si. Como os jogadores são analisados em ordem crescente de $\left(M_{i}-p_{i}^{*}\right)$, cada jogador aceita pagar pelo menos tanto quanto o anterior e o algoritmo continua pagando completamente por todas as arestas.

Com tal modificação, no equilíbrio encontrado para o exemplo da figura 6.8 o jogador $n$ paga $\frac{1}{n}$ enquanto os demais pagam $\frac{1}{n}+\frac{\epsilon}{n-1}$, em uma divisão de custos muito próxima da divisão justa dos capítulos anteriores.

Outra alternativa seria levar os custos dos caminhos alternativos como pesos para os jogadores, aplicando uma ideia semelhante à usada para o valor de Shapley (seção 4.2), calculando a oferta média entre todas as permutações possíveis que o algoritmo original pode ser usado para a análise do jogo. Assim, arestas de corte ainda serão divididas igualmente, mas jogadores com caminhos alternativos baratos pagarão menos. No entanto, não encontramos uma maneira computacionalmente eficiente de fazer tal cálculo.

Como exemplo, para o jogo da figura 6.8 com 3 jogadores, sob tal divisão o jogador 1 pagaria $21 / 36+2 \epsilon / 3>0,583$, o jogador $2,1 / 4+\epsilon / 6>0,25$ e o jogador $3,1 / 6+\epsilon / 6>0,166$.

\subsection{Aproximações}

Como visto nas seções anteriores, jogos STEINEROFERTA podem não admitir equilíbrios e mesmo quando eles existem com custo social baixo para jogos SteinerOferTA. Mesmo que o jogo em questão tenha uma fonte única, quando é garantido que há uma divisão estável da árvore ótima, encontrar tal divisão é um problema computacionalmente difícil, pois depende de encontrar uma árvore de Steiner de custo mínimo, e dinâmicas de melhor resposta podem não convergir. Assim, além de estudar quão longe da solução ótima estão os melhores equilíbrios, também é de interesse analisar quão longe do equilíbrio estão as soluções correspondentes a florestas ótimas do problema FSTEINER e buscar soluções que sejam um meio-termo entre estes dois fatores.

Anshelevich et al. [ADTW08] demonstraram que é possível modificar o algoritmo DIVISAOOFERTA de forma que a partir de uma solução $\alpha$-aproximada para o problema da árvore de Steiner, seja encontrado em tempo polinomial um $(1+\epsilon)$-equilíbrio para o jogo STEINEROFERTA correspondente com custo social não-superior ao da árvore dada.

Para isso, começamos com o algoritmo DivisAOOfERTA com uma árvore $T$ que é uma $\alpha$-aproximação para o problema da árvore de Steiner. Definimos

$$
\gamma=\frac{\epsilon c(T)}{(1+\epsilon) n \alpha}
$$

onde $\epsilon$ é a precisão desejada para o equilíbrio e $n$ o número de jogadores.

Usamos então o algoritmo DivisAOOfERTA para pagar por $c(e)-\gamma$ de cada aresta $e$ em $T$. Como $T$ não é uma árvore de Steiner ótima, é possível que mesmo com o custo reduzido alguma aresta não seja paga. Nesse caso, modificamos a árvore como mostrado anteriormente, reduzindo seu custo em pelo menos $\gamma$ e recomeçamos o algoritmo com a nova árvore.

Cada execução do algoritmo é feita em tempo polinomial, e como em cada execução o custo da árvore diminui ao menos $\gamma$, o algoritmo é executado no máximo $(1+\epsilon) \alpha n / \epsilon$ vezes.

Seja $T^{\prime}$ a árvore construída pelo algoritmo. Para cada jogador $i$ e cada aresta $e$ em $T^{\prime}$, criaremos uma oferta modificada $o_{i}^{\prime}(e)$ aumentando $o_{i}(e)$ em proporção ao custo total de $i$ 
até que $e$ seja completamente paga:

$$
o_{i}^{\prime}(e)=o_{i}(e)+\gamma \frac{p_{i}\left(T^{\prime}\right)}{\sum_{j} p_{j}\left(T^{\prime}\right)},
$$

onde $p_{i}\left(T^{\prime}\right)=\sum_{e \in T^{\prime}} p_{i}(e)$. Note que $i$ pagará por arestas que pode não usar.

Sabemos que $i$ aceitava pagar pelo menos $o_{i}(e)$ por cada aresta $e$. Seja $m^{\prime}$ o número de arestas em $T^{\prime}$.

$$
p_{i}^{\prime}\left(T^{\prime}\right)-p_{i}\left(T^{\prime}\right)=\gamma \frac{p_{i}\left(T^{\prime}\right)}{c\left(T^{\prime}\right)-m^{\prime} \gamma} m^{\prime} \leq \frac{\epsilon c(T) p_{i}\left(T^{\prime}\right)}{\alpha(1+\epsilon)(1-\epsilon) c\left(T^{\prime}\right)} \leq \epsilon p_{i}\left(T^{\prime}\right) .
$$

Para o caso geral do problema, é possível construir uma divisão de custos da floresta ótima que é um 3-equilíbrio para o jogo SteInerOfERTA. Além disso, existem jogos para os quais qualquer divisão de custos da floresta ótima deve ser no mínimo um 1,5-equilíbrio [ADTW08].

Quando cada jogador deseja conectar apenas dois terminais, o método usado para encontrar um 3-equilíbrio que paga pela floresta de Steiner ótima pode ser adaptado para, a partir de uma solução $\alpha$-aproximada para o problema FSTEINER, produzir um $(3+\epsilon)$-equilíbrio com custo social não superior ao da floresta dada. Tal adaptação utiliza uma subrotina que computa uma árvore de Steiner ótima para os terminais de um jogador, o que no caso, corresponde a um caminho mínimo.

Se há mais de dois terminais por jogador, tal subrotina pode ser substituída por um algoritmo aproximado para o problema da árvore de Steiner. Nesse caso, utilizando um algoritmo 2-aproximado para o problema da floresta de Steiner e uma 1,55-aproximação para o problema da árvore de Steiner podemos encontrar um $(4,65+\epsilon)$-equilíbrio para o jogo SteinerOfERTA com custo social não superior a duas vezes o custo da floresta de Steiner ótima correspondente [ADTW08]. 


\section{Capítulo 7}

\section{Comentários Finais}

Neste trabalho analisamos duas políticas de divisão de custos de arestas para jogos de formação de redes, e como tais políticas influenciam a existência e custo social de equilíbrios. Nesta seção apresentamos as principais conclusões e questões em aberto.

\section{Divisão justa dos custos}

A divisão justa de custos garante a existência de equilíbrio (corolário 4.2), porém decidir se existe um equilíbrio "eficiente" é um problema computacionalmente difícil (teorema 4.3), ao menos em grafos orientados.

O preço da anarquia de um jogo SteInERJusto pode crescer linearmente no número de jogadores (seção 4.5), mesmo quando todos os jogadores desejam conectar os mesmos dois terminais.

Para jogos SteinerJusto com $n$ jogadores em grafos orientados, o preço da estabilidade pode chegar a $\Theta(\log n)$ mesmo para o caso de jogos que modelam transmissões de difusão (seção 4.6).

Assim, as análises separadas das variantes do jogo STEINERJUSTO presentes no capítulo 5 consideram apenas o preço da estabilidade em grafos não orientados. A tabela a seguir resume os melhores limites conhecidos para cada variante. Note que, como cada variante é um caso particular da anterior, os limites superiores para uma variante também se aplicam às linhas abaixo dela na tabela, e os inferiores, às linhas acima.

\begin{tabular}{|r|c|c|c|c|}
\hline$n$ & 2 & 3 & $\cdots$ & \\
\hline SteinerJusto & $3 / 2=1,5$ & $\begin{array}{c}\leq 11 / 6 \leq 1,834 \\
\geq 38 / 23 \geq 1,652\end{array}$ & & $\leq \mathcal{H}_{n}=\mathrm{O}(\log n)$ \\
\hline SteINERJUSTOCAM & $4 / 3 \approx 1,333$ & $\begin{array}{c}\leq 1,65 \\
\geq 74 / 48 \geq 1,541\end{array}$ & & $\geq 348 / 155 \geq 2,245$ \\
\hline STEINERJUSTOM & $4 / 3 \approx 1,333$ & $\geq 948 / 623 \geq 1,521$ & & $\geq 1,862$ \\
\hline STEINERJustoB & $4 / 3 \approx 1,333$ & $\geq 18 / 13 \geq 1,384$ & & $\begin{array}{c}\mathrm{O}(\log \log n) \\
\geq 20 / 11 \geq 1,818\end{array}$ \\
\hline
\end{tabular}

Como a tabela acima mostra, sabemos que a restrição de apenas dois terminais por jogador diminui o preço da estabilidade, mas não se sabe se as restrições de que os jogadores tenham um vértice em comum e que todo vértice seja terminal afetam o crescimento do maior preço da estabilidade possível. Além disso, não se sabe se o preço da estabilidade no caso geral em grafos não orientados pode chegar ao limite $\mathcal{H}_{n}$ como no caso orientado.

Sabemos que, dado um jogo SteinerJusto em um grafo orientado, o problema de decidir se há um equilíbrio com custo social no máximo $C$ é NP-completo mesmo para jogos 
de multitransmissão (seção 4.4). No entanto, não se sabe se vale um resultado análogo para jogos SteinerJusto em grafos não-orientados.

\section{Divisão por Ofertas}

Sob o modelo de divisão apresentado no capítulo 6 nem sempre existem equilíbrios (seção 6.1), e mesmo quando equilíbrios existem eles podem ter custo proporcional ao número de jogadores (seção 6.3) e os jogadores poderiam obter resultados equivalentes construindo suas redes independentemente.

Apesar disso, tal modelo é útil para a divisão de custos de multitransmissões, quando sabemos que existe uma divisão dos custos da árvore de Steiner de custo mínimo que é equilíbrio (seção 6.4), e a partir de uma solução $\alpha$-aproximada para o problema da árvore de Steiner é possível obter um $(1+\epsilon)$-equilíbrio para o jogo (seção 6.5). Utilizando o algoritmo proposto por Byrka e colaboradores [BGRS10] para geração da árvore, é possível obter em tempo polinomial um $(1+\epsilon)$-equilíbrio de custo social máximo 1,39 vezes o valor ótimo.

Apesar disso, tal modelo é útil para a divisão de custos de multitransmissões, quando sabemos que existe uma divisão dos custos da árvore de Steiner de custo mínimo que é um equilíbrio (seção 6.4). A partir de uma solução $\alpha$-aproximada para o problema ASTEINER é possível construir um $(1+\epsilon)$-equilíbrio para o jogo SteinerOferta, onde $\epsilon$ é a precisão desejada para o equilíbrio (seção 6.5).

O algoritmo DivisAOOFERTA apresentado por Anshelevich e colaboradores [ADTW08] encontra um equilíbrio que paga por uma árvore ótima, porém tal divisão é influenciada pela ordem na qual os jogadores são analisados e pode fazer com que uma fração dos jogadores não pague nada pela sua parte, independente de tal ordem. Na seção 6.4 apresentamos ideias para modificar o algoritmo de forma a obter uma divisão mais justa, sem aumentar o custo social do equilíbrio.

Para o caso geral do jogo com divisão por ofertas, é conhecido um exemplo em que qualquer perfil de custo social mínimo é no mínimo um 1,5-equilíbrio e Anshelevich e colaboradores mostraram um algoritmo que, a partir de uma floresta de Steiner ótima, devolve um 3-equilíbrio que paga por suas arestas. De forma semelhante ao DIVISAOOFERTA tal algoritmo pode ser adaptado para receber uma $\alpha$-aproximação para o problema da floresta de Steiner. Quando cada jogador tem dois terminais, o algoritmo devolve um $(3+\epsilon)$-equilíbrio em tempo polinomial no tamanho da entrada e em $\epsilon$. Para mais terminais, o algoritmo precisa de uma subrotina que calcula uma árvore de Steiner de custo mínimo para os terminais de cada jogador. Utilizando uma 1,55-aproximação em tal subrotina, é obtido um $(4,65+\epsilon)$-equilíbrio.

\section{Outras divisões}

Existem diversos outros critérios de divisão utilizados em problemas semelhantes que podem ser adaptados para jogos de Steiner [Rou07, TW07, CRV08], gerando jogos semelhantes a STEINERJusto, nos quais cada jogador deve apenas escolher um subgrafo que conecte seus terminais, porém com uma função de custo diferente para os jogadores.

Tais critérios são geralmente divididos em oblivious e não-oblivious [CRV08]. Nos critérios oblivious os custos de cada aresta são divididos de forma independente, utilizando apenas o conjunto de jogadores que as usam, como no caso do jogo SteinerJusto. Já nos critérios não-oblivious a divisão de custos de uma aresta pode depender de quais jogadores aceitam pagar por cada outra aresta do grafo, possibilitando divisões mais complexas. 
Qualquer mecanismo oblivious, ou não garante a existência de um equilíbrio ou possui preço da estabilidade no mínimo $\mathcal{H}_{n}$ no pior caso [CRV08], não havendo vantagem aparente em trocar o modelo de divisão justa por outro critério de divisão oblivious.

Quando há um terminal em comum a todos os jogadores, existe uma divisão de custos (não-oblivious) com preço da anarquia no máximo 2 [TW07]. Tal divisão é obtida utilizandose como heurística o algoritmo de Prim para o AGM onde cada jogador paga completamente pelo caminho entre seu terminal e a parte já árvore que já está construída.

Parece-nos que seria razoável uma divisão de custos, em que o custo total de cada jogador seria o seu valor de Shapley, ou seja a média, sobre todas as permutações, do aumento do custo social ótimo que sua presença no jogo causa. Tal divisão, além de ter preço da estabilidade unitário, também seria à prova de coalizões. Porém, além do problema computacional em calcular tais custos, que envolveria a solução do problema da floresta de Steiner para cada subconjunto de jogadores, não encontramos uma maneira de dividir tais custos pelas arestas, e os jogadores pagariam apenas pelo "serviço" como um todo, não ficando claro o quanto da rede tal jogador poderia aproveitar se desviasse da solução imposta.

\section{Contribuições e correções feitas}

Criamos os jogos SteinerJusto com preço da estabilidade alto para dois e três jogadores apresentados no final da seção 4.6 e a família de jogos STEINERJUSTOCAM analisada na seção 5.2 .

Alteramos as notações utilizadas em certos artigos de forma a padronizar a notação utilizada para a descrição de jogos de divisão de custos.

Na descrição do algoritmo AGEndAmento (seção 5.5), Fiat e colaboradores $\left[\mathrm{FKL}^{+} 06\right]$ utilizam uma busca em largura (BFS) para analisar os vértices no laço OPT. No entanto, a análise assume que os movimentos foram feitos em relação a um caminho de custo mínimo, que pode não ser encontrado por uma BFS. O algoritmo foi modificado de acordo.

Por outro lado, Anshelevich e colaboradores [ADTW08] utilizam uma busca em largura reversa para ordenar as arestas da árvore de Steiner no algoritmo DivisAoOferta (seção 6.4). Notamos que qualquer ordenação em que, quando uma aresta $e$ é analisada, todas as arestas em $T_{e}$ já tenham sido pagas é suficiente para o algoritmo.

$\mathrm{Na}$ demonstração de que o algoritmo paga completamente pela árvore ótima em grafos orientados, os autores afirmam que o caminho alternativo de nenhum jogador passa por um vértice descendente, na árvore de custo mínimo, de um vértice já utilizado por tal caminho. Esta afirmação parece ser incorreta, e não é necessária para a demonstração.

\section{Trabalhos Futuros}

Nesta sessão, apresentamos algumas questões em aberto sobre os problemas apresentados, que podem servir como trabalhos futuros.

Qual o menor preço da estabilidade que pode ser obtido por um critério de divisão nãooblivious no pior caso?

Como a existência e ineficiência do equilíbrio são afetadas quando o grafo possui custos não-constantes nas arestas (dependentes do número de jogadores que as utilizam) ou arestas com capacidade (número máximo de jogadores que podem utilizá-la)?

No caso geral do modelo com ofertas, se o grafo tem custos inteiros e há ao menos um equilíbrio, há um equilíbrio apenas com ofertas inteiras? Não conseguimos demonstrar ou encontrar um contra-exemplo. Sabemos que sempre é possível modificar o equilíbrio para que 
cada jogador pague, no total, um valor inteiro. Para jogos de multitransmissão, o algoritmo apresentado na seção 6.4 determina apenas ofertas inteiras.

Encontrar limitantes (tanto para proximidade do equilíbrio quanto para o custo social do resultado) após a execução de $k$ passos de uma dinâmica de melhor resposta para jogos SteinerJusto. Uma análise semelhante para um problema diferente foi feita por Tardos e Wexler [TW07]

Há um grande intervalo entre os limites inferior e superior para o maior preço da estabilidade possível para jogos STEINERJusto ou suas variantes. Os maiores limites inferiores conhecidos para o preço da estabilidade são constantes (seções 5.2 e 5.3), enquanto os menores limites superiores encontrados são $\mathrm{O}(\log n)(\operatorname{seção~4.6)~em~geral~e~} \mathrm{O}(\log \log n)$ para difusões (seção 5.5). É evidente que seria interessante trabalhar no sentido de diminuir esses intervalos. 


\section{Referências Bibliográficas}

$\left[\mathrm{ADK}^{+} 04\right]$ Elliot Anshelevich, Anirban Dasgupta, Jon Kleinberg, Éva Tardos, Tom Wexler e Tim Roughgarden. The price of stability for network design with fair cost allocation. Em Foundations of Computer Science, 2004. Proceedings. 45th Annual IEEE Symposium on, páginas 295-304. IEEE, 2004. 12, 14

[ADTW08] Elliot Anshelevich, Anirban Dasgupta, Éva Tardos e Tom Wexler. Near-Optimal Network Design with Selfish Agents. Theory of Computing, 4:77-109, 2008. 57, $58,59,63,66,69,70,72,73$

[Aum74] Robert John Aumann. Subjectivity and correlation in randomized strategies. Journal of Mathematical Economics, 1(1):67-96, 1974. 11

[BCFM10] Vittorio Bilò, Ioannis Caragiannis, Angelo Fanelli e Gianpiero Monaco. Improved lower bounds on the price of stability of undirected network design games. Algorithmic Game Theory, páginas 90-101, 2010. 25, 37, 41

[BGRS10] Jarosław Byrka, Fabrizio Grandoni, Thomas Rothvoß e Laura Sanità. An improved LP-based approximation for Steiner tree. Em Proceedings of the 42nd ACM symposium on Theory of computing, STOC '10, páginas 583-592, New York, NY, USA, 2010. ACM. 7, 72

[CCC $\left.{ }^{+} 98\right]$ Moses Charikar, Chandra Chekuri, To-yat Cheung, Zuo Dai, Ashish Goel, Sudipto Guha e Ming Li. Approximation algorithms for directed Steiner problems. Em Proceedings of the ninth annual ACM-SIAM symposium on Discrete algorithms, páginas 192-200. Society for Industrial and Applied Mathematics, 1998. 8

$\left[\mathrm{CCL}^{+} 10\right]$ George Christodoulou, Christine Chung, Katrina Ligett, Evangelia Pyrga e Rob van Stee. On the price of stability for undirected network design. Approximation and Online Algorithms, páginas 86-97, 2010. 25, 26, 27, 28, 29, 37

[CLRS01] Thomas H. Cormen, Charles Eric Leiserson, Ronald Linn Rivest e Clifford Stein. Introduction to Algorithms. The MIT Press, 2 edição, 2001. 7, 40

[CPV05] Bruno Codenotti, Sriram Pemmaraju e Kasturi Varadarajan. On the polynomial time computation of equilibria for certain exchange economies. Em Proceedings of the sixteenth annual ACM-SIAM symposium on Discrete algorithms, páginas 72-81. Society for Industrial and Applied Mathematics, 2005. 11

[CRV08] Ho-Lin Chen, Tim Roughgarden e Gregory Valiant. Designing networks with good equilibria. Em Proceedings of the nineteenth annual ACM-SIAM symposium on Discrete algorithms, páginas 854-863. Society for Industrial and Applied Mathematics, 2008. 72, 73 
[FKL $\left.{ }^{+} 06\right]$ Amos Fiat, Haim Kaplan, Meital Levy, Svetlana Olonetsky e Ronen Shabo. On the price of stability for designing undirected networks with fair cost allocations. Automata, Languages and Programming, páginas 608-618, 2006. 42, 73

[FKW04] Paulo Feofiloff, Yoshiharu Kohayakawa e Yoshiko Wakabayashi. Uma introdução sucinta à teoria dos grafos. IME-USP. Disponivel em: http://www.ime.usp. br/ pf/teoriadosgrafos Acesso em, 7(11):2011, 2004. 5

[GGS03] Georg Gottlob, Gianluigi Greco e Francesco Scarcello. Pure Nash equilibria: Hard and easy games. Em Proceedings of the 9th Conference on Theoretical Aspects of Rationality and Knowledge, páginas 215-230. ACM, 2003. 11

[GJ90] Michael Randolph Garey e David Stifler Johnson. Computers and Intractability: A Guide to the Theory of NP-Completeness. W. H. Freeman \& Co., New York, NY, USA, 1990. 19

[GMA05] Michel Xavier Goemans, Vahab Mirrokni e Vetta Adrian. Sink equilibria and convergence. Em Proceedings of the 46th Annual IEEE Symposium on Foundations of Computer Science, páginas 142-154. IEEE Computer Society, 2005. 11

[GW95] Michel Xavier Goemans e David Paul Williamson. A general approximation technique for constrained forest problems. SIAM Journal on Computing, $24(2): 296-317,1995.7$

[Kar72] Richard Manning Karp. Reducibility Among Combinatorial Problems. Complexity of computer computations: proceedings, página 85, 1972. 7

[KP99] Elias Koutsoupias e Christos Papadimitriou. Worst-Case Equilibria. Em STACS 99: 16th annual Symposium on Theoretical Aspects of Computer Science, Trier, Germany, March 4-6, 1999: proceedings, página 404. Springer Verlag, 1999. 12

[MS96] Dov Monderer e Lloyd Stowell Shapley. Potential games. Games and economic behavior, 14:124-143, 1996. 16

[MS01] Herve Moulin e Scott Shenker. Strategyproof sharing of submodular costs: budget balance versus efficiency. Economic Theory, 18(3):511-533, 2001. 14

[Mye97] Roger Bruce Myerson. Game Theory: Analysis of Conflict. Harvard University Press, 1997. 9, 14

[Nas51] John Forbes Nash. Noncooperative games. Annals of Mathematics, 54(2):286295, 1951. 11

[NRTV07] Noam Nisan, Tim Roughgarden, Éva Tardos e Vijay Virkumar Vazirani. Algorithmic Game Theory. Cambridge University Press New York, NY, USA, 2007. 9

[Olo06] Svetlana Olonetsky. On the price of stability for designing undirected networks with fair cost allocations. Dissertação de Mestrado, Tel-Aviv University, 2006. 42

[Pap01] Christos Papadimitriou. Algorithms, games, and the internet. Em Proceedings of the thirty-third annual ACM symposium on Theory of computing, páginas 749-753. ACM, 2001. 12 
[Pap07] Christos Papadimitriou. The complexity of finding Nash equilibria. Em Noam Nisan, Tim Roughgarden, Éva Tardos e Vijay Virkumar Vazirani, editors, Algorithmic Game Theory, chapter 2, páginas 29-51. Cambridge University Press New York, NY, USA, 2007. 10, 11

[Ros73] Robert W. Rosenthal. A class of games possessing pure-strategy Nash equilibria. International Journal of Game Theory, 2(1):65-67, 1973. 16

[Rou06] Tim Roughgarden. Potential functions and the inefficiency of equilibria. Em Proceedings oh the International Congress of Mathematicians: Madrid, August 22-30, 2006: invited lectures, páginas 1071-1094, 2006. 14

[Rou07] Tim Roughgarden. Routing games. Em Noam Nisan, Tim Roughgarden, Éva Tardos e Vijay Virkumar Vazirani, editors, Algorithmic Game Theory, chapter 19, páginas 461-486. Cambridge University Press New York, NY, USA, 2007. 72

[Sha53] Lloyd Stowell Shapley. A value for n-person games. Em A.E. Roth, editor, The Shapley value: essays in honor of Lloyd S. Shapley, chapter 2. Cambridge Univ Pr, 1953. 15

[SM03] Andreas S. Schulz e Nicolás Stier Moses. On the performance of user equilibria in traffic networks. Em Proceedings of the fourteenth annual ACM-SIAM symposium on Discrete algorithms, página 87. Society for Industrial and Applied Mathematics, 2003. 12

[TW07] Éva Tardos e Tom Wexler. Network formation games and the potential function method. Em Noam Nisan, Tim Roughgarden, Éva Tardos e Vijay Virkumar Vazirani, editors, Algorithmic Game Theory, chapter 19, páginas 487-516. Cambridge University Press New York, NY, USA, 2007. 14, 72, 73, 74 


\section{Índice Remissivo}

$\mathcal{R}$-floresta, 1, 7

$\mu$-equilíbrio, 11

AGM, 8

arborescência, 6

arcos, 5

aresta, 5

chão, 36

de dispositivo, 36

leve, 52

pesada, 52

aresta comprada, 55

árvore, 6

árvore geradora, 6

ASTEINER, 7

atravessa, 32

broadcast, 39

caminho, 5

ciclo, 6

coalizão, 14

componente, 6

conjunto de estratégias, 9

custo social, 11

difusão, 39

digrafo, 5

Dilema do Prisioneiro, 9

dinâmica de melhor resposta, 17

divisão justa, 13

empacotamento perfeito, 19

equilíbrio, 11

aproximado, 11

correlato, 11

de sorvedouro, 11

forte, 11

fracionário, 56

misto, 11

espaço de estratégias, 9

estratégia, 9 dominante, 11

fase, 47

floresta, 6

floresta de Steiner, 1, 7

SteinerJusto, 7

função característica, 14

função de custo, 6,9

função de utilidade, 9

função potencial (exata), 16

grafo, 5

conexo, 6

orientado, 5

igualitarista, 12

inteligência, 9

jogador, 9

nulo, 15

jogo

coalizional, 14

com utilidade transferível, 14

na forma estratégica, 9

potencial, 16

jogo de Steiner

broadcast, 39

caminhos, 25

difusão, 39

justo, 13

multicast, 37,60

multitransmissão, 37, 60

melhor resposta, 11

movimento, 42

multicast, 37

multitransmissão, 37

Par ou Ímpar, 10

perfil de estratégias, 9

perfil de estratégias ótimo, 12

ponto de desvio, 64 
portador, 15

preço da anarquia, 12

preço da estabilidade, 12

problema

da árvore de Steiner, 7

da árvore geradora mínima, 7

da floresta de Steiner, 7

de Steiner orientado generalizado, 8

do empacotamento de 3-conjuntos, 19

raíz, 37

racionalidade, 9

SteinerJustoB, 39

SteinerJustoCam, 25

SteinerJustoM, 37

SteinerOfertaM, 60

subárvore, 6

subgrafo, 6

induzido, 6

transmissões multicast, 37

utilitarista, 11

valor, 14

valor de Shapley, 15

vértice, 5

leve, 53

terminal, 13 